Pacific Northwest

National Laboratory

Operated by Battelle for the

U.S. Department of Energy

\title{
Hanford Radiological Protection Support Services Annual Report for 2001
}

\author{
T.P. Lynch J.A. MacLellan \\ D.E. Bihl R.K. Piper \\ M.L. Johnson
}

May 2002

Prepared for the U.S. Department of Energy under Contract DE-AC06-76RL01830 


\section{Hanford Radiological Protection Support Services Annual Report for 2001}
T. P. Lynch
J. A. MacLellan
D. E. Bihl
R. K. Piper
M. L. Johnson

May 2002

Prepared for

the U.S. Department of Energy

under Contract DE-AC06-76RL01830

Pacific Northwest National Laboratory

Richland, Washington 99352 


\section{Summary}

During calendar year (CY) 2001, the Pacific Northwest National Laboratory (PNNL) continued to provide radiological protection support services in support of the U.S. Department of Energy (DOE) Richland Operations Office (RL), the Office of River Protection (ORP) and the Hanford contractors. These services included 1) external dosimetry, 2) internal dosimetry, 3) in vivo measurements, 4) radiological records, 5) instrument calibration and evaluation, and 6) calibration of radiation sources traceable to the National Institute of Standards and Technology (NIST). The services were provided under the various programs summarized here.

The Hanford External Dosimetry Program (HEDP) supports Hanford radiation protection programs by providing external radiation monitoring capabilities for all Hanford workers and visitors to help ensure their health and safety. The HEDP also provides sitewide nuclear accident and environmental dosimetry services. The 44,039 dose results reported in CY 2001 were comparable to the 43,760 dose results reported in CY 2000. Area dosimeters $(2,190)$, environmental dosimeters (894), and fixed nuclear accident dosimeters (86) were also processed. Personnel neutron dose was monitored with CR-39 tacketch dosimeters for the first time. The CR-39 response was 43\% lower than the TLD response and a decision was made to not continue to maintain the track-etch system. Improvements were made to the algorithms for calculating neutron dose, deep dose from beta radiation, and doses measured by the two types of finger rings. Internal and external blind audit dosimeters were processed to ensure the integrity of the dosimeter processing. The performance testing criteria for the National Voluntary Laboratory Accreditation Program were met or exceeded for all requested categories from the testing performed during the last quarter of 2001. Three external assessments, a self-assessment, and eight surveillances of the program were conducted during the year. Four technical studies were conducted during the year including further development of the Edipus code, the effect on neutron and gamma dosimetry from wearing lead aprons, testing a new finger ring, and testing against the revised HPS N13.11 criteria. The number of skin contaminations remained about the same as in 2000.

The Hanford Internal Dosimetry Program (HIDP) provides for the assessment and documentation of occupational dose from intakes of radionuclides at the Hanford Site. The 5,132 excreta bioassay measurements performed in CY 2001 were slightly less than the number performed in CY 2000. There were 18 incidents with the potential for intake involving 40 workers, 27 had confirmed intakes. Ninetytwo evaluations were started because of routine bioassay results that exceeded the criteria for investigation. Six program assessments or oversight activities of the HIDP were conducted during the year. Three program changes and improvements were made including establishment of a policy for using derived air concentrations (DAC)-hour tracking data for estimating intake, updating tritium air concentration values for specific compounds, and completing the Hanford bioassay system functional requirements and risk assessment. Three technical studies were performed during the year that included an evaluation of the chronic plutonium intake detection capability, investigation of a new internal dosimetry code and a review of uranium bioassay requirements at the Plutonium Finishing Plant. 
The In Vivo Monitoring Program (IVMP) provides the in vivo counting services for the radiation workers at the Hanford Site. The 7,253 in vivo measurements performed in CY 2001 represented a 4\% increase from the 6,983 measurements performed in CY 2000. A uranium lung counting system was installed in the Lead Room and placed into routine service. The electronics for a lung counting system were converted to digital signal processing and the revised system was put into routine use. The effort to store historical records in a more accessible format was completed. A method was also established to copy files containing current data to compact disk. Technical studies were conducted to address issues related to making whole body measurements of larger workers, to participate in a measurement intercomparison study sponsored by the International Atomic Energy Agency, to further develop a voxel phantom and its applications, and to continue investigation of the coincidence summing phenomenon.

The Hanford Radiation Records Program (HRRP) preserves and administers radiological exposure records for all Hanford workers and visitors, past and present, and provides specified and requested reports using these records. It also produces reports for DOE Headquarters, RL, ORP, Hanford contractors, individuals, and other authorized agencies and provides data for epidemiology and research projects. The HRRP also maintains the Hanford Radiological Protection Historical Files. The total number of reports issued in CY 2001 was similar to the CY 2000 total. The nearly 60,000 documents scanned and indexed into the LaserREX and LaserCAL systems represented a $20 \%$ higher total than the number scanned and indexed in CY 2000. A new version of the Access Control Entry System database was implemented. As part of the triennial assessment program at Hanford, contractor representatives conducted an assessment of the program against the requirements in 10 CFR 835.

The Instrumentation Services and Technology Program (IS\&TP) provides complete and reliable radiation protection instrument services for site contractors to ensure personnel safety in the Hanford workplace. This includes administration of the portable instrument pool for the site and supporting the Hanford Instrument Evaluation Committee. The 14,546 calibrations performed in CY 2001 represent a $5 \%$ decrease from the number of calibrations performed in CY 2000. A total of 132 instruments were found to be significantly out of tolerance when returned for calibration, down from 102 in CY 2000. This indicates that the age of the instruments in the portable instrument pool has not significantly affected their reliability. An electronic version of the updated sitewide instrument manual was posted on the web.

The Radiation Standards and Calibration Program (RS\&CP) maintains the radiological standards necessary to support the characterization and calibration needs of IS\&TP and HEDP. The radiological reference fields maintained include gamma, beta, and neutron isotopic sources and X-ray-generating devices. Maintaining the traceability of the calibration sources and radiological reference fields to a national standard is a primary goal for the program. In CY 2001, exposures were made of Hanford dosimeters to support audit and quality control evaluations. Several operational improvements were made during the year, including upgrades to the ${ }^{241} \mathrm{Am}$ exposure facility, measurements of the scatter component for gamma irradiations, and verification of the formula to account for the ${ }^{250} \mathrm{Cf}$ contribution to the neutron emission rate from the ${ }^{252} \mathrm{Cf}$ neutron sources. 


\section{Abbreviations and Acronyms}

ACES Access Control Entry System

ACLS Administrative Control Limits

ANSI American National Standards Institute

BHI Bechtel Hanford Incorporated

BOMAB bottle manikin absorption (phantom)

Bpi bytes per inch

CAR computer-assisted retrieval (system)

CD compact disc

CEDE committed effective dose equivalent

CFR Code of Federal Regulations

CHG CH2M Hill Hanford Group, Inc.

CIEMAT Centro de Investigaciones Energeticas Medicambientales y Tecnologicas

CR\&A Calibration Research and Accreditation (subgroup)

DAC derived air concentration

DNFSB Defense Nuclear Facility Safety Board

DOE U.S. Department of Energy

DOELAP DOE Laboratory Accreditation Program

DSP digital signal processing

EDF Emergency Decontamination Facility

EEOICP Energy Employees Occupational Illness Compensation Program

EH-24 (DOE) Environment, Safety, and Health, Office of Oversight

ERC Environmental Restoration Contractor (team)

FA failed analysis

FH Fluor Hanford, Inc.

FOIA Freedom of Information Act

HCND Hanford combination neutron dosimeter

HEDP Hanford External Dosimetry Program

HEF High Exposure Facility

HEHF Hanford Environmental Health Foundation

HIDP Hanford Internal Dosimetry Program

HLAN Hanford Local Area Network

HPDAC Hanford Personnel Dosimetry Advisory Committee

HPGe high-purity germanium

HPS Health Physics Society 


\begin{tabular}{|c|c|}
\hline HQ & Headquarters \\
\hline HRRP & Hanford Radiological Records Program \\
\hline HSD & Hanford standard dosimeter \\
\hline IAEA & International Atomic Energy Agency \\
\hline ICRP & International Commission on Radiological Protection \\
\hline ID & identifier \\
\hline IMBA & Integrated Modules for Bioassay Analysis (Code) \\
\hline IODR & Investigation of Dosimetry Result \\
\hline IPUL & low-level isotopic plutonium \\
\hline IR & Iron Room \\
\hline IS & insufficient sample volume \\
\hline ISO & International Standards Organization \\
\hline IS\&TP & Instrumentation Services and Technology Project \\
\hline IVMP & In Vivo Monitoring Program \\
\hline IVRRF & In Vivo Radioassay and Research Facility \\
\hline JAERI & Japanese Atomic Energy Research Institute \\
\hline LaserCAL & CD-ROM imaging system for calibration records \\
\hline LaserREX & CD-ROM imaging subsystem to REX \\
\hline $\mathrm{L}_{\mathrm{c}}$ & decision level \\
\hline LC & lost container \\
\hline LEPD & low-energy photon detector \\
\hline LLNL & Lawrence Livermore National Laboratory \\
\hline LMSI & Lockhead Martin Services, Inc. \\
\hline LOLA & computer system for REX database \\
\hline MCNP & Monte Carlo N-Particle (transport code) \\
\hline MDA & minimal detectable activity \\
\hline MDD & minimum detectable (internal) dose \\
\hline NA & not applicable \\
\hline $\mathrm{NaI}$ & sodium-iodide \\
\hline ND & kit not delivered \\
\hline NIM & nuclear instrument module \\
\hline NIST & National Institute of Standards and Technology \\
\hline $\mathrm{NRC}$ & Nuclear Research Corporation \\
\hline NRD & neutron rem detector \\
\hline NS & no sample received \\
\hline NTS & Noncompliance Tracking System \\
\hline NVLAP & National Voluntary Laboratory Accreditation Program \\
\hline OCAS & Office of Compensation Analysis and Support \\
\hline ORP & Office of River Protection \\
\hline
\end{tabular}




$\begin{array}{ll}\text { PA } & \text { Privacy Act } \\ \text { PAAA } & \text { Price Anderson Act Amendment } \\ \text { PAM } & \text { portable alpha monitor } \\ \text { PC } & \text { personal computer } \\ \text { PFP } & \text { Plutonium Finishing Plant } \\ \text { PNNL } & \text { Pacific Northwest National Laboratory } \\ \text { QA } & \text { quality assurance } \\ \text { QC } & \text { quality control } \\ \text { RCT } & \text { Radiation Control Technician } \\ \text { REX } & \text { database that contains radiological exposure records } \\ \text { R\&HT } & \text { Radiation and Health Technology } \\ \text { RL } & \text { U.S. Department of Energy Richland Field Office } \\ \text { RPP } & \text { radiation protection program } \\ \text { RS\&CP } & \text { (Hanford) Radiation Standards and Calibrations Program } \\ \text { RWP } & \text { Radiation Work Permit } \\ \text { SCR } & \text { Software Change Request } \\ \text { SOW } & \text { Statement of Work } \\ \text { SS } & \text { Stainless Steel Room } \\ \text { STL } & \text { Severn Trent Laboratories } \\ \text { SU } & \text { standup counter } \\ \text { TL } & \text { thermoluminescent (dosimetry) } \\ \text { TLD } & \text { thermoluminescent dosimeter } \\ \text { TRIP } & \text { Thyroid Radioiodine Intercomparison Program } \\ \text { TRU } & \text { transuranium radionuclide(s) } \\ \text { UPS } & \text { uninterrupted power supply } \\ \text { USE } & \text { U.S. Ecology } \\ \text { USTUR } & \text { U.S. Transuranium Registries } \\ \text { WB } & \text { whole body } \\ \text { WBC } & \text { whole body count } \\ \text { Y2K } & \\ & \end{array}$




\section{Contents}

Summary......

iii

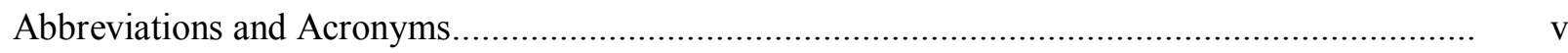

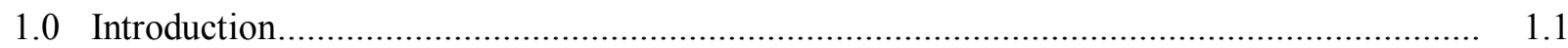

2.0 Hanford External Dosimetry Program.................................................................. 2.1

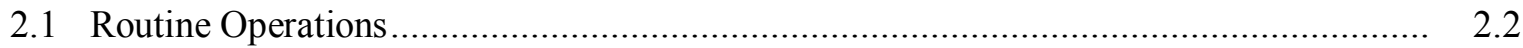

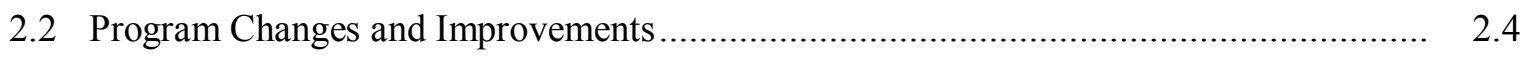

2.2.1 Revised Neutron Algorithm for Plutonium Finishing Plant ............................ 2.4

2.2.2 Revised Algorithm for the HSD to Eliminate Deep Dose from Beta Radiation.... $\quad 2.4$

2.2.3 Relative Response Factor for Finger Rings .................................................. 2.4

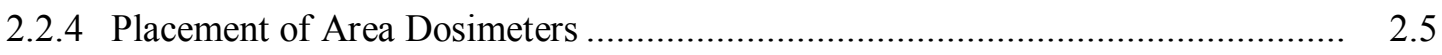

2.2.5 DOE-RL Radiological Health and Safety Document .................................. 2.5

2.3 Program Assessments and Quality Assurance .................................................... 2.5

2.3.1 Blind Audit Personnel Dosimeters.................................................................. 2.6

2.3.2 Blind Audit Environmental Dosimeters .................................................. 2.6

2.3.3 Department of Energy Laboratory Accreditation Program .............................. 2.6

2.3.4 National Voluntary Laboratory Accreditation Program..................................... 2.6

2.3.5 Hanford Contractor Assessment .......................................................... 2.9

2.3.6 Bechtel National Incorporated Assessment .............................................. 2.9

2.3.7 DOE-EH-24 Radiological Assessment of the Plutonium Finishing Plant ............ 2.10

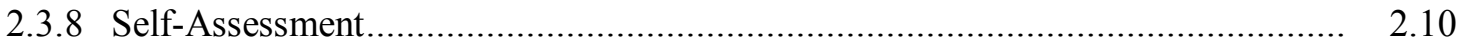

2.3.9 Procedure Surveillances ....................................................................... 2.10 


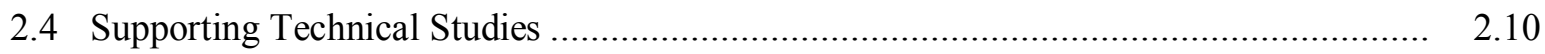

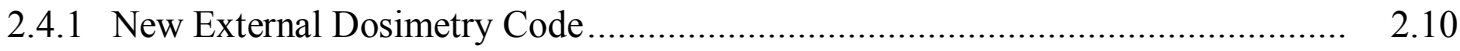

2.4.2 Additional Lead Apron Study............................................................... 2.10

2.4.3 New Finger Ring Ordered for Testing ..................................................... 2.11

2.4.4 Test Against the Revised HPS N13.11 Criteria ........................................... 2.11

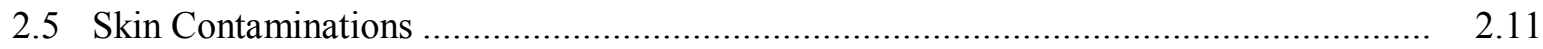

2.6 Program-Related Professional Activities ............................................................. 2.12

2.6 .1 Activities ................................................................................... 2.12

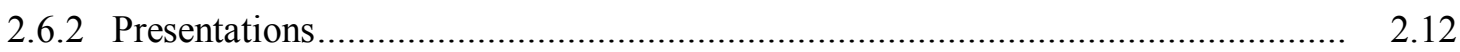

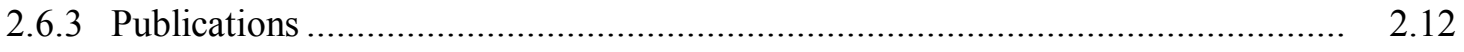

2.6.4 Professional Memberships ..................................................................... 2.13

3.0 Hanford Internal Dosimetry Program................................................................ 3.1

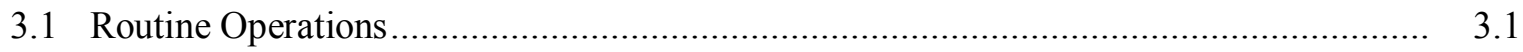

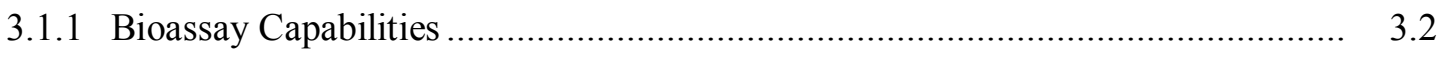

3.1.2 Excreta Bioassay Contract Activities............................................................ 3.3

3.1.3 Excreta Bioassay Monitoring Activities .................................................... 3.5

3.1.4 Potential Intake Evaluations ................................................................... 3.10

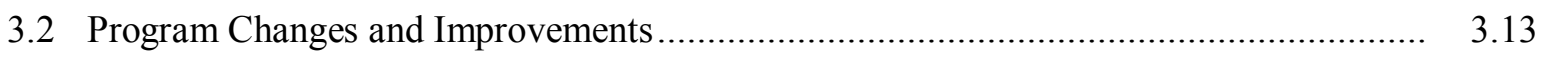

3.2.1 Policy for Using DAC-Hour Tracking Data........................................... 3.13

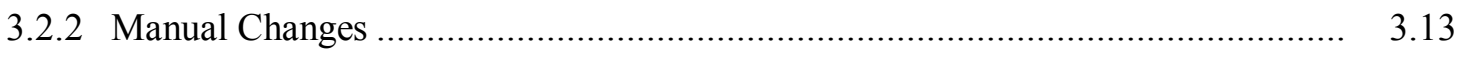

3.2.3 Update on New Decision Level for Alpha Spectrometry............................... 3.14

3.2.4 Hanford Bioassay System Functional Requirements and Risk Assessment.......... 3.14 
3.3 Program Assessments and Oversight .......................................................... 3.15

3.3.1 Excreta Quality Control Oversight Program ........................................... 3.15

3.3.2 Onsite Inspection of the Contracted Excreta Laboratory ................................ 3.15

3.3.3 Testing of Backup Lab for Rapid Plutonium and Strontium Analyses ................ 3.16

3.3.4 Bechtel National Incorporated Assessment .............................................. 3.16

3.3.5 Program Self-Assessments .............................................................. 3.16

3.3.6 Quality Problem Reports ................................................................ 3.16

3.4 Supporting Technical Studies .................................................................. 3.16

3.4.1 Chronic Plutonium Intake Detection Capability ........................................ 3.16

3.4.2 Investigation of a New Internal Dosimetry Code ....................................... 3.17

3.4.3 Review of Uranium Bioassay Requirements at the Plutonium Finishing Plant ..... $\quad 3.17$

3.5 Project-Related Professional Activities ............................................................ 3.17

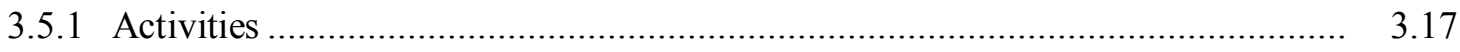

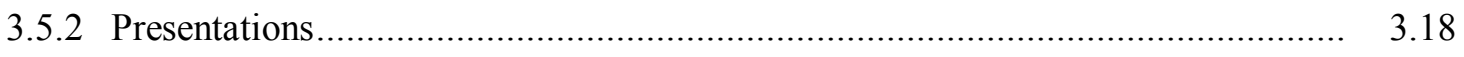

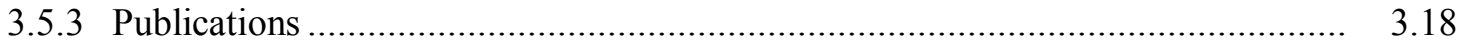

3.5.4 Professional Memberships and Other Activities ...................................... 3.18

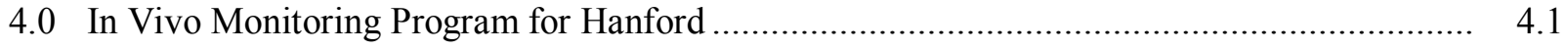

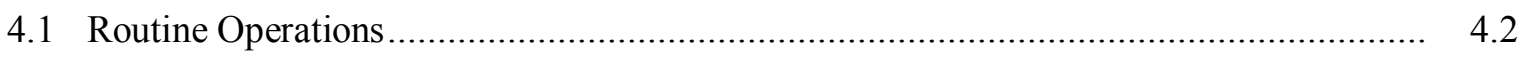

4.1.1 Program Management and Maintenance of Program Documentation ................. 4.3

4.1.2 Department of Energy Laboratory Accreditation Program ............................. 4.4

4.1.3 Equipment Maintenance and Repair …................................................. 4.4

4.1.4 Historical In Vivo Measurement Records ................................................. 4.5 


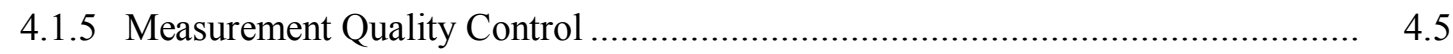

4.2 Program Changes and Improvements ............................................................. 4.6

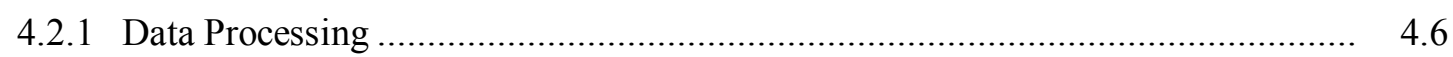

4.2.2 Standup Counter Calibration ................................................................. 4.7

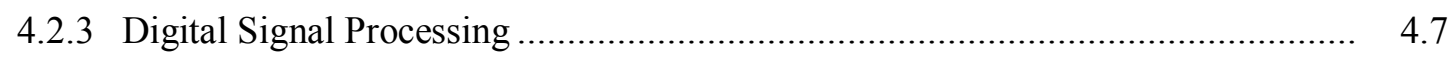

4.2.4 Uranium Lung-Counting System........................................................ 4.7

4.2.5 Calibration for Iodine in the Thyroid ..................................................... 4.7

4.2.6 Upgrade to Computer System Used at Emergency Decontamination Facility....... 4.8

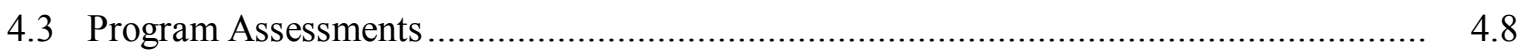

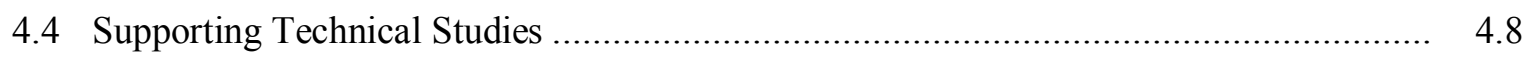

4.4.1 Coaxial HPGe System........................................................................ 4.8

4.4.2 International Atomic Energy Agency Intercomparison ............................... 4.9

4.4.3 Measurement of a High-Activity Phantom................................................ 4.11

4.4.4 NORMAN Voxel Phantom ............................................................. 4.12

4.4.5 ${ }^{241} \mathrm{Am} /{ }^{152} \mathrm{Eu}$ Lung Phantom and Coincidence Summing ................................ 4.13

4.5 Program-Related Professional Activities .......................................................... 4.13

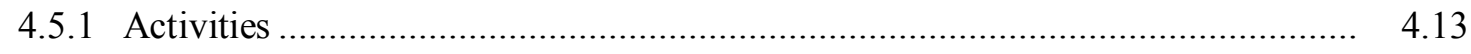

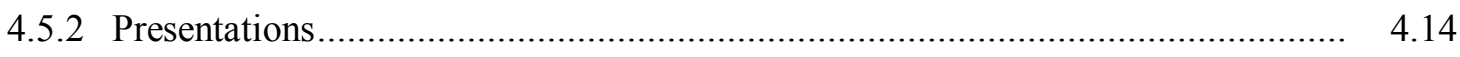

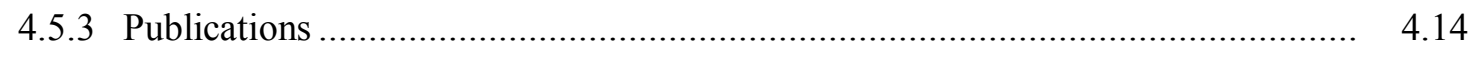

$5.0 \quad$ Hanford Radiation Records Program ............................................................... 5.1

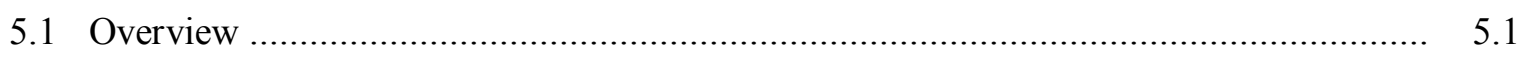

5.1.1 Database Administration .................................................................................. 5.1 


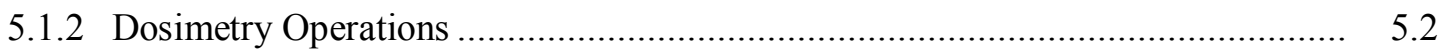

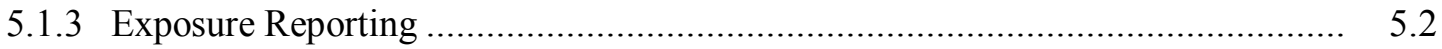

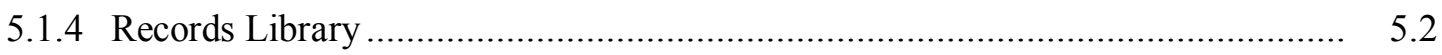

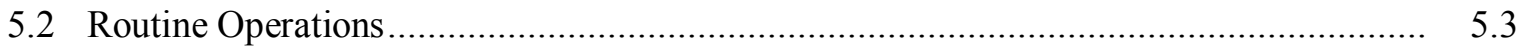

5.2.1 Data Administration.............................................................................. 5.3

5.2 .2 Dosimetry Operations …......................................................................... 5.3

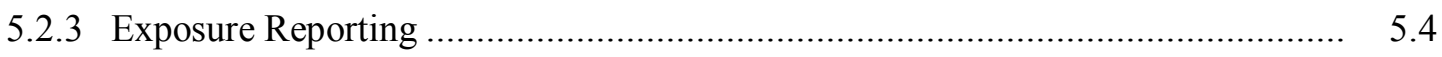

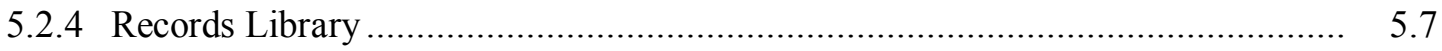

5.3 Program Changes and Improvements ............................................................ 5.7

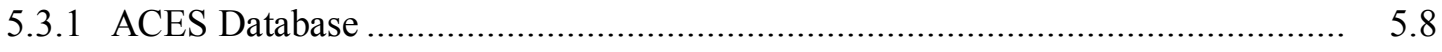

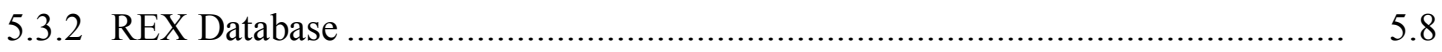

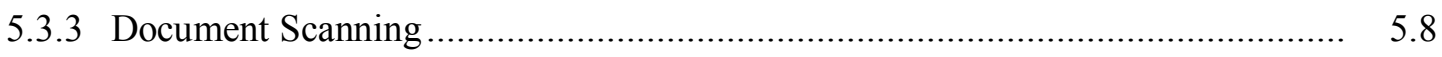

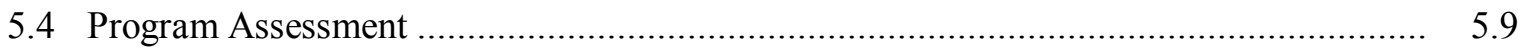

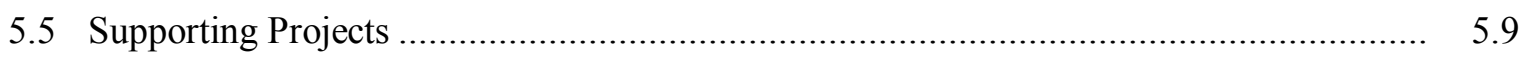

5.6 Program-Related Professional Activities .............................................................. 5.10

6.0 Instrumentation Services and Technology Program............................................. 6.1

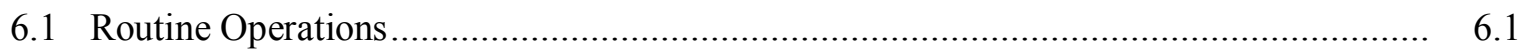

6.1.1 Administration of Portable Instrument Pool........................................... 6.2

6.1.2 Calibration and Maintenance Service - Radiation Detection Instruments ............ 6.2

6.1.3 Calibration and Maintenance; Measuring and Test Equipment......................... 6.8

6.1.4 Calibration As-Founds Out-of-Tolerance …............................................... 6.8

6.1.5 Maintenance of the Calibration Records .......................................................... 6.9 
6.2 Program Improvements in Calibration and Maintenance Operations .......................... 6.9

6.3 Hanford Instrument Evaluation Committee...................................................... 6.10

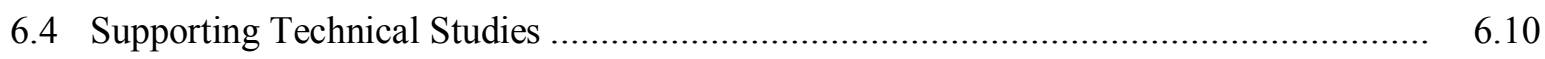

6.5 Program-Related Professional Activities ........................................................... 6.10

6.5.1 External Professional Activities ........................................................... 6.11

7.0 Radiation Standards and Calibrations Program .....................................................

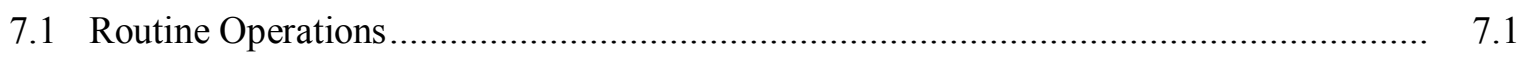

7.1.1 Standards and Capabilities ................................................................ 7.1

7.1.2 Quantitative and Qualitative Confirmation of Standards ............................... 7.2

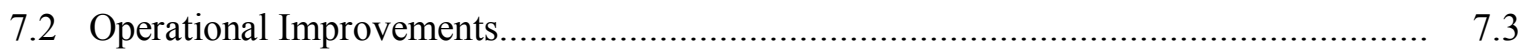

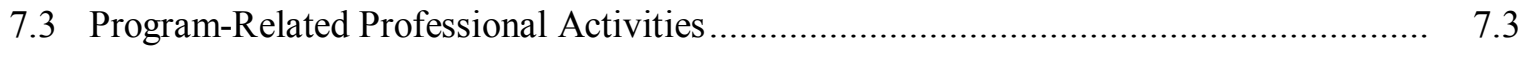

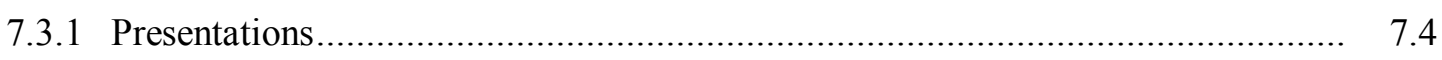

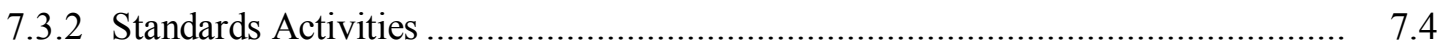

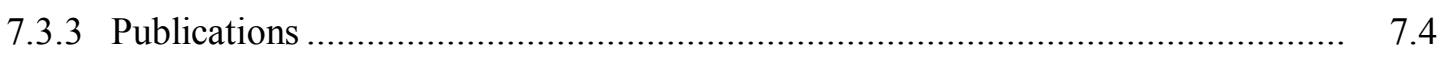

7.4.4 External Professional Activities …............................................................ 7.5

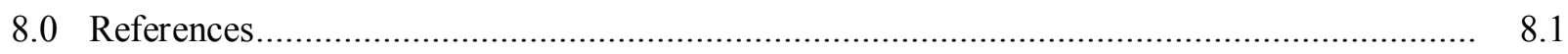




\section{Figures}

1.1 Management Structure and Major Communication Interfaces for Hanford Radiation Protection Services in CY 2001

2.1 Trend in Reported Hanford Personnel Dosimeter Results.

2.2

2.2 NVLAP Performance Test Results for the HSD Whole Body Dosimeter...... 2.8

2.3 NVLAP Performance Test Results for the HCND Whole Body Dosimeter...... 2.8

2.4 NVLAP Performance Test Results for the EXTRAD Ring Dosimeter

3.1 Standard and Nonstandard Excreta Requests by Month for 2001. 3.6

3.2 Routine Urine Measurements Made from 1994 Through 2001 3.7

3.3 Excreta Samples Not Obtained within the Grace Period. 3.9

3.4 Termination Excreta Samples Not Obtained.

3.5 Number of Open Evaluations by Month.

4.1 Summary of the Number and Types of In Vivo Measurements Performed from 1992 Through 2001

4.2 Bias in the Stainless Steel Room for the $202{ }^{241}$ Am Lungs ................................................... 4.6

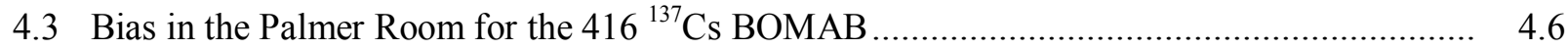

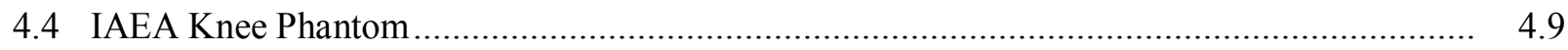

4.5 Three Bone Inserts in the IAEA Knee Phantom ............................................................. 4.10

4.6 JAERI Torso Phantom.................................................................................. 4.10

4.7 Lung Inserts for JAERI and LLNL Phantoms ....................................................... 4.11

4.8 Plot of the Norman Phantom, Slice 650, Showing the Presence of Activity in the Lungs of the Phantom and the HPGe Detectors in Place in Front of the Phantom ................................. 4.12

4.9 Virtual ${ }^{241}$ Am Spectrum from the NORMAN Phantom ................................................... 4.13

5.1 Dosimetry Records Requested by HRRP from Offsite Facilities ..................................... 5.5

5.2 Number of Responses to Requests for Previous Exposure ................................................. 5.6

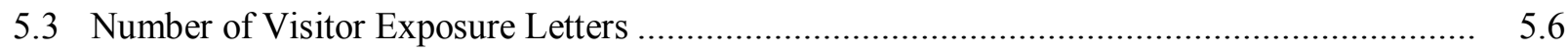

5.4 Number of Dosimetry Termination Letters .............................................................. 5.7

5.5 Number of Documents Scanned/Indexed ............................................................... 5.7

6.1 Total Number of Calibrations for Hanford Clients During CY 2001 _............................. 6.8 


\section{Tables}

2.1 External Whole Body Doses Received by Hanford Workers in 2001 ................................... 2.3

2.2 Audit Dosimeters Processed During 2001 …............................................................ 2.5

2.3 NVLAP Performance Test Results for Hanford Whole Body Dosimeters........................... 2.7

2.4 NVLAP Performance Test Results for the EXTRAD Finger Ring ..................................... 2.7

2.5 Number of Skin Contaminations .......................................................................... 2.12

3.1 Specified Minimum Detectable Activities and Screening Levels for Routine

Excreta Analyses During CY 2001 ............................................................................... 3.3

3.2 Minimum Detectable Activities and Screening Levels for Routine In Vivo Measurements During CY 2001 .................................................................................................. 3.4

3.3 Specified Minimum Detectable Activities for Emergency and Expedited Excreta Bioassay

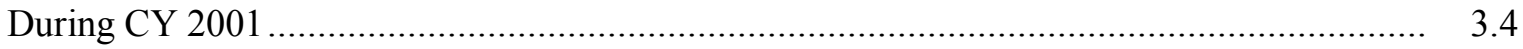

3.4 Worker Excreta Measurements Reported During 2001 ............................................... 3.8

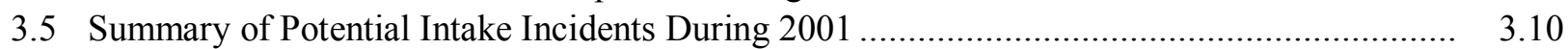

3.6 Comparison of Potential Intakes by Reason Code, 1995 to 2001 ...................................... 3.11

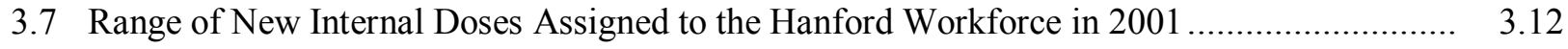

3.8 Changes to the Hanford Internal Dosimetry Program Manual ......................................... 3.14

4.1 In Vivo Measurements Performed During 2001 and Entered in the REX Database............... 4.2

4.2 In Vivo Count Summary from 1992 Through 2001 ........................................................ 4.2

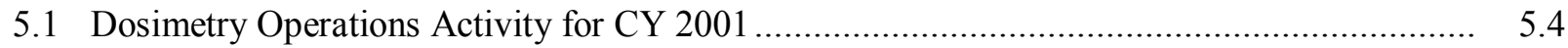

5.2 Number of Responses to Requests for Previous Exposure ............................................. 5.5

5.3 Number of Visitor Exposure Letters .................................................................... 5.5

6.1 Instrument Calibrations by Unit-Price Category and by CY ..................................... 6.2

6.2 CY 2001 Calibration Volume for All Hanford Contractors.................................................... 6.3

6.3 CY 2001 Calibration Volume for Fluor Hanford, Inc...................................................... 6.4

6.4 CY 2001 Calibration Volume for CH2M Hill Hanford Group, Inc. ................................... 6.5

6.5 CY 2001 Calibration Volume for Bechtel Hanford, Inc................................................. 6.6

6.6 CY 2001 Calibration Volume for PNNL ..................................................................... 6.7 


\subsection{Introduction}

Specific radiation protection services are performed routinely by the Pacific Northwest National Laboratory (PNNL) ${ }^{(a)}$ for the U.S. Department of Energy (DOE) Richland Operations Office (RL), the Office of River Protection (ORP) and the Hanford Site contractors. These sitewide services are provided by programs in 1) external dosimetry, 2) internal dosimetry, 3) in vivo monitoring, 4) radiation records, 5) instrument calibration and evaluation, and 6) maintenance of the radiation reference fields traceable to the National Institute of Science and Technology (NIST). Staff in the Radiation and Health Technology (R\&HT) technical group of the Systems and Risk Analysis organization in the Environmental Technology Division implements the programs.

R\&HT is organized into five functional groups: 1) Dosimetry Services, 2) Instrumentation Services and Technology, 3) Radiation Records, 4) Administration, and 5) Dosimetry Research and Technology. The Dosimetry Services group includes the Hanford External Dosimetry Program, the Hanford Internal Dosimetry Program, and the In Vivo Monitoring Program, which includes the operational and technical staff at the In Vivo Radioassay and Research Facility; and the Dosimetry Operations Program, which includes all of the Dosimetry Services technician staff that perform the processing of dosimeters, handling of dosimeters, and bioassay scheduling for Fluor Hanford, Inc. (FH) and RL, and Radiological Exposure (REX) data processing. The Instrumentation Services and Technology group includes four programs: Radiological Calibration Services, Non-Radiological Calibration Services, Instrument Repair, and Instrument Testing and Qualification. The Hanford Radiation Records Program includes the Records Library, Exposure Reporting, and Data Administration tasks. Information Services policy and planning for R\&HT are assigned to a staff position reporting directly to the R\&HT manager. The Administration group is responsible for financial planning and secretarial support.

Although some of the programs described in this report are involved in activities funded by other sources, only those activities funded by RL ORP, DOE-Headquarters (HQ), or the Hanford contractors are addressed here. Services provided for non-RL activities are scheduled to minimize the impact on services to DOE and its contractors. These non-RL services provide funds that support the overall program and reduce costs to RL and to the Hanford contractors.

Each of the six primary programs of R\&HT is described in a separate chapter of this report: 1) the Hanford External Dosimetry Program, 2) the Hanford Internal Dosimetry Program, 3) the In Vivo Monitoring Program, 4) the Hanford Radiation Records Program, 5) the Hanford Instrumentation Services and Technology Program, and 6) the Hanford Radiation Standards and Calibrations Program. Each chapter contains at least these core sections:

- Routine Operations

- Program Changes and Improvements

(a) Pacific Northwest National Laboratory is operated by Battelle Memorial Institute for the U.S. Department of Energy under Contract DE-AC06-76RL01830. 
- Program Assessments

- Program-Related Activities (such as publications, presentations, and professional memberships).

During calendar year (CY) 2001, the Hanford contractors consisted of PNNL, Bechtel Hanford, Inc. (BHI, also referred to as the Environmental Restoration Contract [ERC] team), the Hanford Environmental Health Foundation (HEHF), FH, and CH2M-Hill Hanford Group (CHG). FH consists of these six primary projects: Spent Nuclear Fuel, Waste Management, Nuclear Material Stabilization, River Corridor, Hanford Site Operations, and the Fast Flux Test Facility.

The PNNL and RL management structure and communication interfaces for each PNNL-operated program are shown in the organizational chart in Figure 1.1. The RL Office of Site Services is responsible for PNNL services in this area. 


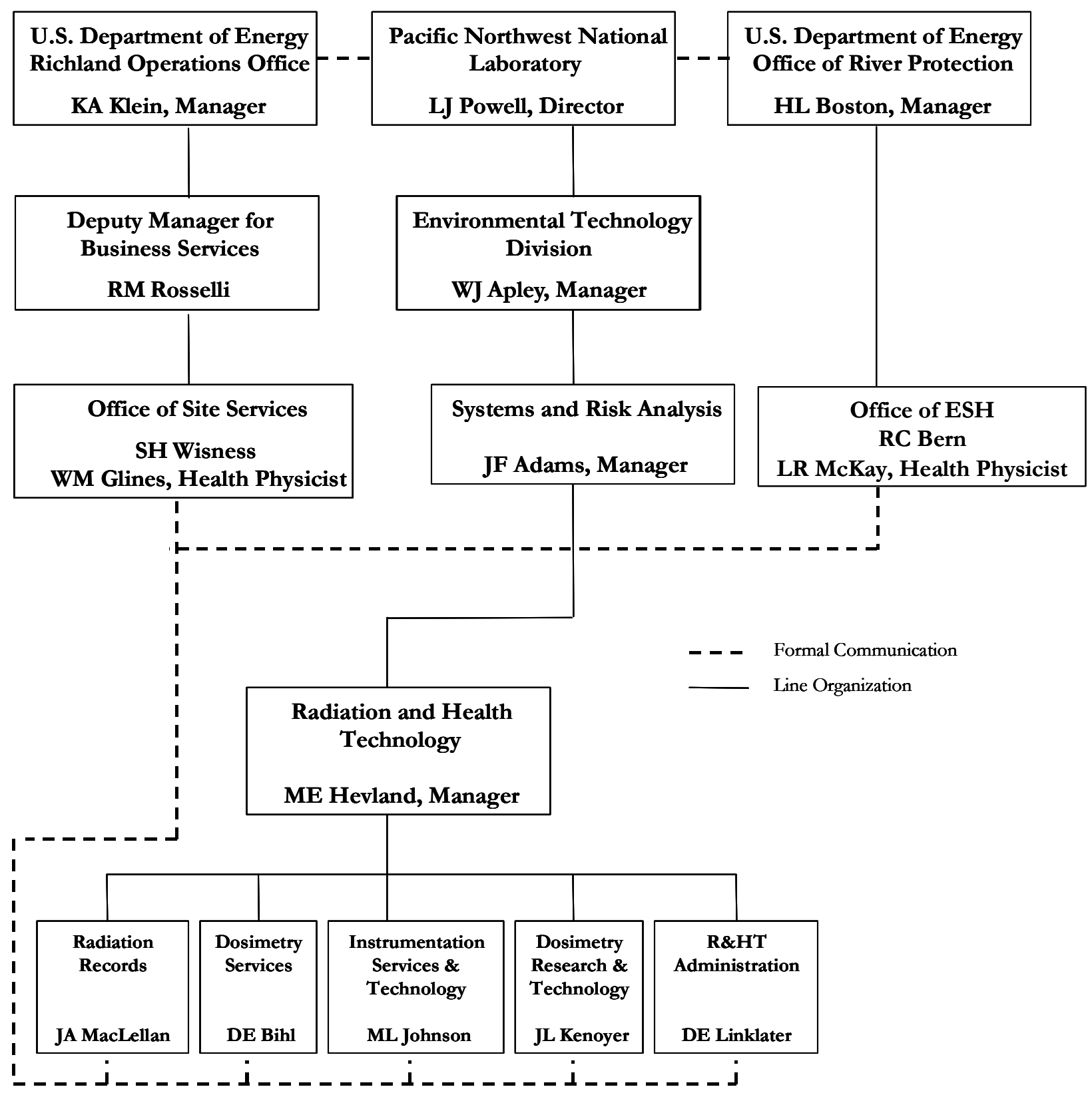

Figure 1.1. Management Structure and Major Communication Interfaces for Hanford Radiation Protection Services in CY 2001 


\subsection{Hanford External Dosimetry Program}

The Hanford External Dosimetry Program (HEDP) provides the official dose from external radiation for all Hanford personnel in support of Hanford radiation protection programs. (The program is available for use by other DOE sites or non-DOE customers as well.) HEDP dosimeter results provide the means used by contractor personnel to project, control, and measure radiation doses received by personnel. The program also provides sitewide nuclear accident, environmental, and building area dosimetry. The program operates in compliance with DOE requirements as set forth in 10 CFR 835, Occupation Radiation Protection, and the program is accredited by both the DOE Laboratory Accreditation Program (DOELAP) and the Department of Commerce National Voluntary Laboratory Accreditation Program (NVLAP).

The Hanford whole body personnel dosimetry system consists of a commercially procured thermoluminescent (TL) dosimetry system (originally manufactured by Harshaw). ${ }^{\text {(a) }}$ Dosimeters include the Hanford standard dosimeter (HSD), the Hanford combination neutron dosimeter (HCND), an extremity dosimeter, and the Hanford environmental dosimeter. The HCND also had the provision for a CR39 track-etch foil, and the track-etch foil was used for the first time in 2001 in 87 personnel dosimeters for a special study (see Section 2.1). The HSD also has a neutron response capability that will detect exposure to neutron radiation. Beginning in 1999, after receiving accreditation in 1998, the HSD was considered acceptable for monitoring neutron exposures, nominally below $100 \mathrm{mrem}$, with the understanding that the HSD will over-respond to low-energy neutrons. The Hanford extremity personnel dosimetry system consists of a commercially procured Harshaw "chipstrate" dosimeter insert enclosed in an ICN/MeasuRing ${ }^{(b)}$ ring casing (DOE contractors only). The HSD is also used as an extremity (wrist or ankle) dosimeter. Both the HSD and the HCND are used for monitoring areas, the HCND being mounted on 19-L (5-gal) water-filled carboys.

Physical and functional details concerning the HSD, HCND, finger ring, and the environmental dosimeter are provided in the Hanford External Dosimetry Technical Basis Manual. ${ }^{(\mathrm{c})}$ Additional details on program operation are documented in the Hanford External Dosimetry Quality Manual, ${ }^{(d)}$ the Hanford External Dosimetry Project Procedures Manual, ${ }^{(e)}$ the Quality Assurance Plan for Hanford External

(a) Now Saint-Gobain Crystals and Detectors, Solon, Ohio.

(b) ICN Biomedicals, Inc., Costa Mesa, California.

(c) Pacific Northwest National Laboratory. Current version. Hanford External Dosimetry Technical Basis Manual. PNL-MA-842, Richland, Washington. (Internal manual.) Available URL: http://www.pnl.gov/eshs/pub

(d) Pacific Northwest National Laboratory. 1998. Hanford External Dosimetry Quality Manual. PNL-MA-859, Richland, Washington. (Internal manual.)

(e) Pacific Northwest National Laboratory. Current version. Hanford External Dosimetry Project Procedures Manual. PNNL-MA-841, Richland, Washington. (Internal manual.) 
Dosimetry, ${ }^{(a)}$ and the Hanford External Dosimetry Program Data Management Manual. ${ }^{(b)}$ Technical agreements with Hanford contractors concerning responsibilities under 10 CFR 835 are established by contractual Statements of Work (SOWs).

\subsection{Routine Operations}

During 2001, 44,039 official personnel dose results were reported for Hanford customers. This processing volume represented virtually no change from the total of 43,760 during 2000 . The annual number of dose results is illustrated in Figure 2.1 for 1996 through 2001 for each type of dosimeter. The use of HSDs continued to decline in 2001, decreasing 6\% from 2000, but the use of HCNDs and finger rings increased (14\% and $11 \%$, respectively). The reduction in HSDs continues a trend from 1998 resulting primarily from reducing the dosimeter exchange frequency for many workers (e.g., from monthly to quarterly and quarterly to annual). The numbers in Figure 2.1 do not include internal quality control (QC) dosimeter cards or cards processed in support of DOELAP testing, and each HCND counts as one even though there really are two dosimeters in the packet.

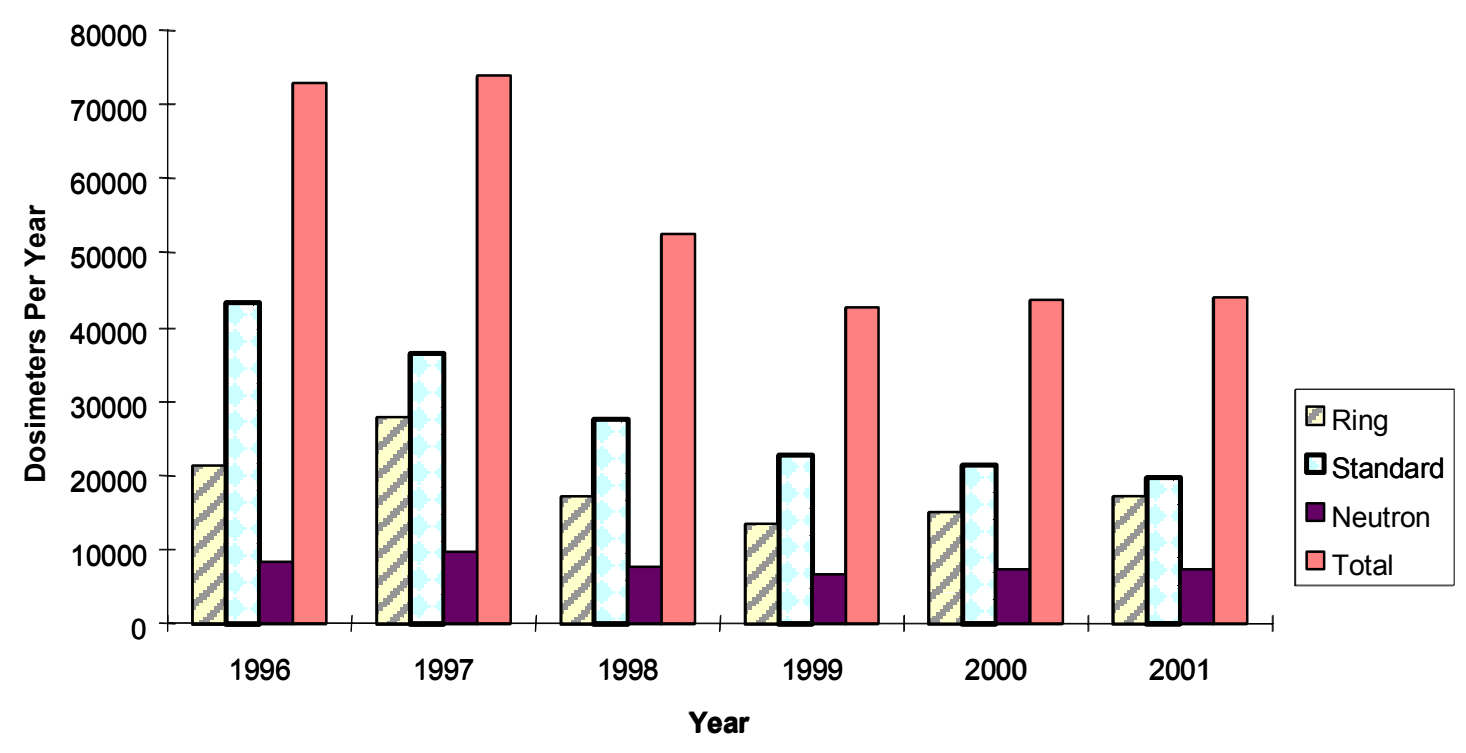

Figure 2.1. Trend in Reported Hanford Personnel Dosimeter Results

(a) Pacific Northwest National Laboratory. Current version. Quality Assurance (QA) Plan. No. LSC-022, Richland, Washington. (Internal document.)

(b) Pacific Northwest National Laboratory. Current version. Hanford External Dosimetry Program Data Management Manual. PNL-MA-844, Pacific Northwest National Laboratory, Richland, Washington. (Internal manual.) 
For the first time since converting to the Harshaw system, the CR39 track-etch capability of the HCND was used for personnel, although the results were not incorporated into official dose records. The purpose was to compare the track-etch results with TLD results for neutron conditions actually encountered by workers at the Plutonium Finishing Plant (PFP). Dosimeters for 87 workers, chosen based on previous neutron dose, were loaded with the track-etch foils, but only dosimeters with a TLD neutron reading at least 100 mrem were processed (35). The track-etch results averaged $43 \%$ lower than the TLD results, reflecting the exposure to highly scattered neutrons in the workplace. This information combined with information from the room characterization study performed in 1999 (Scherpelz, Fix, and Rathbone 2000) led the Hanford Personnel Dosimetry Advisory Committee (HPDAC) to endorse the decision to discontinue maintaining the track-etch system.

Statistics on external whole body doses received by the Hanford workforce are provided in Table 2.1. The total number of monitored workers was 10,027 in 2001, a 3\% increase from 2000 and essentially the same as in 1999. The highest external dose for an individual worker was $1,328 \mathrm{mrem}$ in 2001, down slightly from the previous 2 years. The number of workers in the 1,000- to 1,999-mrem range showed a marked decrease from 32 last year.

Table 2.1. External Whole Body Doses Received by Hanford Workers in $2001^{\text {(a) }}$

\begin{tabular}{|c|c|c|c|c|c|c|c|c|}
\hline \multirow{2}{*}{$\begin{array}{c}\text { Dose } \\
\text { Range } \\
\text { (mrem) }\end{array}$} & \multicolumn{8}{|c|}{ Number of Workers in Dose Range } \\
\hline & ERC & FH & CHG & PNNL & $\mathbf{D O E}^{(\mathbf{b})}$ & HEHF & Other & Total \\
\hline Zero & 899 & 3174 & 933 & 1234 & 976 & 29 & 582 & 7827 \\
\hline $1-99$ & 83 & 965 & 253 & 159 & 35 & 0 & 157 & 1652 \\
\hline $100-249$ & 25 & 160 & 49 & 28 & 1 & 0 & 39 & 302 \\
\hline $250-499$ & 5 & 101 & 4 & 16 & 0 & 0 & 26 & 152 \\
\hline $500-749$ & 1 & 59 & 1 & 1 & 0 & 0 & 0 & 62 \\
\hline $750-999$ & 0 & 23 & 0 & 1 & 0 & 0 & 0 & 24 \\
\hline $\begin{array}{c}1000- \\
1999\end{array}$ & 0 & 8 & 0 & 0 & 0 & 0 & 0 & 8 \\
\hline$>2000$ & 0 & & 0 & 0 & 0 & 0 & 0 & 0 \\
\hline $\begin{array}{ll}\text { (a) For mo } \\
\text { (b) Include }\end{array}$ & d wor & . & & & & & & \\
\hline
\end{tabular}

There were 482 Investigation of Dosimeter Results (IODRs) processed relating to doses incurred in 2001, a 20\% decrease from year 2000 (DOE - 16, FH - 363, CHG - 42, ERC - 30, and PNNL - 31).

In addition to personnel dosimeters, the HEDP also processed 2,190 area dosimeters, 894 environmental dosimeters, and 86 fixed nuclear accident dosimeters. The number of area dosimeters increased considerably compared to 2000 but was similar to the number employed in 1998 and 1999; the number of environmental dosimeters increased slightly, and the number of fixed nuclear accident dosimeters remained the same. 
For a variety of reasons, not all dosimeters that are issued are returned. After a reasonable lag period after the expected date of return, the dosimeters are declared lost. The lag periods are 60 days for monthly exchanged dosimeters, 180 days for quarterly exchanged dosimeters, and 465 days for annually exchanged dosimeters. The numbers of dosimeters declared lost in 2001 were as follows: 200 HSDs, 26 HCNDs, 140 finger rings, and 18 area dosimeters.

\subsection{Program Changes and Improvements}

Major modifications to HEDP practices are discussed and endorsed by the HPDAC. Changes in program practices made during 2001 are described in the following sections.

\subsubsection{Revised Neutron Algorithm for Plutonium Finishing Plant}

Based on information gathered in 1999 comparing the HCND response to tissue-equivalent proportional counter response at various locations in PFP (Scherpelz, Fix, and Rathbone 2000), the algorithm used to calculate neutron dose from HCND readings was revised and implemented on May 1. (See also Section 2.2.4 in last year's report [Lynch et al. 2001].) After processing the first batch of dosimeters in May, an error was discovered in the line of code that established the threshold for dose reporting. Consequently, no doses below $30 \mathrm{mrem}$ were reported. In addition to correcting and resubmitting all the affected doses, long-term corrective actions were developed that involved improvement in the code change verification procedure. All corrective actions were completed by year-end.

\subsubsection{Revised Algorithm for the HSD to Eliminate Deep Dose from Beta Radiation}

Following up on the study discussed in last year's report (Lynch et al. 2001) that showed a small deep dose being recorded by the HSD from beta radiation from ${ }^{90} \mathrm{Y}$, algorithm changes were implemented on April 16, 2001 to reduce this response to near zero. The study had concluded that the over-response of the HSD was due to the curvature of the plastic bubble over the deep dose chip. The curvature effectively reduces the density thickness of the material overlying the chip.

\subsubsection{Relative Response Factor for Finger Rings}

Previously the relative response factor for both types of rings used by HEDP (ICN MeasuRing with Harshaw chipstrate for Hanford, Harshaw EXT-RAD for non-Hanford customers) was assumed to be 1.00. In August a study was conducted to measure the actual relative response factor for the rings, which determined the factors to be $0.985 \mathrm{mR} / \mathrm{mrem}$ and $1.037 \mathrm{mR} / \mathrm{mrem}$ for the MeasuRing and the EXT-RAD, respectively. These slight improvements in accuracy were incorporated into the ring algorithms on September 7. 


\subsubsection{Placement of Area Dosimeters}

Upon realizing that some users of area dosimeters were placing the face of the dosimeter toward the wall, because the principal source of radiation was located in the room on the other side of the wall, HEDP staff provided a technical justification paper for the policy in the Hanford External Dosimetry Technical Basis Manual to place the back of the dosimeter to the wall. This issue was discussed by the HPDAC and contractors indicated that there were times when facing the dosimeter toward the wall simply made sense for the situation and that the amount of under-response was acceptable for their purposes. The HPDAC agreed to let the recommendation in the manual stand while recognizing that contractors may use the dosimeters as they see fit. Contractors, on the other hand, bear ultimate responsibility for interpretation and use of the data with cognizance of its limitations when not used according to recommendations.

\subsubsection{DOE-RL Radiological Health and Safety Document}

With concurrence from the Office of River Protection, the RL issued a Radiological Health and Safety Document as a contractual requirements document in November. ${ }^{(a)}$ This document replaced the Hanford Site Radiological Control Manual (RL 1994). The external dosimetry requirements were similar to but fewer in number than those in the Hanford Site Radiological Control Manual. The only anticipated impact on the HEDP came from the definition of dose assessment that stated that a dose assessment included uncertainty. Although general uncertainties have been determined and reported in the Hanford External Dosimetry Technical Basis Manual, uncertainties are not calculated and reported for each dose. The discussion of options for complying with this new requirement had just begun at year-end.

\subsection{Program Assessments and Quality Assurance}

Each year internal audit dosimeters are processed to ensure the integrity of dosimeter processing. During 2001, 1,140 internal audit dosimeters were processed. A breakdown of the internal audit dosimeters is shown in Table 2.2.

Table 2.2. Audit Dosimeters Processed During 2001

\begin{tabular}{|c|c|}
\hline Dosimeter Type & Number of Dosimeters \\
\hline HSD & 555 \\
\hline HCND & 265 \\
\hline Rings & 320 \\
\hline CR39 Track-Etch & 85 \\
\hline
\end{tabular}

(a) U.S. Department of Energy-Richland Operations Office (DOE-RL). 2001. "Hanford Radiological Health and Safety Document.” Richland, Washington. (November 26, 2001) 
Data analysis programs are used to statistically evaluate the performance for each of the audit dosimeter categories against DOELAP criteria. Irradiation of audit dosimeters has always been performed by the NVLAP-accredited calibration laboratory (Calibration Research and Accreditation Group), and, beginning in 2001, the same group was given responsibility for analyzing the results of the processed dosimeters and generating the written reports. These reports are prepared for every quarterly batch of audit dosimeters and provided to HEDP with a copy to the Hanford Radiation Protection Historical Files.

\subsubsection{Blind Audit Personnel Dosimeters}

Fluor Hanford Inc. routinely submits audit dosimeters for the Hanford Blind Audit Program to be processed along with the personnel dosimeters. Audit dosimeters are submitted each month of the year, and performance is analyzed each quarter for shallow, deep, and neutron dose, and dose to the finger ring dosimeters. HEDP successfully passed each of the quarterly evaluations in 2001 using DOELAP performance criteria. Documentation of HEDP results of these audits is included in the Hanford Radiation Protection Historical Files.

\subsubsection{Blind Audit Environmental Dosimeters}

Staff from PNNL's Surface Environmental Surveillance Program routinely submit audit dosimeters to be processed along with their quarterly exchanged environmental dosimeters. The given exposures typically range between 15 and $30 \mathrm{mrem}$ of ${ }^{137} \mathrm{Cs}$ gamma radiation. For the 12 audit dosimeters submitted during 2001, the overall bias in the reported dose compared with the delivered dose was $0.76 \%$, with a range in the bias of individual dosimeters from $-6.1 \%$ to $4.9 \%$. The bias plus precision statistic was 0.042 . These are all excellent results. The draft environmental performance standard sets the limit for bias plus precision at 0.5 .

\subsubsection{Department of Energy Laboratory Accreditation Program}

Performance testing of personnel dosimeters and an onsite inspection occur every 2 years for DOELAP accreditation. The last testing and onsite inspection occurred in 2000 and was reported in last year's report.

\subsubsection{National Voluntary Laboratory Accreditation Program}

Performance testing and an onsite inspection occur approximately every 2 years for the NVLAP, which is operated by the National Institute for Science and Technology (NIST). Performance testing was conducted during the last quarter of 2001, but the onsite inspection had not occurred yet by the end of the year. The HEDP was tested for the HSD, HCND, and the EXTRAD finger ring in a total of 14 categories. HEDP successfully passed all requested categories. Testing results for Hanford whole body and extremity dosimeters are summarized in Tables 2.3 and 2.4, respectively. Exposures included personnel and accident-level (as high as 500-rem) doses for personnel whole body dosimeters. Whole body and extremity dosimeter performance testing followed recommendations in the American National 
Table 2.3. NVLAP Performance Test Results for Hanford Whole Body Dosimeters

\begin{tabular}{|c|c|c|c|c|c|}
\hline \multirow[b]{3}{*}{ NVLAP Category Description } & \multirow{3}{*}{$\begin{array}{l}\text { NVLAP } \\
\text { Criterion }\end{array}$} & \multicolumn{4}{|c|}{ Performance $^{(a)}$} \\
\hline & & \multicolumn{2}{|c|}{ HSD } & \multicolumn{2}{|c|}{ HCND } \\
\hline & & Shallow & Deep & Shallow & Deep \\
\hline Accident, Low-Energy Photons & 0.3 & $\mathrm{NA}^{(\mathrm{b})}$ & 0.055 & & \\
\hline Accident, High-Energy Photons & 0.3 & NA & 0.034 & & \\
\hline IIIA. Low-Energy Photons, General & 0.5 & 0.374 & 0.106 & & \\
\hline IV. High-Energy Photons, $137 \mathrm{Cs}$ & 0.5 & NA & 0.048 & & \\
\hline VC. Beta Particles: General & 0.5 & 0.248 & NA & & \\
\hline VI. Photon Mixtures & 0.5 & 0.215 & 0.120 & & \\
\hline VII. Photon Plus Beta Particles & 0.5 & 0.148 & 0.093 & & \\
\hline VIII. Photons Plus Neutrons (Total) & 0.5 & NA & 0.073 & NA & 0.032 \\
\hline VIII. Photons Plus Neutrons (Neutron) & 0.5 & NA & 0.132 & NA & 0.065 \\
\hline \multicolumn{6}{|c|}{$\begin{array}{l}\text { (a) Performance quotients (P) for Hanford standard dosimeter (HSD) and Hanford combination neutron dosimeter (HCND } \\
\text { are calculated as } \mathrm{P}=|\mathrm{B}|+\mathrm{S} \text { where } \mathrm{B} \text { is the systematic error in the reported dose and } \mathrm{S} \text { is the random error. Dosimeter } \\
\text { performance quotients must be less than the NVLAP criterion in each category for satisfactory performance } \\
\text { (b) NA = not applicable. }\end{array}$} \\
\hline
\end{tabular}

Table 2.4. NVLAP Performance Test Results for the EXTRAD Finger Ring

\begin{tabular}{|c|c|c|}
\hline \multirow[b]{2}{*}{ NVLAP Category Description } & \multirow{2}{*}{$\begin{array}{l}\text { NVLAP } \\
\text { Criterion }\end{array}$} & \multirow{2}{*}{$\frac{\text { Performance }}{\text { Shallow }}$} \\
\hline & & \\
\hline Accident, Low-Energy Photons & 0.3 & 0.141 \\
\hline Accident, High-Energy Photons & 0.3 & 0.119 \\
\hline IIIA. Low-Energy Photons, Mixed X-rays & 0.5 & 0.107 \\
\hline IVA High-Energy Photons, ${ }^{137} \mathrm{Cs}$ & 0.5 & 0.107 \\
\hline VC. $\quad$ Beta Particles, General & 0.5 & 0.077 \\
\hline \multicolumn{3}{|c|}{$\begin{array}{l}\text { (a) Performance quotients }(\mathrm{P}) \text { for Hanford extremity ring dosimeter are calculated as } \mathrm{P}=|\mathrm{B}|+\mathrm{S} \text { where } \mathrm{B} \text { is } \\
\text { the systematic error in the reported dose and } \mathrm{S} \text { is the random error. Dosimeter performance quotients } \\
\text { must be less then the NVLAP criterion in each category for satisfactory performance. }\end{array}$} \\
\hline
\end{tabular}

Standards Institute/Health Physics Society standards N13.11-1993, An American National Standard for Personnel Dosimetry Performance - Criteria for Testing, and N13.32, An American National Standard for Performance Testing of Extremity Dosimeters, respectively (ANSI/HPS 1993; ANSI/HPS 1995). Even though the same algorithm is used for both DOELAP and NVLAP performance testing, and even though the dose conversion factors are different for the two testing programs, the Hanford dosimeters performed well. This is demonstrated in Tables 2.3 and 2.4 by comparing the calculated performance of the respective dosimeters with the NVLAP criterion in each irradiation category. In all but two categories, the Hanford performance was well below the 0.3 or 0.5 criterion. Figures 2.2 through 2.4 illustrate the performance using Horlick diagrams, where each point represents the bias and precision results for a category and each point must fall within the six-sided figure. 


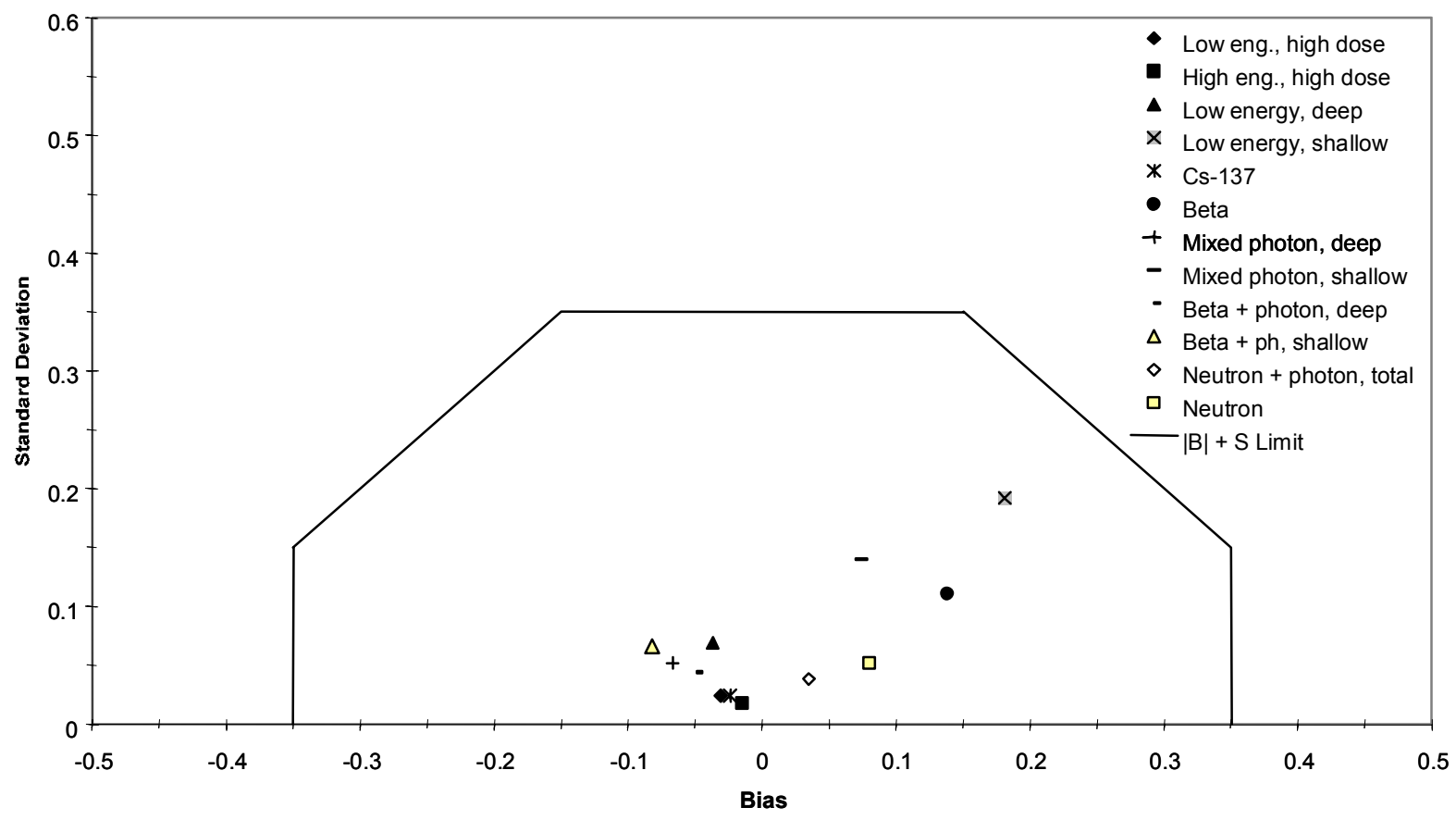

Figure 2.2. NVLAP Performance Test Results for the HSD Whole Body Dosimeter

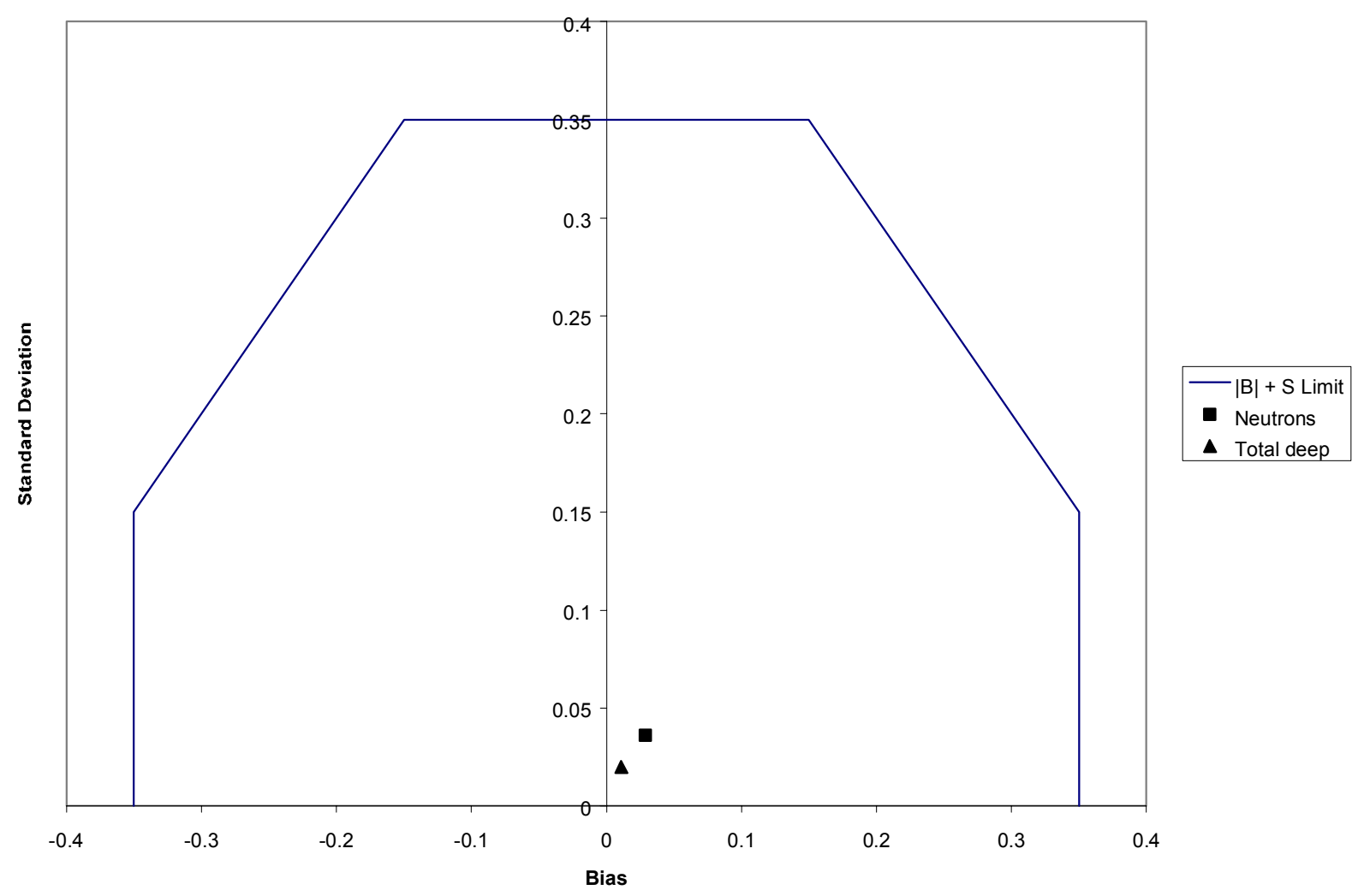

Figure 2.3. NVLAP Performance Test Results for the HCND Whole Body Dosimeter 


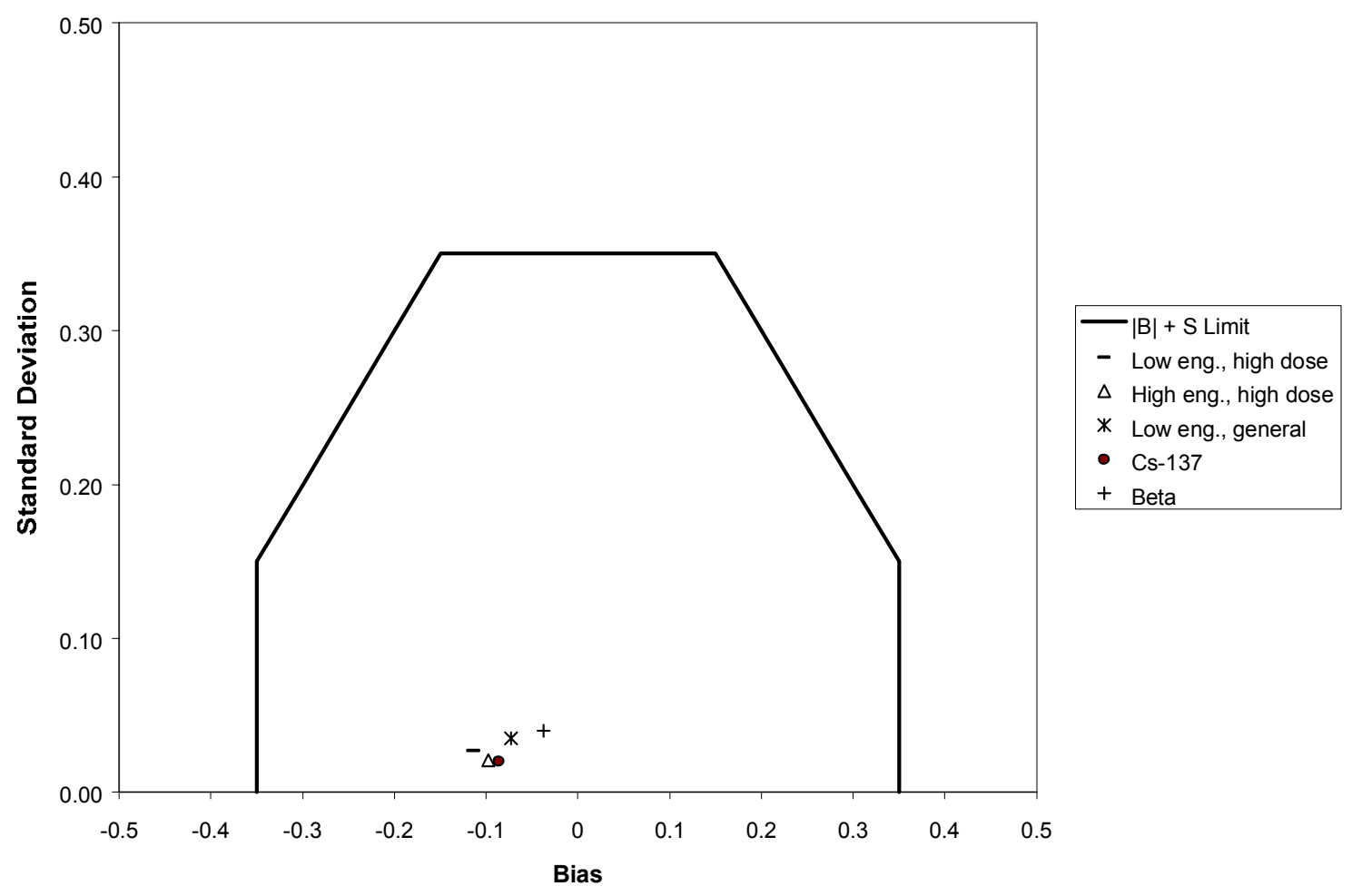

Figure 2.4. NVLAP Performance Test Results for the EXTRAD Ring Dosimeter

\subsubsection{Hanford Contractor Assessment}

The Hanford contractors conducted a triennial assessment for compliance with 10 CFR 835 on May 29 through 31. There were four observations involving an incomplete list of definitions, and out-ofdate processing backup agreement, an incorrect statement in the Quality Manual, and a procedure improvement. A corrective action plan was developed and corrective actions to three of the observations were completed by year-end, with corrective action on the remaining observation (the backup agreement) nearly completed.

\subsubsection{Bechtel National Incorporated Assessment}

Bechtel National Incorporated conducted an audit in September that focused on annealing dosimeters. A finding was made concerning the linking of the thermometer used to monitor the annealing oven temperature with the paperwork for each batch of dosimeters and with the traceability of the thermometer calibration. Corrective actions were completed promptly. 


\subsubsection{DOE-EH-24 Radiological Assessment of the Plutonium Finishing Plant}

In August, DOE Environment, Safety, and Health, Office of Oversight (EH-24) conducted an assessment of PFP, which included radiological control and dosimetry. The assessment expressed praise for the neutron characterization study that was conducted in 1999 and the subsequent revision of the neutron algorithm (see also Section 2.2.1). The assessor raised a question about the adequate use of multiple dosimetry based on workers' comments, but he did not make a finding on this topic. The HPDAC subsequently reviewed the sitewide policy for assigning multiple dosimeters and reaffirmed the present policy. Another byproduct of the assessment was a discussion at the HPDAC and later with the PFP radiological control organization concerning the need for routine workplace studies comparing the TLD neutron response to tissue-equivalent proportional detector response. Agreement was reached that such studies should be conducted every 3 years.

\subsubsection{Self-Assessment}

Self- (or internal) assessments of the HEDP are conducted annually. The 2001 self-assessment was conducted in August and focused on the status of corrective actions from previous assessments by various groups and on the new assessment checklist used by NVLAP, which is based on the International Standards Organization (ISO) standard 17025, General Requirements for the Competence of Testing and Calibration Laboratories (ISO 1999).

\subsubsection{Procedure Surveillances}

Routine procedure surveillances conducted approximately bimonthly by HEDP's Quality Engineer were instituted in November 2000. In 2001, 8 surveillances were conducted covering 12 procedures.

\subsection{Supporting Technical Studies}

Four technical studies or tasks were undertaken during 2001, as described in the following sections.

\subsubsection{New External Dosimetry Code}

Work continued on the code, Edipus, that will operate on the Sun Enterprise computer, which also houses the REX database. The Edipus code will replace the series of external dosimetry codes presently operating on the VAX cluster. In 2001 most of the forms and several reports were drafted, and migration of data from the VAX cluster to Edipus, to allow for testing of the forms, was essentially completed. The software documentation plan was written.

\subsubsection{Additional Lead Apron Study}

A major study of the effect of wearing a lead apron on gamma-ray and neutron dosimetry, with recommendations for placement of dosimeters, was conducted in 2000 (Section 2.4.5 in last year's report [Lynch et al. 2001]). In 2001, the PFP radiological control organization asked for a continuation of that study for a lead apron of different composition and thickness from the apron used in the original study. This study was nearly complete but had not been documented by year-end. 


\subsubsection{New Finger Ring Ordered for Testing}

St. Gobain Crystals and Detectors released a newly designed finger ring that provides improved response to low-energy beta particles (response is flatter over a broader range of beta particle energies). In addition, a group of workers decontaminating the 324 Building expressed concern about the ergonomics of the hard-plastic ring in use at Hanford since 1996. These two factors led the HEDP to purchase a single conversion kit for one of the finger ring readers and a few TLD chips and rings for testing. Concurrently, a study was in progress using the Monte Carlo Neutron Proton (MCNP) code to better quantify the response of the present ring system at various beta energies and glove thicknesses. Earlier, less sophisticated, calculations indicated that the present ring significantly under-responds to lowenergy beta particles. The purpose of these two activities is to provide information leading to a decision by the Hanford contractors whether to purchase and implement the new finger ring system.

\subsubsection{Test Against the Revised HPS N13.11 Criteria}

The document that provides guidance to groups that test personnel dosimetry systems (namely DOELAP and NVLAP), HPS N13.11, An American National Standard for Personnel Dosimetry Performance - Criteria for Testing (HPS 2001), was revised and issued in 2001. The revised standard has more testing categories (i.e., radiation beams) and more challenging criteria than the previous version. Shortly after release of the revised standard, NVLAP announced that they will begin to use the new criteria starting in July 2002. Although DOELAP had not made a similar announcement by year-end, it was anticipated that DOELAP would also start using the new criteria in the next year or so. DOELAP did offer participants a chance to test one type of dosimeter against categories in the new standard involving only photons, i.e., no beta radiation. HEDP tested the HSD in two categories - general photons and plutonium photons. The HSD performed well for deep dose but marginally for shallow dose. The HSD failed the new $10 \%$ rule $^{(a)}$ for shallow dose in the plutonium photon category. HEDP plans to perform extensive in-house testing using the new categories in upcoming months to prepare for official testing against the new criteria.

\subsection{Skin Contaminations}

Hanford skin contamination statistics are provided in Table 2.5. These statistics were first included in this report in 1999. The number of skin contaminations in 2001 was essentially unchanged from 2000. Skin dose calculations were conducted for three skin contaminations and four events involving personal clothing, but none of the doses exceeded the criterion for recording of the dose (>100 mrem).

(a) The new criterion is that less than $10 \%$ of the test dosimeters can individually exceed the performance criterion, whereas previously the performance criterion only applied to the average of all the dosimeters. 
Table 2.5. Number of Skin Contaminations (Worker-Events) ${ }^{(a)}$

\begin{tabular}{|c|c|c|c|}
\hline \multirow[t]{2}{*}{ Contractor } & \multicolumn{3}{|c|}{ Number of Contaminations } \\
\hline & 1999 & 2000 & 2001 \\
\hline PHMC $^{(b)}$ & 39 & $\mathrm{NA}^{(\mathrm{c})}$ & $\mathrm{NA}^{(\mathrm{c})}$ \\
\hline FH & & 10 & 13 \\
\hline CHG & & 7 & 1 \\
\hline PNNL & 18 & 1 & 2 \\
\hline ERC & 0 & Not provided & 2 \\
\hline DOE & 0 & 0 & 0 \\
\hline Total & 57 & 18 & 18 \\
\hline \multicolumn{4}{|c|}{$\begin{array}{l}\text { (a) Each contamination event for a single worker counted separately; does } \\
\text { not include clothing contamination. } \\
\text { (b) PHMC included both FH and CHG in } 1999 . \\
\text { (c) NA = not applicable. }\end{array}$} \\
\hline
\end{tabular}

\subsection{Program-Related Professional Activities}

Staff activities, presentations, publications, and professional memberships during 2001 are listed in this section.

\subsubsection{Activities}

Bruce A. Rathbone participated in professional external dosimetry activities, outside of the Hanford Site, in the following roles:

- DOELAP assessor of the Waste Isolation Pilot Plant dosimetry program during January 18-19, 2001.

- DOELAP assessor of the Nevada Test Site dosimetry program during May 21-24, 2001.

\subsubsection{Presentations}

Rathbone, B. A. 2001. "Current Challenges in Personnel Dosimetry at the U.S. DOE Hanford Site." Presented at the 13th International Conference on Solid State Dosimetry, Athens, Greece, July 10, 2001, PNNL-SA-35482, Pacific Northwest National Laboratory, Richland, Washington.

\subsubsection{Publications}

Scherpelz, R. I., B. A. Rathbone, and R. A. Fox. 2001. Validation of Personnel Neutron Dosimeters in the Workplace at Mound. PNWD-3118, Pacific Northwest National Laboratory, Richland, Washington. 


\subsubsection{Professional Memberships}

Rathbone, B. A., Member, HPS Working Group for ANSI N13.37, American National Standard for Environmental Dosimeters. 


\subsection{Hanford Internal Dosimetry Program}

The Hanford Internal Dosimetry Program (HIDP) was initiated in 1946 to provide for the assessment and documentation of occupational doses from intakes of radionuclides at the Hanford Site. The program is administered in support of Hanford radiation protection programs, as required by 10 CFR 835, Occupational Radiation Protection. Additional guidance is provided by the implementation guide (DOE 1999a) and the technical standard (DOE 1999b). The program provides the following internal dosimetry services:

- administration of a routine excreta monitoring program

- investigation and assessment of potential intakes

- monitoring performance of the contract excreta bioassay laboratory

- selection and application of models, procedures, and practices for evaluating intakes

- technical support to RL, DOE-Office of River Protection (ORP) and to Hanford Site contractors

- 24-hour, single-point-of-contact technical support for radiological incidents at Hanford

- bioassay scheduling for the Fluor Hanford companies, CHG, DOE-ORP, and DOE-RL. ${ }^{\text {(a) }}$

\subsection{Routine Operations}

Operational details of the HIDP are described in the following documents:

- The technical aspects of internal dose calculations are established in Methods and Models of the Hanford Internal Dosimetry Program. ${ }^{(b)}$

- The protocols and practices for operation of the program and coordination with the Hanford Site contractors are established in the Hanford Internal Dosimetry Program Manual. ${ }^{(\mathrm{c})}$

(a) This function was transferred to the Radiation Records group on October 1.

(b) Pacific Northwest National Laboratory. Current version. Methods and Models of the Hanford Internal Dosimetry Program. PNNL-MA-860, Richland, Washington. (Internal Manual; available at http://www.pnl.gov/eshs/cap/dss/epub.html)

(c) Pacific Northwest National Laboratory. Current version. Hanford Internal Dosimetry Program Manual. PNL-MA-552, Rev. 3, , Richland, Washington. (Internal manual; available at http://www.pnl.gov/eshs/cap/dss/epub.html) 
- Detailed procedures are contained in the Hanford Internal Dosimetry Procedures Manual. ${ }^{(a)}$

- Protocols for responding to radiological incidents are contained in the On-Call Exposure Evaluator Manual. ${ }^{(b)}$

- Quality assurance for the program is covered in the Quality Assurance Plan for the Operation of the Hanford Internal Dosimetry Project. ${ }^{(\mathrm{c})}$

- The technical agreements with the excreta lab are established by a contractual SOW. Technical agreements with Hanford contractors concerning responsibilities under 10 CFR 835 are established by contractual SOWs. An additional agreement for conducting work under the HIDP was established in May 2001 to clarify mutual expectations (see Section 3.2.3).

The practices and technical aspects of operating the In Vivo Monitoring Program for Hanford are established in the In Vivo Monitoring Program Manual ${ }^{(\mathrm{d})}$ (see Chapter 4.0). Individual assessments of internal dose are documented in each individual's file in the Hanford Radiological Records Program files. Bioassay measurement results and internal doses are maintained in the REX database, which is operated by the Hanford Radiological Records Program (see Chapter 5.0).

Intakes of radionuclides are generally prevented by containment or other protective measures; therefore, intakes are normally assumed to result from an acute intake. Dose assessment is based on this assumption, except for work with tritium, for which chronic or intermittent acute intakes may be assumed. In 2001, only one case of intermittent tritium intake occurred and was tracked throughout the year and assessed at the end of the year.

\subsubsection{Bioassay Capabilities}

Bioassay monitoring is performed regularly for workers who might inhale, ingest, or absorb radionuclides into their bodies in the course of their jobs. Measurement types and frequencies are based on the radionuclides of concern, their anticipated physical and chemical form, the relative risks of intakes for workers, and the costs of the bioassay (both analysis cost and cost of the worker's time away from the job). Minimum detectable activities (MDAs) and screening levels for routine excreta and in vivo bioassay measurements are shown in Tables 3.1 and 3.2. MDAs for emergency and expedited excreta measurements are provided in Table 3.3.

(a) Pacific Northwest National Laboratory. Current version. Hanford Internal Dosimetry Procedures Manual. PNL-MA-565, Richland, Washington. (Internal manual)

(b) Pacific Northwest National Laboratory. Current version. On-Call Exposure Evaluator Manual. PNL-MA-857, Richland, Washington. (Internal manual)

(c) Pacific Northwest National Laboratory. Current version. Quality Assurance Plan for the Operation of the Hanford Internal Dosimetry Project. LSC-026, Richland, Washington. (Internal manual)

(d) Pacific Northwest National Laboratory. Current version. In Vivo Monitoring Program Manual. PNL-MA-574, Richland, Washington. (Internal manual) 
Table 3.1. Specified Minimum Detectable Activities and Screening Levels for Routine Excreta Analyses During CY 2001

\begin{tabular}{|c|c|c|}
\hline Analysis $^{(a)}$ & Contractual MDA $^{(\mathbf{b}, \mathbf{c})}$ & $\begin{array}{c}\text { Screening Level And Sampling } \\
\text { Frequency }\end{array}$ \\
\hline${ }^{238} \mathrm{Pu},{ }^{239} \mathrm{Pu}$ & $0.02 \mathrm{dpm}$ & $0.01 \mathrm{dpm}^{(\mathrm{e})}(\mathrm{A})$ \\
\hline${ }^{238} \mathrm{Pu},{ }^{239} \mathrm{Pu}$ (IPUL) & $0.005 \mathrm{dpm}$ & $0.003 \mathrm{dpm}^{(\mathrm{e})}(\mathrm{A})$ \\
\hline${ }^{90} \mathrm{Sr}$ & $10 \mathrm{dpm}$ & $\begin{array}{c}5 \mathrm{dpm}(\mathrm{A}) \\
5 \mathrm{dpm}(\mathrm{BE})\end{array}$ \\
\hline${ }^{234} \mathrm{U}^{(\mathrm{f})},{ }^{238} \mathrm{U}$ & $0.02 \mathrm{dpm}$ & $0.15 \mathrm{dpm}^{(\mathrm{g})}(\mathrm{A}, \mathrm{Q})$ \\
\hline${ }^{235} \mathrm{U}$ & $0.02 \mathrm{dpm}$ & $0.01 \mathrm{dpm}^{(\mathrm{e})}(\mathrm{A}, \mathrm{Q})$ \\
\hline${ }^{241} \mathrm{Am},{ }^{243} \mathrm{Am},{ }^{242} \mathrm{Cm}$ & $0.02 \mathrm{dpm}$ & $0.01 \mathrm{dpm}^{(\mathrm{e})}(\mathrm{A})$ \\
\hline${ }^{228} \mathrm{Th},{ }^{229} \mathrm{Th},{ }^{232} \mathrm{Th}$ & $0.10 \mathrm{dpm}$ & $0.05 \mathrm{dpm}$ (not established) \\
\hline${ }^{225} \mathrm{Ac},{ }^{227} \mathrm{Th}$ & $0.10 \mathrm{dpm}$ & $0.05 \mathrm{dpm}$ (not established) \\
\hline Elemental U & $0.06 \mu \mathrm{g}$ & $0.2 \mu \mathrm{g}^{(\mathrm{g})}(\mathrm{Q})$ \\
\hline Tritium & $20 \mathrm{dpm} / \mathrm{ml}$ & $80 \mathrm{dpm} / \mathrm{ml}^{(\mathrm{h})}(\mathrm{M})$ \\
\hline \multicolumn{3}{|c|}{$\begin{array}{l}\text { (a) Analysis of urine samples, unless otherwise indicated. } \\
\text { (b) Specified MDA based on Type I and Type II errors of no greater than } 5 \% \text {, as described in the SOW (a copy is } \\
\text { available in the Hanford Radiation Protection Historical Files). } \\
\text { (c) Amount per total sample volume, unless otherwise indicated. } \\
\text { (d) Follow-up actions are taken when this value is exceeded (routine bioassay monitoring frequency: A - annual, } \\
\mathrm{BE} \text { - biennial, } \mathrm{BW} \text { - biweekly, } \mathrm{M} \text { - monthly, } \mathrm{Q} \text { - quarterly). } \\
\text { (e) Screening level is anything detected. The decision level for detection varies from sample to sample. Value listed } \\
\text { is nominal. } \\
\text { (f) The lab cannot discriminate between }{ }^{233} \mathrm{U} \text { and }{ }^{234} \mathrm{U} \text { and reports the results as }{ }^{234} \mathrm{U} \text { (beginning in 1994). } \\
\text { (g) Upper level of expected environmentally derived uranium in urine for the Hanford region. } \\
\text { (h) Special screening levels are established for short-term tritium work where beginning and ending work samples are } \\
\text { obtained instead of monthly routine sampling. }\end{array}$} \\
\hline
\end{tabular}

The routine excreta screening levels were changed for radionuclides analyzed by alpha spectrometry (except ${ }^{234} \mathrm{U}$ and ${ }^{238} \mathrm{U}$ ) from a fixed value of $0.01 \mathrm{dpm} / \mathrm{sample}$ to the decision level for the specific sample, where the decision level is calculated as 2 times the total propagated uncertainty. For alpha-emitting isotopes of plutonium, the decision level usually varies from about 0.005 to $0.01 \mathrm{dpm} / \mathrm{sample}$.

\subsubsection{Excreta Bioassay Contract Activities}

The bioassay contract laboratory (Severn-Trent Laboratory of Richland [STL]) remained timely with results throughout 2001. Excessive failed analyses for the ${ }^{243} \mathrm{Am}$ procedure were discussed with the laboratory early in the year, and none were reported after July. That procedure also showed early signs of not meeting the MDA criterion, but final results for the year were acceptable. The false positive problem mentioned last year was corrected, even though reagent blank subtraction was not implemented until December. 
Table 3.2. Minimum Detectable Activities and Screening Levels for Routine In Vivo Measurements During CY 2001

\begin{tabular}{|c|c|c|}
\hline Measurement/Radionuclide (a) $^{(\text {Ra }}$ & $\operatorname{MDA}^{(\mathbf{b})}(\mathrm{nCi})$ & Screening Level $^{(\mathrm{c})}(\mathrm{nCi})$ \\
\hline \multicolumn{3}{|l|}{ Standup Whole Body Count } \\
\hline${ }^{60} \mathrm{Co}$ & 1.3 & 4 \\
\hline${ }^{154} \mathrm{Eu}$ & 3.7 & Any detected \\
\hline${ }^{137} \mathrm{Cs}$ & 1.3 & Any detected \\
\hline \multicolumn{3}{|l|}{ Coaxial Germanium Whole Body Count } \\
\hline${ }^{137} \mathrm{Cs}$ & 0.80 & Any detected \\
\hline${ }^{60} \mathrm{Co}$ & 0.60 & 4 \\
\hline${ }^{154} \mathrm{Eu}$ & 1.7 & Any detected \\
\hline \multicolumn{3}{|l|}{ Lung Count } \\
\hline${ }^{235} \mathrm{U}$ & 0.090 & Any detected \\
\hline${ }^{238} \mathrm{U}\left(\right.$ by $\left.{ }^{234} \mathrm{Th}\right)$ & 1.5 & Any detected \\
\hline${ }^{241} \mathrm{Am}$ & 0.16 & Any detected \\
\hline \multicolumn{3}{|c|}{$\begin{array}{l}\text { (a) For selected radionuclides. (The detection of radionuclides not listed resulted in follow-up, except for }{ }^{40} \mathrm{~K},{ }^{214} \mathrm{Bi} \text {.) } \\
\text { (b) For each in vivo count, the decision levels (approximately half of the MDAs) were reported under the heading "detection } \\
\text { limit" to REX, but, in terms of overall detectability for all measurements, the above MDAs were still applicable. } \\
\text { (c) Level for which an investigation of internal exposure was considered. Any detected activity above background (i.e., above } \\
\text { the decision level) was reported to the HIDP. }\end{array}$} \\
\hline
\end{tabular}

Table 3.3. Specified Minimum Detectable Activities for Emergency and Expedited Excreta Bioassay During CY 2001

\begin{tabular}{|c|c|c|}
\hline \multirow[t]{2}{*}{ Analysis $^{(a)}$} & \multicolumn{2}{|c|}{ Contractual MDA (Per Sample) } \\
\hline & Urine & Feces \\
\hline \multicolumn{3}{|l|}{ Emergency Analyses $^{(\mathrm{b})}$} \\
\hline Isotopic Plutonium by Alpha Spectrometry & $0.5 \mathrm{dpm}$ & $9 \mathrm{dpm}$ \\
\hline Isotopic Uranium by Alpha Spectrometry & $1.0 \mathrm{dpm}$ & $12 \mathrm{dpm}$ \\
\hline${ }^{241}$ Am by Alpha Spectrometry & $1.0 \mathrm{dpm}$ & $20 \mathrm{dpm}$ \\
\hline${ }^{241} \mathrm{Am}$ by $\mathrm{LEPD}^{(\mathrm{c})}$ & $20 \mathrm{dpm}$ & $20 \mathrm{dpm}$ \\
\hline Total Radiostrontium & $80 \mathrm{dpm}$ & $450 \mathrm{dpm}$ \\
\hline Elemental Uranium & $7 \mu \mathrm{g}$ & $8 \mu \mathrm{g}$ \\
\hline Tritium & $100 \mathrm{dpm} / \mathrm{ml}$ & $\mathrm{NA}^{(\mathrm{e})}$ \\
\hline \multicolumn{3}{|l|}{ Expedited Analyses $^{(\mathrm{d})}$} \\
\hline Isotopic Plutonium by Alpha Spectrometry & $0.08 \mathrm{dpm}$ & $3 \mathrm{dpm}$ \\
\hline Isotopic Uranium by Alpha Spectrometry & $0.12 \mathrm{dpm}$ & $4 \mathrm{dpm}$ \\
\hline${ }^{241}$ Am by Alpha Spectrometry & $0.08 \mathrm{dpm}$ & $6 \mathrm{dpm}$ \\
\hline${ }^{241}$ Am by LEPD & $5 \mathrm{dpm}$ & $5 \mathrm{dpm}$ \\
\hline Total Radiostrontium & $50 \mathrm{dpm}$ & $150 \mathrm{dpm}$ \\
\hline Elemental Uranium & $0.5 \mu \mathrm{g}$ & $5 \mu \mathrm{g}$ \\
\hline Tritium & $100 \mathrm{dpm} / \mathrm{ml}$ & NA \\
\hline \multicolumn{3}{|c|}{$\begin{array}{l}\text { (a) For the more critical analyses only. The list does not contain all of the analyses covered in the contract. } \\
\text { (b) Verbal reporting time was generally within } 8 \text { hours after receipt of the sample; reporting times were even shorter for some analyses. } \\
\text { (c) LEPD = low-energy photon detector; direct counting of X-rays without radiochemical separation. } \\
\text { (d) Verbal reporting time was by 9:00 a.m. on the second business day after receipt of the sample. } \\
\text { (e) NA = not applicable. }\end{array}$} \\
\hline
\end{tabular}


Investigations concerning a high result for a worker's routine plutonium urinalysis did not identify a credible potential for intake. However, it was noted that a double-blind QC sample was analyzed in the same batch, and the high routine result was consistent with the spike activity and volume of the QC sample. The QC sample was spiked with both ${ }^{238} \mathrm{Pu}$ and ${ }^{239} \mathrm{Pu}$ in a ratio inconsistent with the normal Hanford source term. The analytical laboratory determined that the internal tracking numbers assigned to the two samples differed only by the third character in an eight character alphanumeric field, and the samples were most likely switched at the time the samples were poured into beakers to start the digestion process. Laboratory management attended team meetings with the involved analysts, and stressed the importance of matching the sample identifications on the original sample container, on the glassware prepared to contain the sample, and on the paperwork associated with the analysis. They also pointed out to the analysts that the paperwork should be examined at the start of the process to identify sample numbers that are sufficiently similar that extra vigilance should be exercised.

A review of bioassay kit delivery procedures was prompted when a urine bioassay kit was delivered in place of the requested fecal kit twice to the same individual. In response, the analytical laboratory implemented the following changes: the computer-printed labels for fecal kits now show a prominent "F," and the bioassay kit delivery scheduler highlights the "F" on the list of kits to be assembled and adds a comment to draw additional attention to the fecal request.

The contract with the analytical laboratory was amended this year to require reporting of replicate analyses of worker samples, and 96 pairs of aliquots were reported (this applies to elemental uranium analyses). The results for only one of the 96 pairs differed from zero by more than three standard deviations of the difference. The other 95 pairs differed from zero by less than two standard deviations, and the regression line for the two analyses had a $\mathrm{R}^{2}$ value of 0.992 . Consequently, the elemental uranium aliquoting procedure was determined to be adequate.

\subsubsection{Excreta Bioassay Monitoring Activities}

Sample requests can be categorized as standard or nonstandard. Standard requests are those generated by the REX database from a predetermined, routine schedule (e.g., a worker may be scheduled for an annual sample collected every April). These requests are downloaded from REX and electronically transferred to the analysis laboratory just before the start of each month. All other requests are considered nonstandard requests. Contractors and HIDP staff manually enter the nonstandard requests into REX. HIDP staff checks the nonstandard request file in REX for input errors and perform the electronic transfer of the requests to the laboratory. Figure 3.1 shows the monthly distribution of standard and nonstandard requests for 2001. A total of 5,045 samples was requested in 2001, an increase of about $8 \%$ from the number of requests in 2000 . The number of nonstandard requests $(52 \%)$ slightly exceeded the number of standard requests. In general the ratio of nonstandard to standard requests has been hovering around 50:50 over the last 4 years. The reason for distinguishing between standard and nonstandard requests has not been particularly important in recent years so with concurrence from the Hanford contractors only the total requests will be tracked from here on. 


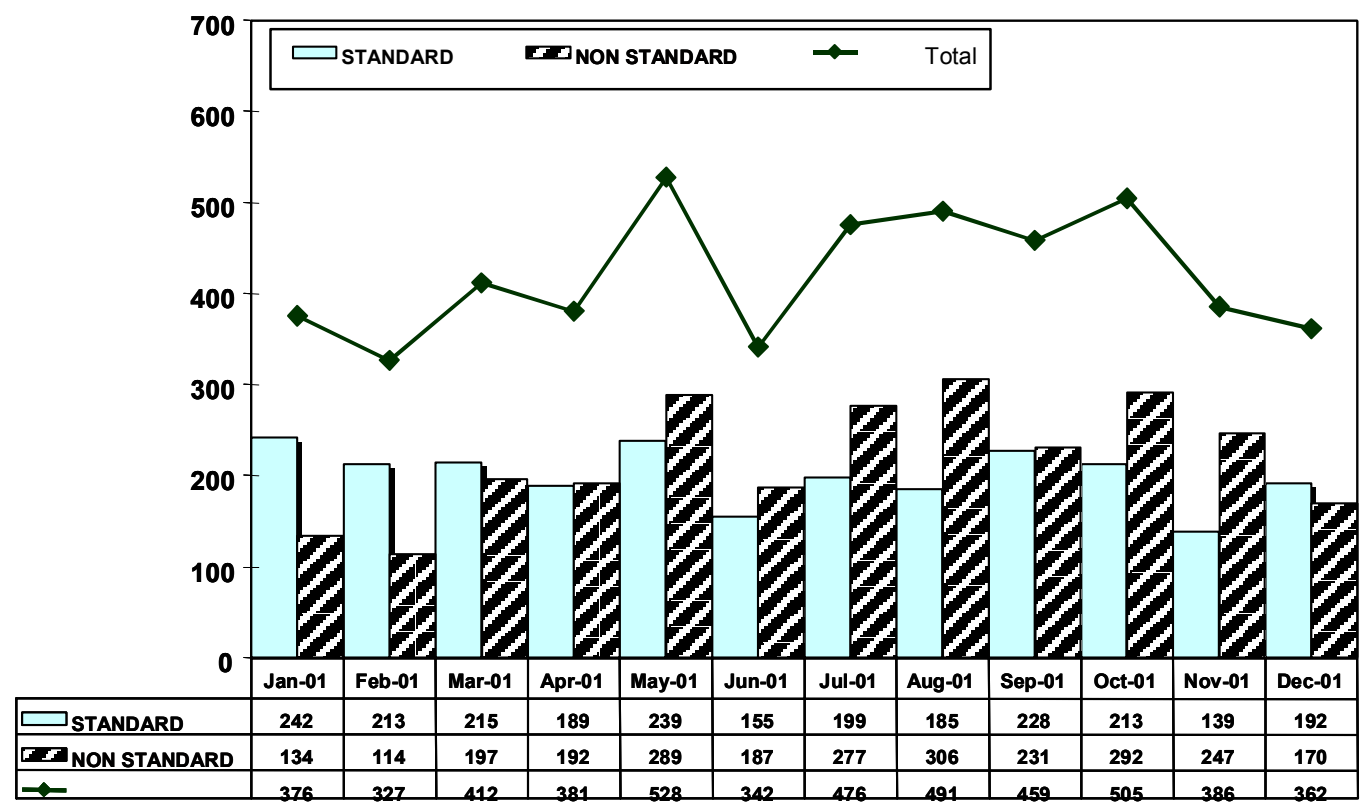

Figure 3.1. Standard and Nonstandard Excreta Requests by Month for 2001

During 2001, 5,132 excreta bioassay measurements were successfully performed in support of Hanford activities, excluding cancellations, no-samples, samples without valid results, and QC samples (isotopic results for each element count as one measurement if measured by the same technique). Of these, $96 \%$ were classified as routine (including measurements on visitors) and $4 \%$ were due to special circumstances, such as response to unplanned potential intakes or follow-up analyses to high routine measurements. The percentages of routine and special measurements were essentially the same as for previous years.

Figure 3.2 shows the trend in routine urinalyses since 1994. The figure shows that the number of routine measurements in 2001 was slightly less than in 2000 but roughly similar to the trend of the last 4 years. The large decrease between 1994 and 1995 through 1997 demonstrates the results of major efforts to tighten the requirements for placing workers on routine bioassay schedules and to remove workers from routine schedules who were at negligible risk for intakes. The increase since 1997 reflects more work in contaminated areas.

Details on the type of excreta measurements categorized by contractor are provided in Table 3.4. Overall, the number of excreta measurements decreased about $4 \%$ from 2000 , but was consistent with the average per year for the last 4 years. Tritium urinalysis increased $15 \%$ due to increased tritium work at PNNL. Implementation of a new radiological entry control system may also have contributed to the increase. Strontium urinalyses decreased $28 \%$ reflecting more use of whole body counting for ${ }^{137} \mathrm{Cs}$ as an indicator of intake of ${ }^{137} \mathrm{Cs}^{90} \mathrm{Sr}$ mixtures. PNNL showed a slight increase in its percentages of the total excreta measurements in 2001 while FH and CHG showed slight decreases in their percentages. The latter two companies had aggressive programs to discover and waive unnecessary bioassay, whereas PNNL did not. 


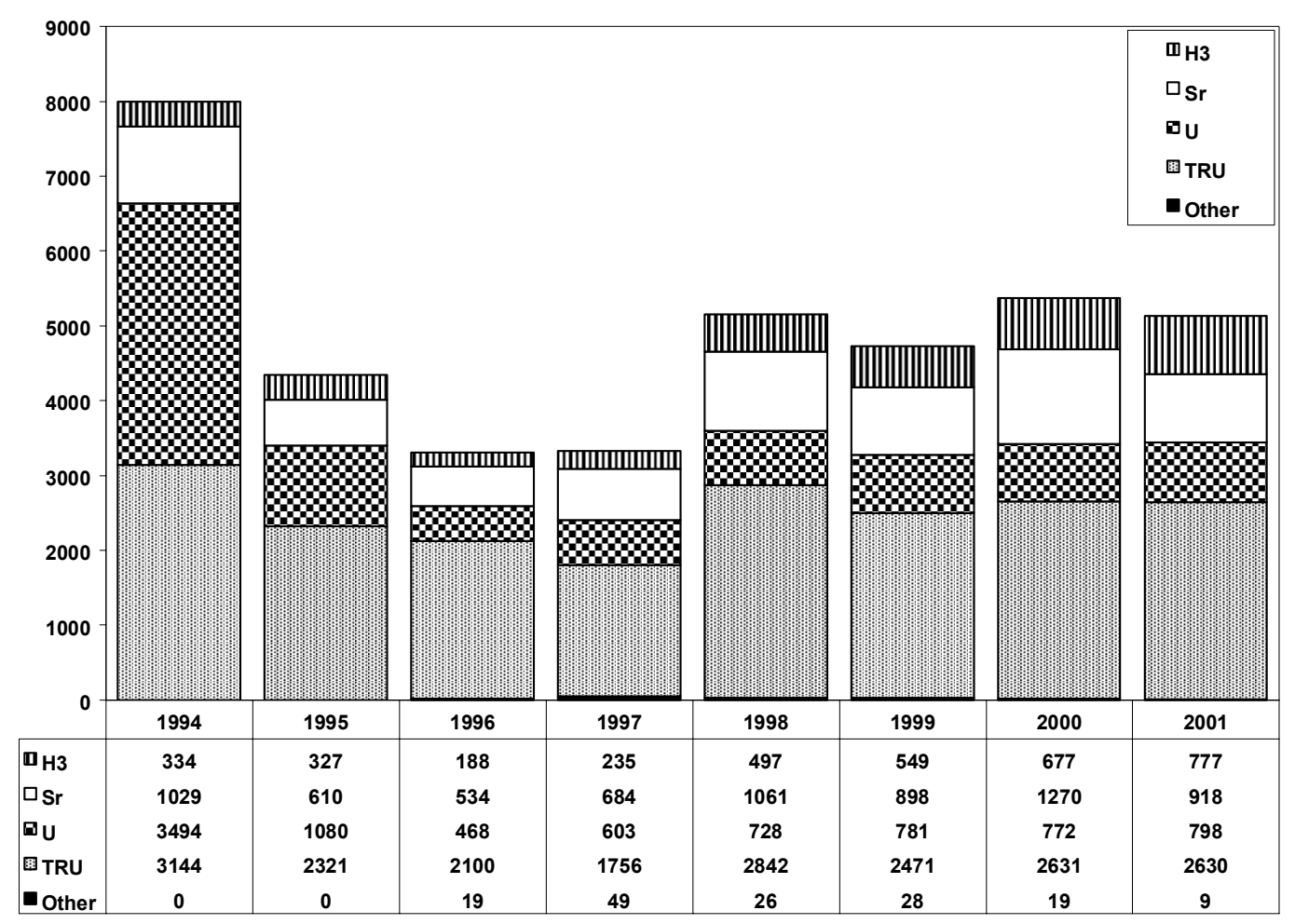

Figure 3.2. Routine Urine Measurements Made from 1994 Through 2001

Not all excreta bioassay requests produce valid measurement results; these are referred to as "nosamples." When a sample is not obtained, it has to be requested again. (Note: the following statistics refer to the number of unsuccessful attempts to obtain a sample within the 10-day window specified in the SOW with the laboratory; statistics in the next paragraph address the question as to whether or not a sample was eventually collected). In 2001, 779 excreta sample requests were designated as no-samples, compared with 611 no-samples in 2001. This increase explains in part why the number of sample requests increased but the number of measurements decreased because a second sample has to be ordered for each no-sample. In terms of percentage of total requests, the 2001 rate (15\%) was consistent with previous years $(11 \%, 15 \%, 18 \%$, and $21 \%$ in $2000,1999,1998$, and 1997 , respectively). In addition, there were 168 canceled requests that show in the records. Unsuccessful sample collections (their associated no-sample code and percentage of the total no-samples) were attributed to the following causes: kit not delivered (ND, 5\%), no sample received (NS, 25\%), lost container (LC, 39\%), insufficient sample volume (IS, 8\%), and failed analyses (FA, 22\%). The percentage of each type of unsuccessful sample is similar to previous years except for a marked decrease in the insufficient sample volume category. 
Table 3.4. Worker Excreta Measurements Reported During CY 2001

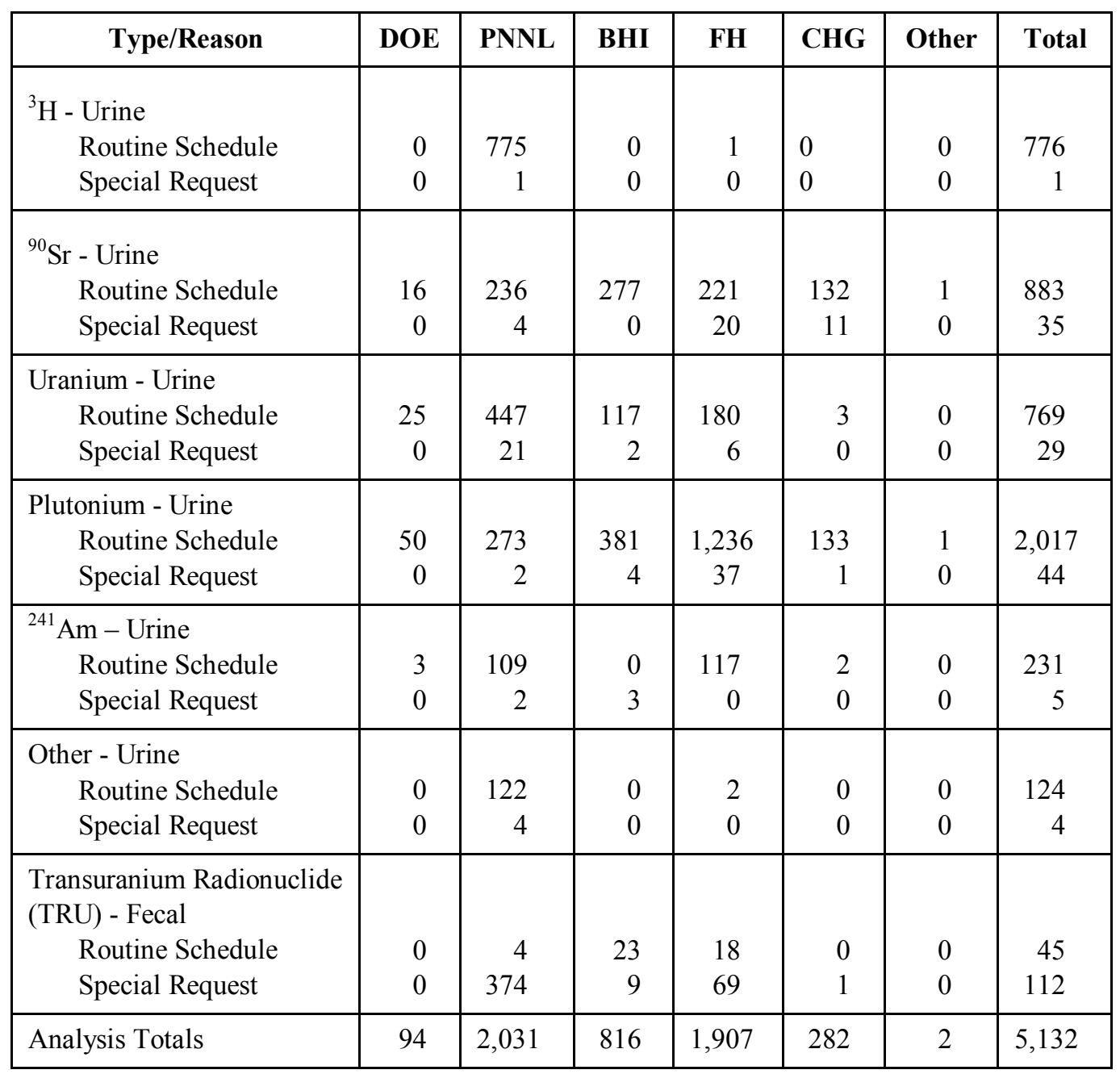

There is special interest in whether or not bioassay samples are ultimately (i.e., after several attempts) collected within the grace period (a period extending about a month beyond the due date, after which a worker is barred from entering radiation areas). Figure 3.3 shows the number of excreta bioassay samples not collected within the grace period, excluding confirmatory samples scheduled by Bechtel Hanford, which are not compliance samples. The 44 not collected within the grace period represent about $1 \%$ of the total samples obtained. The statistics do not include situations where collecting a sample was not considered reasonable, such as during pregnancy leave, short- or long-term disability leave, or a longterm work assignment at another location. Figure 3.4 shows a similar statistic for compliance samples requested from terminating workers, i.e., samples not ultimately obtained. 2001 was a very successful year for obtaining excreta samples from terminating workers. 


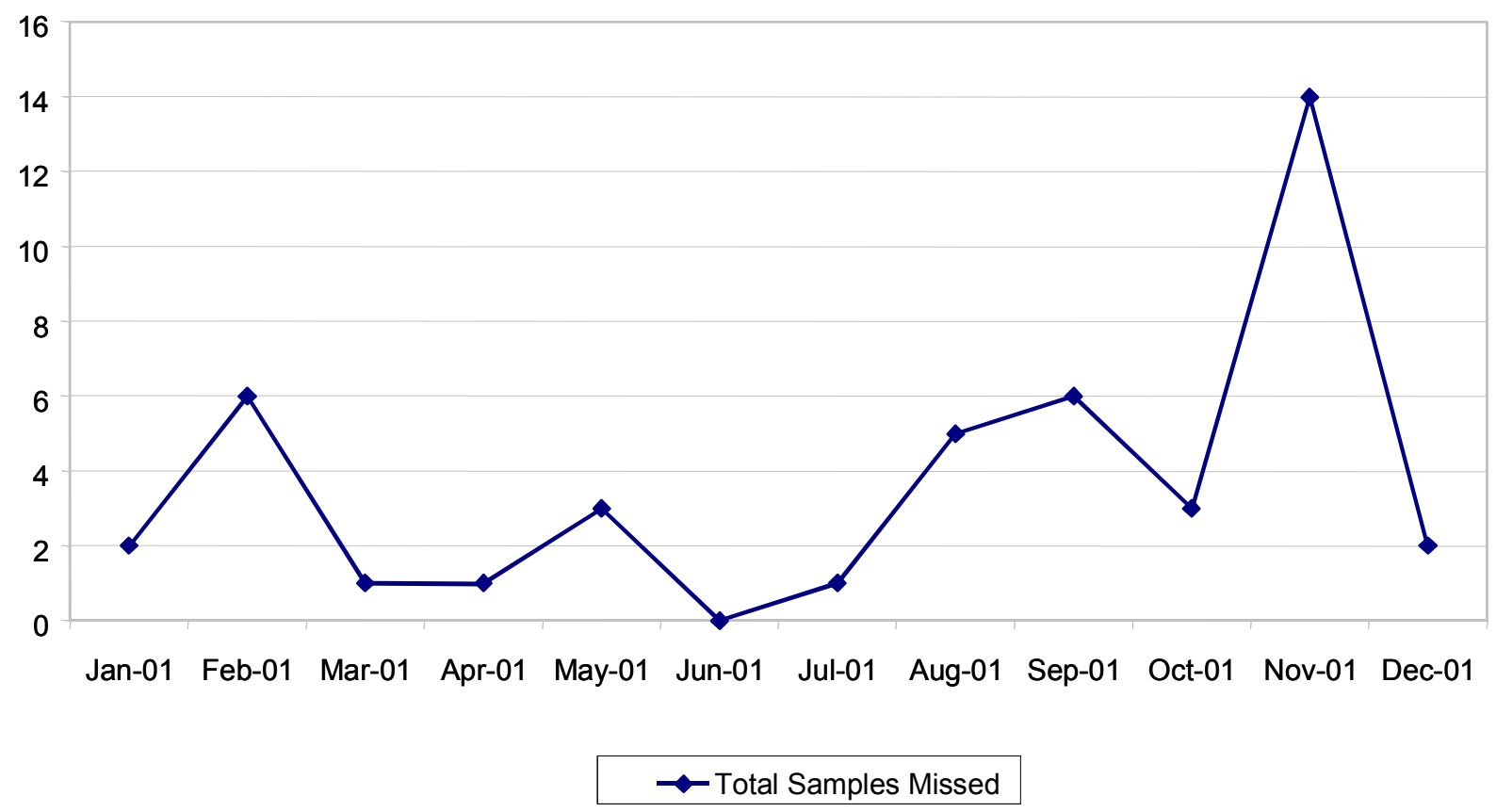

Figure 3.3. Excreta Samples Not Obtained within the Grace Period

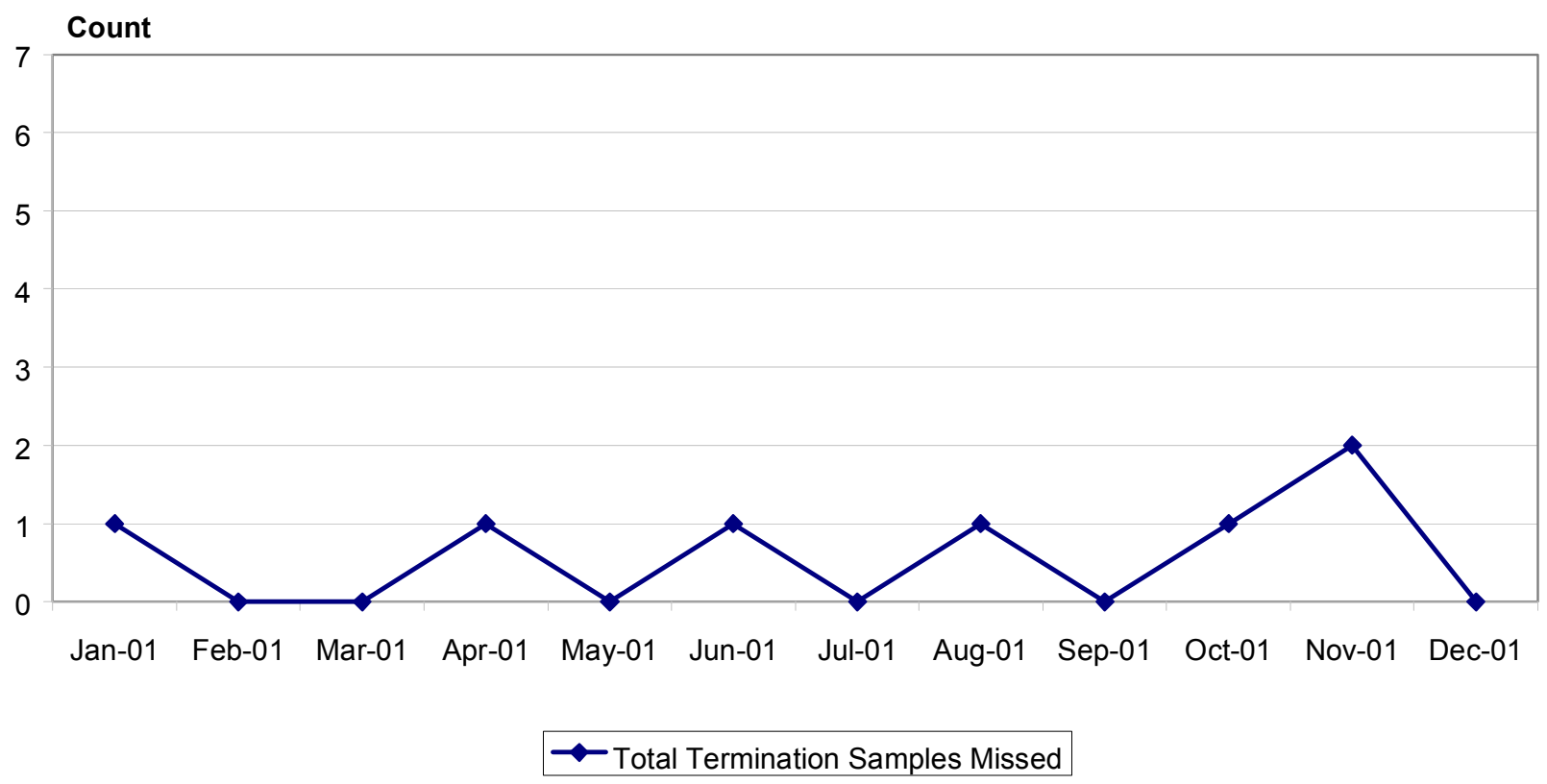

Figure 3.4. Termination Excreta Samples Not Obtained 


\subsubsection{Potential Intake Evaluations}

Investigations of possible radionuclide intakes are performed following an indication from a routinely scheduled bioassay measurement (high routine) or for a potential exposure incident identified in the workplace (incident). Potential exposure incidents are identified by workplace indicators such as air sampling, contamination surveys, nasal smears, or smears from potentially contaminated wounds. Evaluations are also performed for newly hired workers who incur intakes prior to their Hanford employment to ensure that the pre-Hanford intake information is converted to dose in a manner consistent with DOE regulations. Reevaluations of internal dose may also be conducted for workers with significant long-term body burdens (reevaluations).

During 2001, 18 incidents with the potential for intake, involving 40 workers, were identified through workplace monitoring. Of the 40 workers involved in the incidents, intakes were confirmed for 27 workers (one worker had two confirmed intakes) coming from 14 of the incidents. One worker's internal dose from a plutonium-contaminated wound was still under investigation but was preliminarily estimated to be between 300- to 1000-mrem committed effective dose equivalent (CEDE). All other intakes resulted in internal doses less than 100-mrem CEDE. Internal doses for four workers from one incident were assigned based entirely on air sample data. Table 3.5 shows the incident breakdown by contractor, facility, and principal radionuclides.

In addition to incidents, potential intakes can be discovered through the routine bioassay program, although in recent years very few actual (i.e., confirmed) intakes have been discovered this way. In 2001, 92 evaluations were started because of routine bioassay results that exceeded the criteria for investigation (excluding evaluations started because of intakes incurred prior to employment at Hanford). Intakes were assigned for one worker who had intermittent exposure to tritium, which was treated as chronic intake. The internal dose from this series of tritium intakes was 1-mrem CEDE. (Normally routine intakes resulting in internal dose less than $10 \mathrm{mrem}$ are not confirmed, but chronic tritium intakes are treated differently.) Table 3.6 indicates the trends in all types of potential intake evaluations since 1995.

Table 3.5. Summary of Potential Intake Incidents During 2001

\begin{tabular}{|c|c|c|c|c|c|c|}
\hline Area & Facility & Custodian & $\begin{array}{l}\text { Number of } \\
\text { Incidents }\end{array}$ & $\begin{array}{c}\text { Number of } \\
\text { Workers }\end{array}$ & $\begin{array}{c}\text { Worker } \\
\text { Contractor }\end{array}$ & $\begin{array}{c}\text { Principal } \\
\text { Radionuclides }\end{array}$ \\
\hline $200-E$ & 241-AZ & $\mathrm{CHG}$ & 1 & $\begin{array}{l}1 \\
2\end{array}$ & $\begin{array}{c}\text { CHG } \\
\text { FH }\end{array}$ & ${ }^{137} \mathrm{Cs},{ }^{90} \mathrm{Sr}$, Pu-mix \\
\hline $200-W$ & $233-\mathrm{S}$ & $\mathrm{BHI}$ & 5 & 5 & $\mathrm{BHI}$ & Pu-mix \\
\hline $200-W$ & $276-\mathrm{S}$ & BHI & 1 & 1 & BHI & Pu-mix \\
\hline $200-W$ & $234-5 Z$ & $\mathrm{FH}$ & 4 & 5 & $\mathrm{FH}$ & Pu-mix \\
\hline $200-W$ & $236-Z$ & $\mathrm{FH}$ & 1 & 11 & $\mathrm{FH}$ & Pu-mix \\
\hline 300 & 325 & PNNL & 4 & $\begin{array}{r}11 \\
1 \\
\end{array}$ & $\begin{array}{c}\text { PNNL } \\
\text { FH }\end{array}$ & Pu-mix \\
\hline 300 & 326 & PNNL & 1 & 1 & PNNL & ${ }^{137} \mathrm{Cs}$ \\
\hline 300 & 3720 & PNNL & 1 & 2 & PNNL & Pu-mix \\
\hline \multicolumn{3}{|l|}{ Total } & 18 & 40 & & \\
\hline
\end{tabular}


Table 3.6. Comparison of Potential Intakes by Reason Code, 1995 to 2001

\begin{tabular}{|l|c|c|c|c|r|r|r|}
\hline & $\mathbf{1 9 9 5}$ & $\mathbf{1 9 9 6}$ & $\mathbf{1 9 9 7}$ & $\mathbf{1 9 9 8}$ & $\mathbf{1 9 9 9}$ & $\mathbf{2 0 0 0}$ & $\mathbf{2 0 0 1}$ \\
\hline Confirmed & 12 & 11 & 12 & 8 & 15 & 33 & 27 \\
Unconfirmed & 39 & 30 & 33 & 178 & 42 & 32 & 13 \\
Open & & 1 & 6 & & 0 & 0 & 0 \\
$\quad$ Incident, Total & 51 & 42 & 51 & 186 & 57 & 65 & 40 \\
\hline Confirmed & 1 & 5 & 10 & 22 & 5 & 2 & 0 \\
Unconfirmed & 58 & 33 & 75 & 114 & 91 & 97 & 91 \\
Open & & & & & 0 & 0 & 0 \\
$\quad$ High Routine, Total & 59 & 49 & 85 & 136 & 96 & 99 & 91 \\
\hline Confirmed & & & 2 & & 12 & 4 & 1 \\
Unconfirmed Chronic & & & 0 & & 0 & 0 & 0 \\
$\quad$ Exposure, Total & 0 & 0 & 2 & 0 & 12 & 4 & 1 \\
\hline Confirmed & 9 & 11 & 10 & 9 & 23 & 37 & 12 \\
Unconfirmed & & 1 & & 4 & 1 & 0 & 1 \\
Open $\quad$ & & & & & 0 & 0 \\
$\quad$ Pre-Hanford, Total & 9 & 12 & 10 & 13 & 24 & 37 & 13 \\
\hline Confirmed & 22 & 27 & 34 & 39 & 55 & 76 & 40 \\
Unconfirmed & 97 & 64 & 108 & 296 & 134 & 129 & 105 \\
Open & & & & & 0 & 0 & 0 \\
$\quad$ Totals & 119 & 94 & 148 & 335 & 189 & 205 & 145 \\
\hline Reevaluations Completed & 17 & 1 & 0 & 3 & 0 & 0 & 1 \\
\hline
\end{tabular}

Figure 3.5 shows the workload of open cases as recorded at the end of each month. This figure suggests that about 40 evaluations per month were in process during the first half of the year and a bit over 50 evaluations per month during the second half. The latter increase was due to the spike in new cases in July coupled with the loss of a dosimetrist to short-term disability for the whole summer.

The range of internal doses assigned to the Hanford workforce in 2001 is summarized in Table 3.7. The total number in Table 3.7 differs from the total number of confirmed intakes in Table 3.6 because one worker had two intakes. In the last 3 years, there has been only one intake resulting in a CEDE that exceeded 100 mrem. 


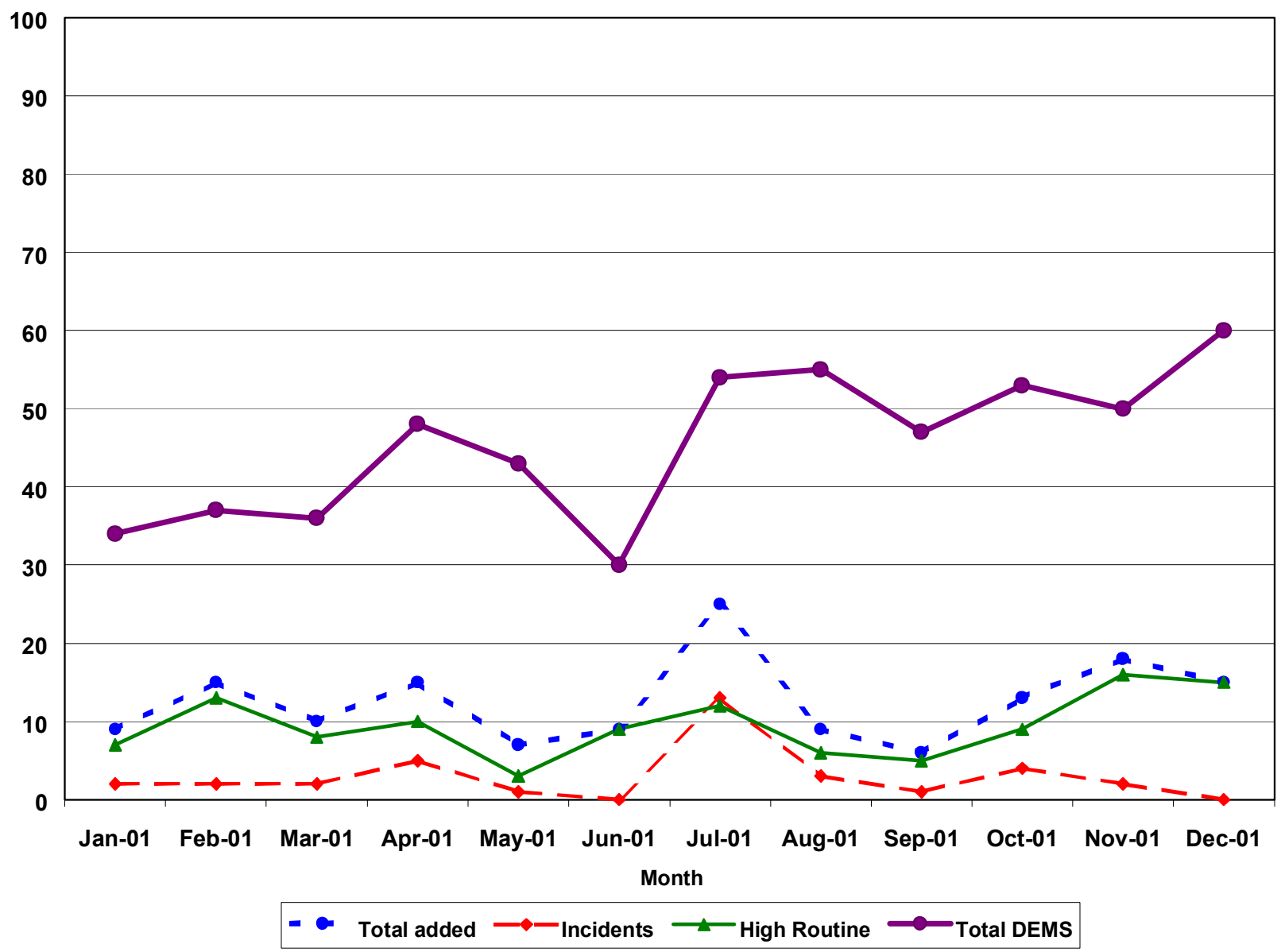

Figure 3.5. Number of Open Evaluations by Month. (Top curve shows the number of evaluations open on the last day of each month.)

Table 3.7. Range of New Internal Doses Assigned to the Hanford Workforce in 2001

\begin{tabular}{|l|c|c|c|c|c|c|}
\hline \multirow{2}{*}{ Dose (mrem) } & \multicolumn{7}{|c|}{ Number of Workers } \\
\cline { 2 - 7 } & DOE & FH & PNNL & BHI & CHG & Total \\
\hline$<100$ & 0 & 13 & 7 & 5 & 1 & 26 \\
\hline $100-<500$ & 0 & 0 & 0 & $1^{(b)}$ & 0 & 1 \\
\hline $500-<2000$ & 0 & 0 & 0 & 0 & 0 & 0 \\
\hline $2000-<5000$ & 0 & 0 & 0 & 0 & 0 & 0 \\
\hline$>5000$ & 0 & 0 & 0 & 0 & 0 & 0 \\
\hline
\end{tabular}

(a) CEDE, based on 2001 evaluations, although the intake could have occurred in any year; excludes reevaluations. (b) Estimated, final dose for this case has not been quantified yet. 


\subsection{Program Changes and Improvements}

Four program changes and improvements were made during CY 2001 as described in the following sections.

\subsubsection{Policy for Using DAC-Hour Tracking Data}

HIDP led a subcommittee of the HPDAC that developed a sitewide policy for using air sample data for internal dosimetry purposes. Over the last several years, contractors have been expanding their linkage of air sample data to specific workers and tracking worker-specific cumulative intake potential throughout a calendar year. Each worker's intake potential was determined as the multiple of the fraction of the derived air concentration (DAC) times the worker's time breathing the contaminated air in hours. The unit is called a DAC-hour (hr). The DAC-hr for each exposure was summed for each worker over the calendar year. Because the cumulative DAC-hrs can be used as an estimate of intake, a policy was needed to decide when intake (and resulting internal dose) would be determined from bioassay data and when from DAC-hr data.

The recommendations endorsed by the HPDAC and incorporated into the Hanford Internal Dosimetry Program Manual are to

- maintain a DAC-hour tracking log for single intakes exceeding 1 DAC-hr

- initiate special bioassay for acute potential intakes exceeding 40 DAC-hrs

- consider special bioassay for acute potential intakes between 10 to 40 DAC-hrs, but use judgment in deciding whether bioassay or the air sample data are more representative of the actual intake

- allow calculation of intake and internal dose from air sample data without bioassay data for acute potential intakes below 10 DAC-hrs and for multiple acute or chronic intakes resulting in a cumulative potential intake between 10 to 40 DAC-hrs

- recognize that a cumulative potential intake less than 10 DAC-hrs need not be converted to official intake and internal dose of record

- require documentation of the representativeness of air sample data relative to air breathed by Field Dosimetry for inclusion in the dose assessment when air sample data are used to assign intake and dose.

\subsubsection{Manual Changes}

Chapter 4 of the internal manual, Methods and Models of the Hanford Internal Dosimetry Program, was revised to include air concentration values for organically bound tritium and stable tritiated particles. The air concentration values were obtained from the DOE Radiological Control Technical Position RCTP 2001-02, “Acceptable Approach for Developing Air Concentration Values for Controlling Exposures to Special Tritium Compounds" (DOE 2001).

Changes to the program instituted through the Hanford Internal Dosimetry Program Manual are summarized in Table 3.8 . 
Table 3.8. Changes to the Hanford Internal Dosimetry Program Manual

\begin{tabular}{|l|l|}
\hline \multicolumn{1}{|c|}{ Section } & \multicolumn{1}{c|}{ Changes } \\
\hline 2. Practices of the HIDP & $\begin{array}{l}\text { Added 10-DAC-hr criterion for intake assessment. Clarified timing of intake } \\
\text { assessments. }\end{array}$ \\
\hline 3. Assessment of Internal Dose & $\begin{array}{l}\text { Added policy to have statement from contractors concerning representativeness } \\
\text { of air sample results if those results are used for dose assessment. }\end{array}$ \\
\hline 5. Bioassay Monitoring & $\begin{array}{l}\text { Revised bioassay program recommendations for Sr:Pu, Sr:Cs-137, Cs-137:Pu } \\
\text { mixtures based on dose conversion factors in Methods and Models of the } \\
\text { Hanford Internal Dosimetry Program. Added new Hanford policy on DAC-hr } \\
\text { tracking and use of DAC-hrs for dose assessment (see Section 3.2.1). Added } \\
\text { statement about assumption of class Y for dry legacy Pu. Revised the bioassay } \\
\text { capability exhibits based on the dose conversion factors mentioned above. }\end{array}$ \\
\hline $\begin{array}{l}\text { 7. Internal Contamination Incident } \\
\text { Response }\end{array}$ & $\begin{array}{l}\text { Added 40-DAC-hr criterion for special bioassay and 10 DAC-hr criterion for } \\
\text { dose assessment. }\end{array}$ \\
\hline
\end{tabular}

\subsubsection{Update on New Decision Level for Alpha Spectrometry}

As discussed in last year's annual report, the computational method for determining the decision level for excreta bioassay analyzed by alpha spectrometry was revised to

$$
\mathrm{L}_{\mathrm{c}}=2 \bullet(\mathrm{TPU})
$$

where TPU is the total propagated uncertainty for the reported result. As of January 18, 2001, this change was used by HIDP in dose assessments and when reviewing results in REX using the Incorrect High Flag Report. However, the excreta laboratory did not make the programming changes and did not start setting a high flag for results exceeding the decision level using this formula until September 13, 2001. For January through September then, the lab was setting the high flag using a method that generally produced slightly higher decision levels than was anticipated by HIDP. Nevertheless HIDP used the lower value when reviewing the database and for deciding when to initiate follow-up activities so in essence the lower value was in effect despite what the lab reported.

\subsubsection{Hanford Bioassay System Functional Requirements and Risk Assessment}

Four quality problem reports related to bioassay were filed in 2000. These were presented as a group to PNNL's Price Anderson Amendment Act (PAAA) Working Group in November 2000 and were determined to be reportable as a management concern in January 2001. The problems were not entirely within the HIDP, but were isolated cases of breakdown of the complex of systems that together constitute the methods for scheduling, obtaining, and tracking status of bioassay and the prompt reporting of results of concern. In addition to the corrective actions associated with each quality problem report, the PAAA Working Group recommended that the functional requirements for the entire bioassay system be developed with input from the Hanford contractors and RL. This along with an assessment of how well the system met the requirements and if there were weak links in the system subject to potential 
breakdown was issued in May. ${ }^{\text {(a) }}$ The risk assessment uncovered several areas where human error could lead to a breakdown in the system for which there was no backup. Some of these items were fixed promptly, some were tracked as corrective actions as part of the DOE Noncompliance Tracking System (NTS) management concern, and others were presented to the HPDAC but ultimately were not considered significant enough to pursue. All of the corrective actions were completed and the NTS item was closed by November.

\subsection{Program Assessments and Oversight}

Six program assessments or oversight activities were conducted as described in the following sections.

\subsubsection{Excreta Quality Control Oversight Program}

The excreta QC oversight program operated as usual throughout 2001. The Quality Control Report for the second operational year of the new contract (September 2000 through September 2001) was still being drafted at the end of the year. Preliminary results indicated laboratory performance was consistent with previous years, but there continued to be significant discrepancies between the ${ }^{239} \mathrm{Pu}$ spike activities reported by the preparation laboratory and analytical results during the first half of the year (see also Section 3.3.1 in last year's report). These discrepancies were considered to be the result of problems in the spiking laboratory, not with the analytical contractor. Last year, modifications to the spike preparation laboratory procedure included minimizing the time sample containers are open by pre-weighing added water and completing the task as quickly as possible, preparing blank samples in a laminar flow hood, replacing all reagent materials with new stock, and using quartz-distilled water instead of just nanopure water. Because these steps did not appear to solve the problem, it was agreed at a meeting in July 2001 that the repipettor should also be replaced (pipette tips are replaced after each use). By year-end no new discrepancies had surfaced, so the problem may be solved; however, testing continues.

\subsubsection{Onsite Inspection of the Contracted Excreta Laboratory}

The annual QA assessment of the analytical laboratory under Contract 313500 was conducted in November 2001. In addition to the contract's QA requirements, the audit covered the contractor's procedures and Quality Assurance Management Plan. Requirements not specifically evaluated during the Environmental Management Consolidated Audit Program audit conducted in September were also assessed.

Three findings and one observation were noted during the audit. The findings noted that 1) procedures were inadequate to assure collection of appropriate sample type, 2) several proportional counter calibrations exceeded the annual interval, and 3) the procurement document for calibration services did not provide for audit of subcontractor quality systems by Battelle. The observation noted that the Internal Chain of Custody program did not have the logic to prevent the analyst from skipping steps in the process. Due to illness and other work obligations of the lead auditor, STL did not receive the audit report before the end of the year, but all findings are expected to be corrected satisfactorily.

(a) Internal report, 2001, D. E. Bihl and E. F. Talbott, "Hanford Bioassay System Functional Requirements and Risk Assessment," available from the Radiation Record Historical File. 


\subsubsection{Testing of Backup Lab for Rapid Plutonium and Strontium Analyses}

Capabilities for performing rapid urinalyses for plutonium and radiostrontium (assumed to be ${ }^{90} \mathrm{Sr}$ ) by PNNL's Radiomaterials Chemistry Team are tested annually. These capabilities are intended to serve as backup for the contract laboratory. The Radiomaterials Chemistry Team satisfactorily completed the analyses of the blind performance samples again this year.

\subsubsection{Bechtel National Incorporated Assessment}

Quality Assurance representatives from Bechtel National Inc. conducted a vendor-approval audit, using NQA-1 criteria (ASME 1989), in September. They listed three deficiencies involving an incomplete training requirements list (missing a procedure) and an incorrect Table of Contents for the procedures manual. The latter deficiency was promptly corrected and the former deficiencies were corrected by implementing a new electronic training database and revising the training procedure accordingly.

\subsubsection{Program Self-Assessments}

A self-assessment of the program is conducted annually by the program's quality engineer. This year's assessment was conducted in April and found minor discrepancies between actual practice and four procedures. Corrective actions were completed by August.

\subsubsection{Quality Problem Reports}

Two quality problem reports related to bioassay were filed in 2001. Both involved not initiating follow-up actions to excreta bioassay results within the time period specified in the new Hanford Bioassay System Functional Requirements (see Section 3.2.4). Corrective actions included improvements to the format for printing the Excreta Bioassay Positive Exam Results report and more frequent printing of the Incorrect High Flag Report for Excreta Bioassay.

\subsection{Supporting Technical Studies}

Three supporting studies were conducted as described in the following sections.

\subsubsection{Chronic Plutonium Intake Detection Capability}

The Defense Nuclear Facilities Safety Board (DNFSB) raised a concern to DOE about the potential for undocumented chronic intakes of plutonium to be occurring at various plutonium facilities in the DOE complex. This issue was discussed among the DOE Working Group on Plutonium Internal Dosimetry, on which HIDP is represented, in preparation for a subsequent teleconference between the DNSFB and representatives of the various DOE sites with significant plutonium facilities. HIDP was also represented at the latter teleconference. HIDP was able to show for the routine plutonium bioassay program at Hanford that the minimum detectable internal dose (MDD) from chronic intakes is much smaller (approximately $350 \mathrm{mrem}$ for inhalation class W detected in urine and approximately $1200 \mathrm{mrem}$ for 
inhalation class Y) than the similar MDD from an acute intake assumed to have occurred on the day after the previous bioassay measurement. Hence, the monitoring program designed on an assumption of acute intakes is adequate for detecting chronic intakes. Prompt detection of intakes in the workplace followed by prompt bioassay is still the best approach. HIDP is not aware of additional concerns from the DNSFB on this topic after the teleconference, so the issue appears to be resolved.

\subsubsection{Investigation of a New Internal Dosimetry Code}

HIDP contributed funds, design criteria, and feedback on the early design of the Integrated Modules for Bioassay Analysis (IMBA) Code - DOE Edition. IMBA, developed by the British National Radiological Protection Board and being marketed in North America by ACJ \& Associates, will eventually replace CINDY as the code at Hanford for internal dose calculations. IMBA incorporates the new lung model from International Commission on Radiological Protection (ICRP) 66 (1994) and the recent ICRP recycling biokinetic models. The DOE Edition is being written to specifications supplied by the DOE sites, and allows use of either ICRP 60 (1991) or 10 CFR 835 tissue weighting factors. The IMBA DOE Edition is being developed in two phases, with phase II development scheduled for 2002 pending funding. The beta version from phase I was issued for testing in late December.

\subsubsection{Review of Uranium Bioassay Requirements at the Plutonium Finishing Plant}

The potential need for uranium bioassay at PFP was reviewed by HIDP staff, FH dosimetry, and PFP personnel. There is a substantial amount of uranium at PFP, however it is intimately mixed with plutonium in mixed oxides and unirradiated fuel pin assemblies. It was concluded that the plutonium was far more dosimetrically significant, that bioassay for only plutonium was adequate and, with the possible exception of those dealing with purified standards solutions in the laboratory, that uranium bioassay was not warranted.

\subsection{Project-Related Professional Activities}

HIDP staff activities, presentations, and professional memberships during 2001 are listed in this section.

\subsubsection{Activities}

Eugene H. Carbaugh was involved in professional dosimetry activities, outside of the Hanford Site, in the following roles:

- member of the DOELAP Radiobioassay Oversight Board, and attended the Board's meeting March 19-21 in Las Vegas, Nevada. In addition he participated in on-site assessments at the Waste Isolation Pilot Plant, February 12-15, Mound Environmental Management Project, October 16-18, and Lawrence Livermore National Laboratory, October 29-November 1. 
- panel member in a University of Washington sponsored public meeting of the Former Hanford Worker Medical Monitoring Program, April 2, in Richland, Washington.

Jay A. MacLellan was involved in professional dosimetry activities, outside of the Hanford Site, as follows:

- DOELAP onsite assessments at the West Valley Demonstration Project, Oak Ridge National Laboratory, and Wastren Laboratory in Grand Junction, Colorado.

\subsubsection{Presentations}

MacLellan, J. A. 2001. "Workshop on Decision Levels and Minimum Detectable Activity." Presented at the $47^{\text {th }}$ Radiochemical Measurements Conference, Honolulu, Hawaii, November 4-8, 2001. Pacific Northwest National Laboratory, Richland, Washington.

\subsubsection{Publications}

Strom, D. J., and J. A. MacLellan. 2001. "Evaluation of Eight Decision Rules for Low-Level Radioactivity Counting." Health Physics, 81(1):27-34.

\subsubsection{Professional Memberships and Other Activities}

Carbaugh, E. H. Member of the HPS Standards Committee N13.25, Internal Dosimetry Standard for Plutonium.

Carbaugh, E. H. Member Bioassay/ Internal Dosimetry DOELAP Oversight Board.

Carbaugh, E. H. Member DOE Working Group on Stable Tritium Compounds.

Carbaugh, E. H. Instructor for Columbia Chapter Health Physics Society Certification Review Class for the American Board of Health Physicists Certification Exam.

MacLellan, J. A. Chair of the HPS Standards Committee N13.30, Performance Testing for Radiobioasay.

MacLellan, J. A. Chair of the American Academy of Health Physics Appeals Committee.

MacLellan, J. A. President of the Columbia Chapter of the Health Physics Society. 


\subsection{In Vivo Monitoring Program for Hanford}

The In Vivo Monitoring Program (IVMP; formerly the Hanford Whole Body Counting Program) has been an integral part of the comprehensive radiological protection program for Hanford workers since 1959. The IVMP staff provide routine and emergency in vivo counting services. The majority of the measurements are performed in the 747-A Building at the corner of Knight Street and Goethals Avenue in Richland. Additional radiation detection equipment is maintained and operated at the Emergency Decontamination Facility located next to the Kadlec Medical Center. Mobile in vivo equipment is also maintained in a trailer located near the 747-A Building. Collectively, the facilities are called the In Vivo Radioassay and Research Facility (IVRRF).

Four shielded counting systems in the 747-A Building were used to perform the routine measurements for Hanford workers during 2001. The standup counter (SU) employs five large sodium-iodide detectors for measuring fission and activation products in the body with energies $>200 \mathrm{keV}$. It is used primarily as a screening counter to determine whether activity is present above the decision level $\left(\mathrm{L}_{\mathrm{C}}\right)$. The Palmer Room contains a system with seven coaxial high-purity germanium (HPGe) detectors. It is also used to detect and quantify radionuclides that emit high-energy photons. Because the system in the Palmer Room has excellent resolution, it is used to obtain the final results when activity is detected. The Iron Room (IR) and Stainless Steel Room (SS) each contain planar HPGe detector arrays optimized for the detection of uranium, transuranic radionuclides, and other nuclides that emit low-energy photons. A lung-counting system composed of two HPGe detectors was installed in the Lead Room this year and is used to count non-DOE clients thus reducing overall program costs to the Hanford contractors.

When activity is detected and confirmed, the results are provided to the HIDP to be used in determining the dose to workers from the internally deposited radionuclides. Records of the measurement results, counting system calibrations, and measurement QC are ultimately transmitted to the Hanford Radiological Records Program. Information copies of the records may be maintained at the IVRRF.

The IVMP is accredited through the DOELAP, as required by the Statement of Work established with the Hanford contractors, for direct bioassay and is operated in compliance with 10 CFR 835, Occupational Radiation Protection. The program documentation includes the In Vivo Monitoring Project Manual, PNL-MA-574, ${ }^{(a)}$ the Quality Assurance Plan for the Operation of the In Vivo Monitoring Program for Hanford, LSC-021, and the In Vivo Monitoring Program Procedures Manual, PNL-MA$5544^{(b)}$

(a) Pacific Northwest National Laboratory. Current version. In Vivo Monitoring Project Manual. PNL-MA-574, Richland, Washington. (Internal manual.)

(b) Pacific Northwest National Laboratory. Current version. In Vivo Counting Program Procedures Manual. PNL-MA-554, Richland, Washington. (Internal manual.) 


\subsection{Routine Operations}

A total of 7,253 in vivo measurement results were sent to the REX database for DOE and the Hanford contractors during 2001. This included 6,060 whole body measurements, 1,180 chest measurements, and 13 miscellaneous measurements. The miscellaneous measurements included wound, skeletal, and thyroid measurements. The total number of counts represents a $4 \%$ increase compared with CY 2000 . There were 410 more whole body counts performed than in 2000 and 139 fewer chest counts performed than in 2000. The statistical breakdown by contractor is shown in Table 4.1. A summary of the number of in vivo counts made from 1992 through 2001 is presented in Table 4.2 and depicted graphically in Figure 4.1.

Table 4.1. In Vivo Measurements Performed During 2001 and Entered in the REX Database

\begin{tabular}{|c|c|c|c|c|c|}
\hline Count Type and Reason & CHG & FH & PNNL & BHI & $\begin{array}{c}\text { Other (DOE } \\
\text { and US) }\end{array}$ \\
\hline \multicolumn{6}{|l|}{ Whole Body Counts } \\
\hline Routine Schedule & 1,092 & 3,024 & 611 & 927 & 321 \\
\hline Special Request & 8 & 7 & 1 & 4 & 1 \\
\hline Contractor Request & 16 & 39 & 5 & 4 & 0 \\
\hline Total & 1,116 & 3,070 & 617 & 935 & 322 \\
\hline \multicolumn{6}{|l|}{ Chest Counts } \\
\hline Routine Schedule & 87 & 772 & 263 & 2 & 38 \\
\hline Special Request & 1 & 11 & 1 & 0 & 2 \\
\hline Contractor Request & 0 & 3 & 0 & 0 & 0 \\
\hline Total & 88 & 786 & 264 & 2 & 40 \\
\hline \multicolumn{6}{|l|}{ Other Counts } \\
\hline Routine Schedule & 0 & 0 & 0 & 0 & 0 \\
\hline Special Request & 4 & 5 & 0 & 4 & 0 \\
\hline Contractor Request & 0 & 0 & 0 & 0 & 0 \\
\hline Total & 4 & 5 & 0 & 4 & 0 \\
\hline Grand Total & 1,208 & 3,861 & 881 & 941 & 362 \\
\hline
\end{tabular}

Table 4.2. In Vivo Count Summary from 1992 Through 2001

\begin{tabular}{|c|c|c|c|c|c|c|c|c|c|c|}
\hline Year & 1992 & 1993 & 1994 & 1995 & 1996 & 1997 & 1998 & 1999 & 2000 & 2001 \\
\hline $\mathrm{WBC}^{(\mathrm{a})}$ & 12,197 & 11,401 & 11,031 & 9,020 & 7,407 & 6,506 & 6,478 & 6,421 & 5,650 & 6060 \\
\hline Lung & 3,164 & 2,838 & 2,752 & 1,915 & 1,632 & 1,433 & 1,734 & 1,657 & 1,319 & 1180 \\
\hline Special & 56 & 38 & 82 & 27 & 26 & 4 & 21 & 7 & 14 & 13 \\
\hline Total & 15,417 & 14,277 & 13,865 & 10,962 & 9,065 & 7,943 & 8,233 & 8,085 & 6,983 & 7,253 \\
\hline
\end{tabular}




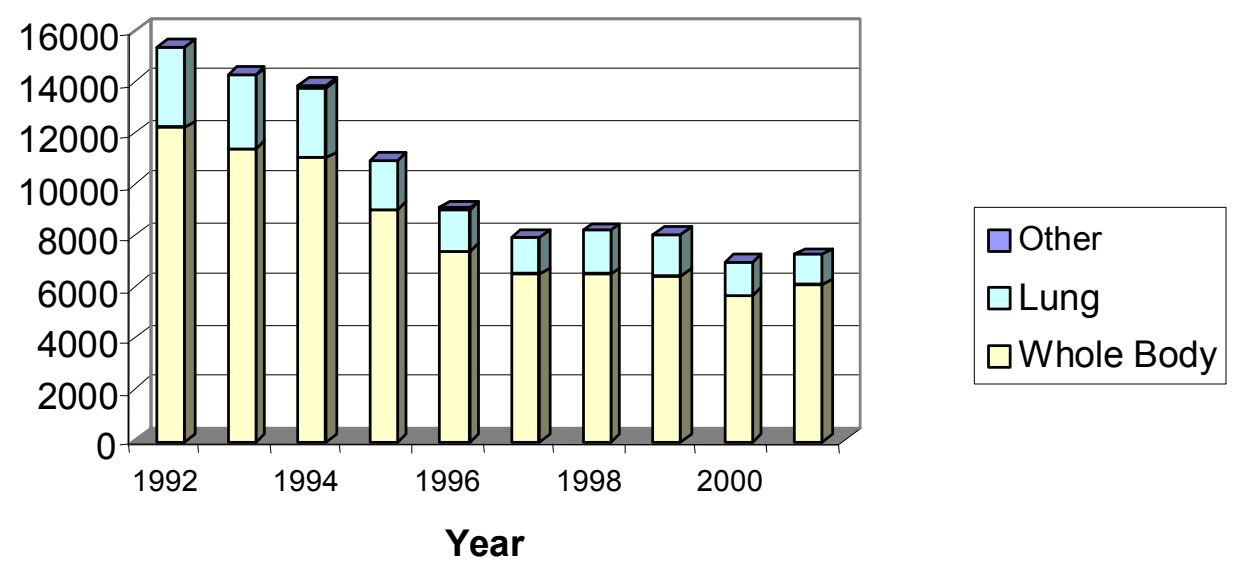

Figure 4.1. Summary of the Number and Types of In Vivo Measurements Performed from 1992 Through 2001

The IVMP operated under budget in 2001. Work was scheduled and prioritized at regularly scheduled planning meetings. Periodic safety meetings were conducted to address program-specific topics. Quarterly safety self-assessments were conducted. No off-normal events were recorded. Each quarter, formal presentations were made to RL and the contractors to summarize the status of the program. The daily measurement QC data were reviewed and analyzed quarterly for trends.

The CY 2001 daily QC measurement results indicated that the performance of the counting systems when measuring workers was comparable to the performance when measurements of the calibration phantoms were made to establish the calibration factors used to estimate the activity in workers. If the daily QC results were out of tolerance, the measurement results were reviewed for validity and if results were found to be invalid then workers were scheduled for recounts.

\subsubsection{Program Management and Maintenance of Program Documentation}

The program documentation was kept current. Revision 6 of the LSC-021 QA Plan was issued on September 17. The changes, which resulted from the annual review of the plan, included the addition of an appendix containing a matrix of DOELAP requirements and the corresponding IVMP documentation that addresses the requirement. The Records Inventory and Disposition System schedule was updated. A .pdf version of the PNL-MA-574 program manual was developed and posted on the external PNNL and the IVRRF websites.

Participation in the Thyroid Radioiodine Intercomparison Program conducted by Lawrence Livermore National Laboratory was stopped. This was done because while the program cost remained the same the number of samples was reduced in half, and the measurement geometry is very different than the one used to calibrate a thyroid counter at the IVRRF. 
The operating procedures in PNL-MA-574 were revised as needed to ensure that the procedures accurately reflect the methods used to perform the work. The required 2-year reviews were performed for several procedures and as a result some less frequently performed procedures were consolidated into a single procedure. A review of variance reports over the past year showed some procedure noncompliances with procedure steps; however, the noncompliances did not have an adverse effect on the measurement results. A further review of these routinely used procedures was instituted late in the year to verify that the steps actually being performed are accurately described in the procedures. The review will be completed in early CY 2002.

\subsubsection{Department of Energy Laboratory Accreditation Program}

The IVMP received the DOELAP Certificate of Accreditation for the Hanford Site Radiobioassay Laboratories dated March 21, 2001 and the conditions of accreditation. The IVMP was reaccredited in all six of the available direct bioassay categories. The current accreditation extends through March 2004.

The documentation to establish technical equivalence for the use of the digital signal processing (DSP) electronics in the Stainless Steel Lung Counting System was submitted to DOELAP. This included copies of the calibration results, calibration verification measurements, and QA measurement results for setting control chart limits.

\subsubsection{Equipment Maintenance and Repair}

The IVMP staff have developed a mature preventive maintenance and repair program for the radiation detection equipment and associated electronics. Except for reworking the sodium-iodide or germanium crystals themselves all repairs are made by IVMP staff. Inevitably detectors or more likely electronic components such as amplifiers, nuclear instrument module (NIM) bins, analog-to-digital converters, and high-voltage power supplies will require repair during any given year. In fact, staff repaired 13 NIM bins and retired many older amplifiers for spare parts this year. They repaired $12 \mathrm{HPGe}$ detectors and a like number of electronic components for Hanford clients during the year. This results in a considerable savings and much less time out-of-service compared to returning instrumentation to the vendor for repair. The major maintenance and repair efforts performed in CY 2001 are summarized below.

Staff installed defragmentation software (Diskeeper) in preparation for deletion of archived spectral files from the Alphastation. To prevent interference from the defragmentation software during nightly disk backup the backup command procedure was changed to suspend Diskeeper operation during the backup. The command procedure was also changed to perform a verification pass after backing up the disk on tape. Testing of this new version of the backup command procedure resulted in failure of the backup command procedure due to an excessive rate of tape drive device errors. Multiple tape cleaning passes and the use of a new tape cartridge as suggested by the Compaq technician did not reduce the device error rate so the technician replaced the tape drive on March 2. Replacement of the tape drive successfully eliminated the device error problem and the new version of the backup command procedure was placed in service. 
A Sensaphone ${ }^{(a)}$ environmental monitoring system was installed to monitor building power, temperature, and the performance of the uninterruptible power supply unit. The Sensaphone Model 1104 is a programmable unit that can provide local and remote monitoring capability. The system was set-up to provide telephone notification to selected numbers in the event of a power failure, extreme temperature change, or a failure of the UPS unit. A 44-minute power outage occurred on Saturday, December 1, and did not cause any problems other than the need to adjust the time on clocks. The Sensaphone system operated as expected and provided a telephone warning of the power failure. The UPS unit functioned properly and provided battery power to the computers and instrumentation.

The micro-switches that control power to the door's motor were repositioned to increase the travel length of the Lead Room door. This provides a wider entrance to the room and reduces the potential for tripping over a wheel guard while entering and exiting the room.

The electro-mechanical valve for the SS door was replaced on November 23 with a new device. The change was made because a gradual loss of air pressure over weekends did not allow the shielded door to close completely on the first couple attempts on Monday mornings without physically pushing the door. The new valve assembly was designed so that it could more easily be removed intact when maintenance is required in the future.

\subsubsection{Historical In Vivo Measurement Records}

This year culminated a multi-year effort to transfer files stored on different storage media to a common medium in order to improve access to the channel-by-channel spectral data for the in vivo measurements. These data are not stored online in REX. The spectral data from 1977 through 1986 on 800 bytes per inch (bpi) nine-track tapes were sent offsite to a commercial data conversion company. The ASCII files were transferred from the 800 bpi nine-track tapes to compact disks (CDs).

The results and spectral data from 1986 through 1995 in both binary and ASCII format were copied from the magneto-optical disks to CD. After attempts using several other computers failed, the Inspire drive was finally used to access the files on the Verbatim magneto-optical disks, transfer them to a personal computer (PC) and copy the files to CD. All the binary files were transferred to CD and all but 2 months of the ASCII files were transferred to CD.

The spectral data for in vivo measurements made from 1995 through October 21, 1999, are also stored on CD. See Section 4.2.1 for details on handling similar records since 1999.

\subsubsection{Measurement Quality Control}

As part of the ongoing measurement QC program, measurements are performed to estimate the activity content of phantoms as they become available. These phantoms may come from various sources and their activity is not known to the IVMP staff prior to making the measurements. This year several

(a) Phonetics, Inc., 901 Tryens Road, Aston, Pa 19014. 
lung phantoms were counted; however the activity in the phantoms was not yet available at publication time. Therefore the accuracy of the measurements could not yet be determined.

Measurements were also made of calibration phantoms during the year. Figures 4.2 and 4.3 illustrate the bias from measurements in two of the counting rooms. All results were well within the DOELAP criteria of $-25 \%$ to $+50 \%$.

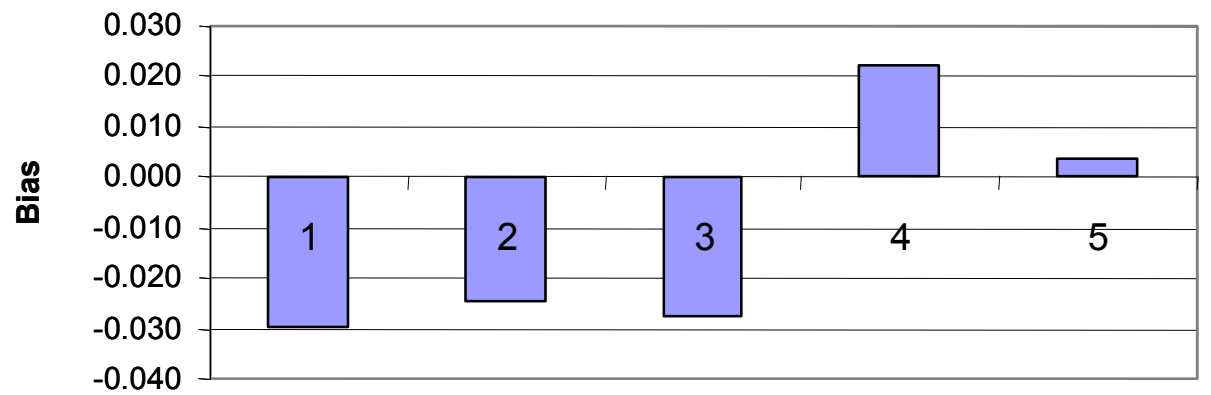

Figure 4.2. Bias in the Stainless Steel Room for the $202{ }^{241}$ Am Lungs

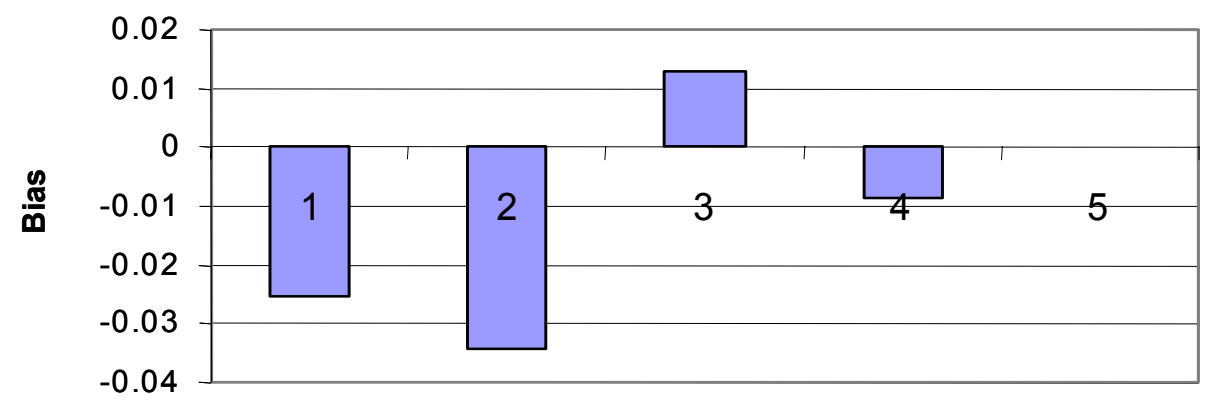

Figure 4.3. Bias in the Palmer Room for the $416{ }^{137} \mathrm{Cs}$ BOMAB

\subsection{Program Changes and Improvements}

Staff strive for continuous improvement in the methods and equipment used to perform the in vivo measurements to maintain a core capability as equipment ages and technology advances, to respond to client needs, and to continue to provide the measurement services in a cost effective manner. The significant improvements to the program made during the year are summarized in this section.

\subsubsection{Data Processing}

As the number of files stored on the Alphastation hard disk increased, the amount of time required to save the spectra files to disk increased. The time required to save some spectra files to disk had increased from 30 seconds or less to 10 to 15 minutes. This condition eventually would have limited the number of measurements that could be performed daily especially on the coaxial HPGe detector system. Instead, staff decided to develop a method to archive the files to CD and remove files from the hard disk. This 
procedure is in addition to the nightly backup of the user disk to tape. After several iterations, a working protocol was developed that did not include the use of LaserREX as originally planned.

The files identified for archiving on the Alphastation are copied to LOLA using the file transfer protocol (FTP). The files are then copied from LOLA to CD by PNNL Information Sciences staff. The files on the $\mathrm{CD}$ are checked and the filenames written to a temporary directory using the Genie 2000 software and a PC-based batch-programming tool (REXX) both purchased from Canberra Industries. ${ }^{\text {(a) }}$ A program is then executed on the Alphastation that compares the filenames in the temporary directory with the files in the specific counter directory and when a match is found both files are deleted.

\subsubsection{Standup Counter Calibration}

The SU was recalibrated and new QA parameters for efficiency and resolution were established. The recalibration was performed in response to the fact that daily QA results were two to three standard deviations different from the mean established at the last primary calibration. Although this amounted to only a 1 to $2 \%$ difference, it was deemed prudent to reset the control chart limits. In addition, the calibration procedure for this counter was revised to include more detail on how to perform the calibration.

\subsubsection{Digital Signal Processing}

Preparations for lung counting in the SS using the DSP electronics were completed and the system was put into routine operation on December 31. A package was submitted to DOELAP in early CY 2002 to inform them of the change and to demonstrate the technical equivalence of the new system with the analog system previously used in the room. The system performs reliably and has slightly better (10\%$15 \%$ ) resolution compared to the previous analog system.

\subsubsection{Uranium Lung-Counting System}

The bed-style detection system using seven sodium-iodide ( $\mathrm{NaI}$ ) detectors was removed from the Lead Room to make room for the uranium lung-counting system. The NaI detectors were loaned to another PNNL organization. A screening uranium lung-counting system using two detectors was subsequently installed in the Lead Room. Routine operations were started August 10. The system is used solely for uranium lung counting for non-DOE clients. The system is not DOELAP accredited. The income from this contract helps reduce the price of the in vivo measurement services to the Hanford contractors.

\subsubsection{Calibration for Iodine in the Thyroid}

Efficiency calibrations for ${ }^{125} \mathrm{I}$ and ${ }^{131} \mathrm{I}$ were completed using a solid thyroid phantom containing

${ }^{133} \mathrm{Ba}$ activity in a tissue-equivalent polyurethane. Barium-133 emits photons with energies that can be

(a) Canberra Industries, Inc. 800 Research Parkway, Meriden, Connecticut. 
used for both iodine calibrations. Staff verified the ${ }^{181} \mathrm{I}$ and ${ }^{125} \mathrm{I}$ calibrations using an aliquot from the solutions used for the Thyroid Radioiodine Intercomparison Program (TRIP).

\subsubsection{Upgrade to Computer System Used at Emergency Decontamination Facility}

The outdated VAX 3100 computer used at the Emergency Decontamination Facility (EDF) was replaced with a PC running the Genie 2000 software from Canberra Industries, Inc. The low-energy HPGe wound counter and the high-energy NaI counter were recalibrated. The operating procedure was revised and staff were trained in the use of the revised procedure.

\subsection{Program Assessments}

The annual management self-assessment was delayed until January 2002 due to other priorities but is summarized here. The QA engineer for the program performed a procedure compliance surveillance. The surveillance focused on the documentation for the primary calibrations of the routine counting systems. Corrective actions for the findings were identified and action plans developed.

Representatives from U.S. Ecology (USE) conducted a one-day audit of the program. No findings resulted from the audit. The IVMP remains on the USE-approved vendor listing for in vivo services.

On September 26, two representatives from Bechtel National conducted an audit of the IVMP as part of the Bechtel process to include Battelle's Dosimetry Services on their approved vendors list. No findings resulted from the audit.

\subsection{Supporting Technical Studies}

Five supporting technical studies were undertaken during 2001, as described in the following sections.

\subsubsection{Coaxial HPGe System}

Several large workers $(>350 \mathrm{lb})$ deflected the 0.5 -inch-thick plastic sheet they lie on while being counted with the coaxial HPGe system in the Palmer Room. This makes the plastic contact one or more detector endcaps causing microphonic interference and interferes with the completion of the total body scan. It also introduces the potential for the plastic to break, thereby likely injuring the worker and damaging $\$ 400,000$ worth of equipment. A 0.75 -inch-thick plastic sheet was purchased that can support 400 to 500 pounds without deflection. Check source measurements performed with the 0.75 -inch-thick Plexiglas sheet indicated that the system would need to be recalibrated when the sheet is installed. This is scheduled for the first half of CY 2002. A variable-velocity scanning mode will also be implemented at the same time to improve the detection efficiency. Ninety percent of the scan time will be from the head to just above the knees. Preliminary testing suggests that counting in a variable scan mode will increase efficiency and lower the MDA. 
In addition, measurements of a bottle-manikin absorption (BOMAB) phantom representing a fouryear-old child were made on the coaxial HPGe system in the Palmer Room. Calibration factors for ${ }^{137} \mathrm{Cs}$ and ${ }^{40} \mathrm{~K}$ were calculated and could be used for quantifying activity in children in an emergency. The calibration results were added to the coaxial HPGe calibration record.

\subsubsection{International Atomic Energy Agency Intercomparison}

The IVMP staff participated in the International Atomic Energy Agency (IAEA) Intercomparison on Direct Measurements of Radionuclides in Simulated Organs. While this was done as part of the continuous improvement process, it also responded to a DOELAP recommendation to participate in intercomparison studies. In CY 2001, radioactivity in a knee phantom and a torso phantom was measured. The knee phantom consisted of a simulated leg section extending from the thigh to the shin as shown in Figure 4.4. Three removable bone inserts are fitted into the knee phantom as shown in Figure 4.5. One set of inserts contains ${ }^{241} \mathrm{Am}$ activity; a second set of inserts contains ${ }^{210} \mathrm{~Pb}$ activity, and the third set contains ${ }^{152} \mathrm{Eu}$ activity. Activities in the knee phantoms were estimated based on a calibration derived from measurements of the U.S. Transuranium and Uranium Registries (USTUR) Case 102 skeletal phantom.

The torso phantom shown in Figure 4.6 was manufactured by the Japanese Atomic Energy Research Institute (JAERI) and represents a reference Japanese male. Figure 4.7 shows that the lung inserts for this phantom are more elongated compared to the lung inserts for the Lawrence Livermore National Laboratory (LLNL) torso phantom. Measurements were made of six JAERI lung phantoms. The

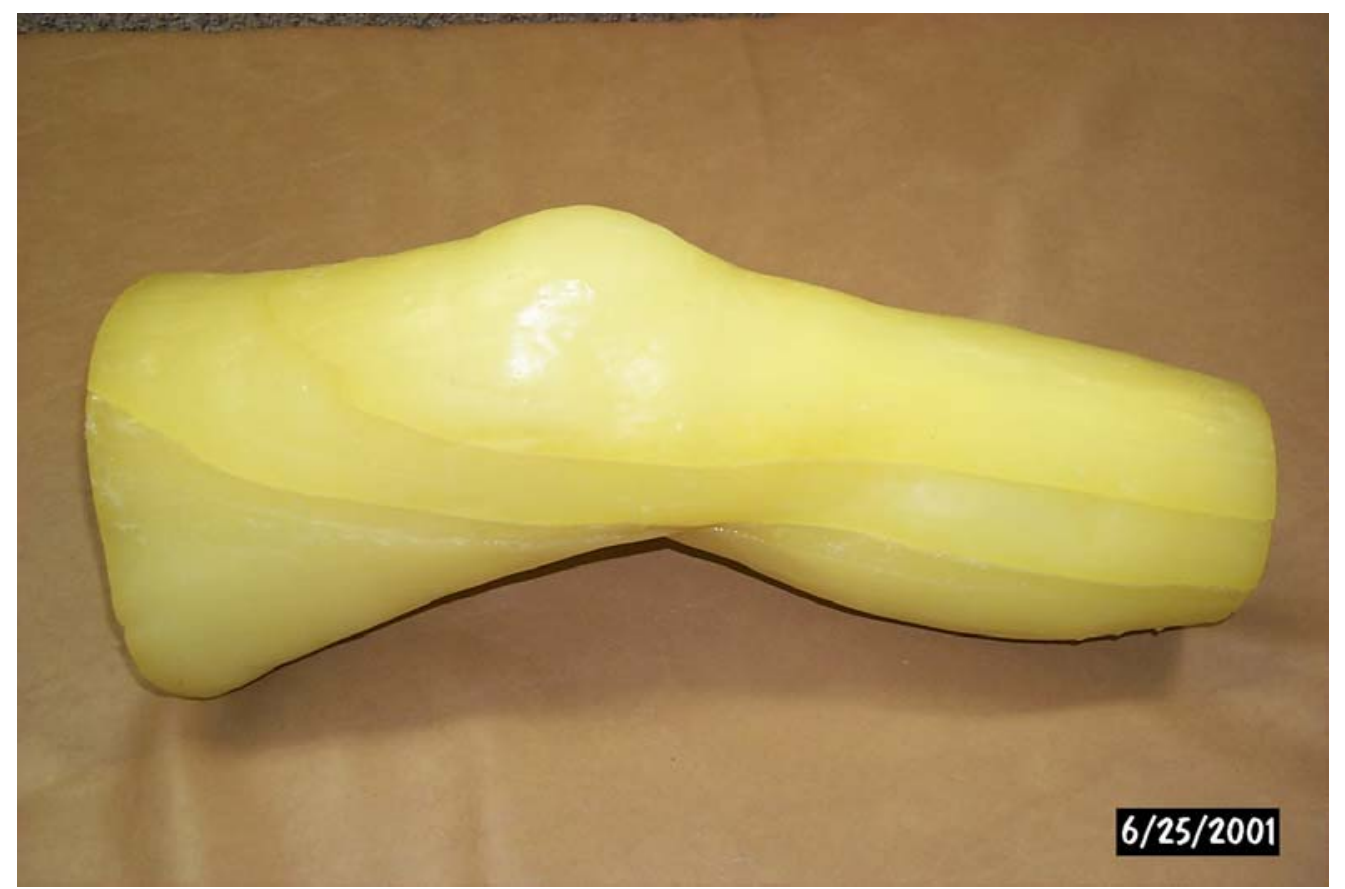

Figure 4.4. IAEA Knee Phantom 


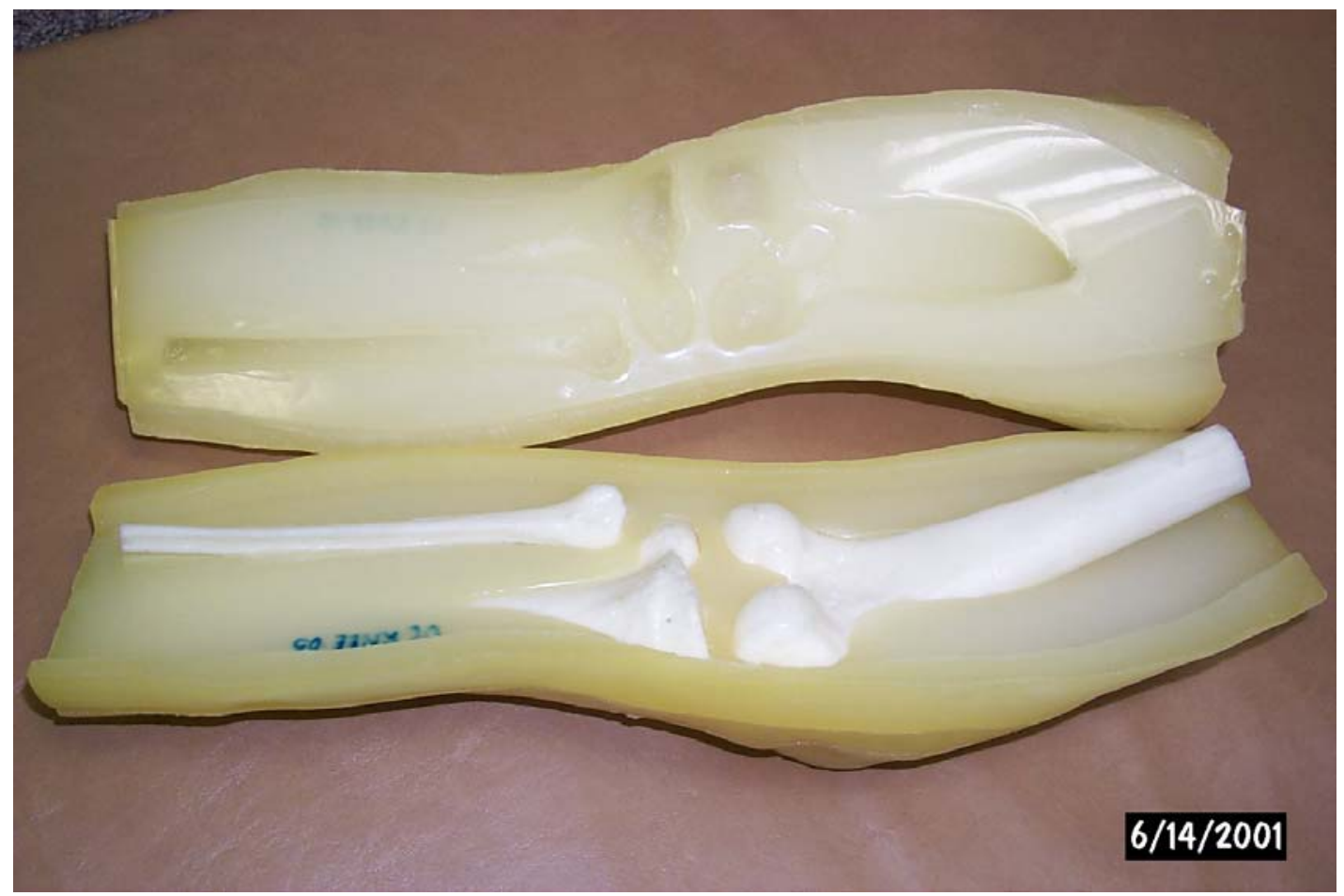

Figure 4.5. Three Bone Inserts in the IAEA Knee Phantom

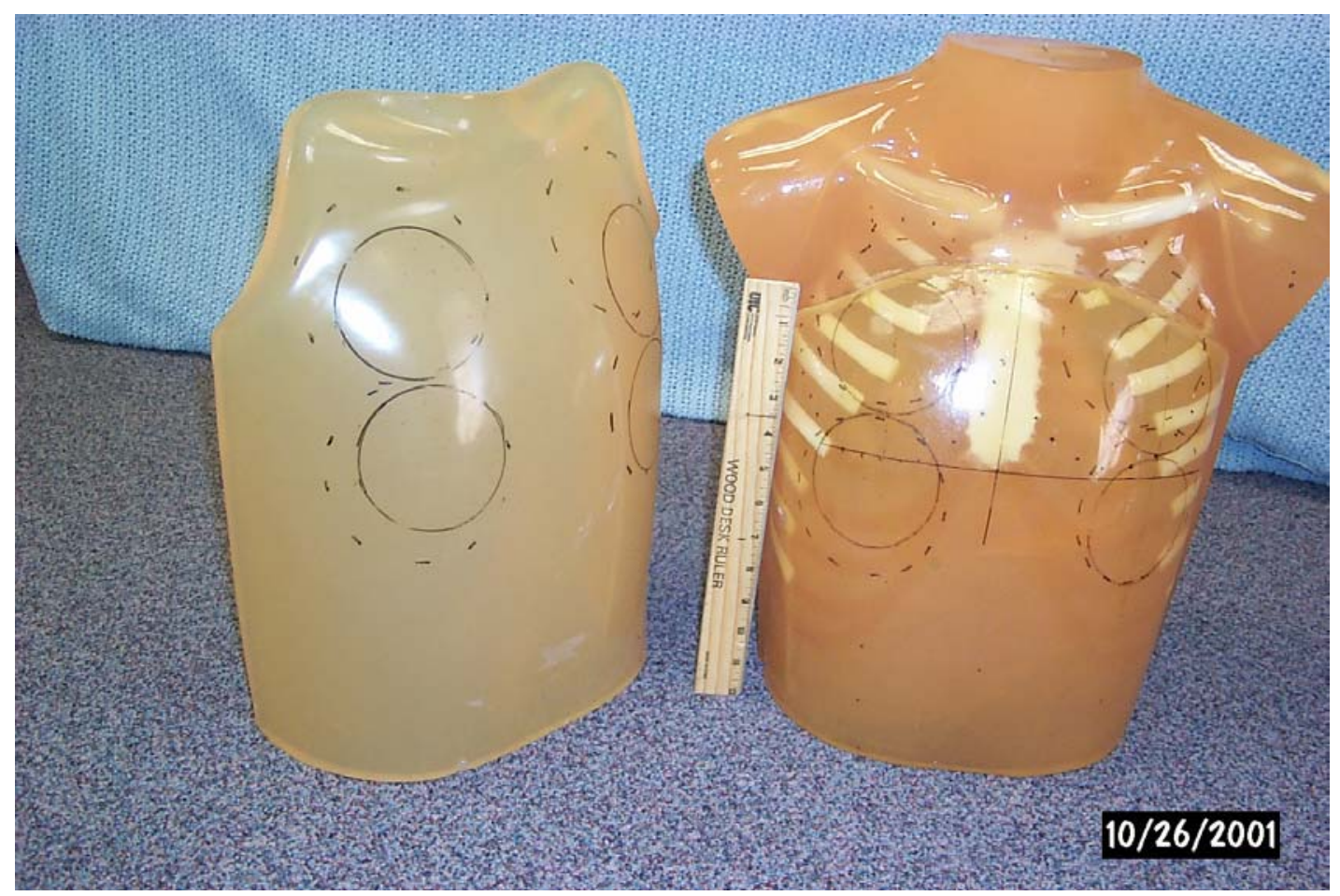

Figure 4.6. JAERI Torso Phantom 


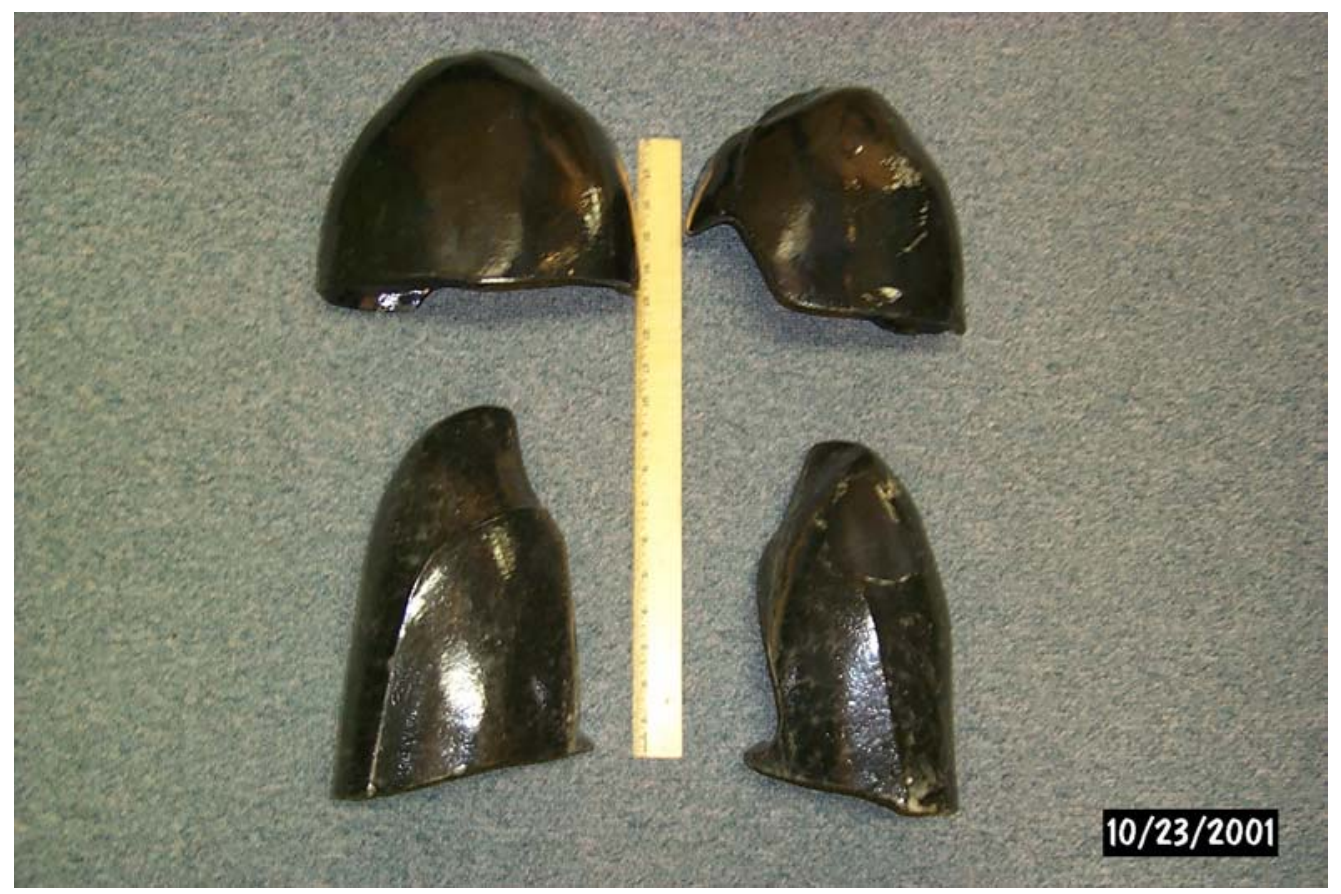

Figure 4.7. Lung Inserts for JAERI (bottom) and LLNL (top) Phantoms

phantoms contained ${ }^{241} \mathrm{Am},{ }^{238} \mathrm{Pu}$ (one low- and one high-activity set), natural uranium, ${ }^{235} \mathrm{U}$, and ${ }^{232} \mathrm{Th}$. The accuracy of the knee and torso measurements was not available at the time this 2001 annual report was published.

\subsubsection{Measurement of a High-Activity Phantom}

Staff measured a BOMAB phantom containing $5 \mathrm{uCi}$ each of ${ }^{137} \mathrm{Cs}$ and ${ }^{60} \mathrm{Co}$. The phantom represents a $95^{\text {th }}$ percentile male. Both the SU and the coaxial HPGe system responded differently compared to counting a low-activity phantom. The SU exhibited a positive gain shift due to changes in the dynode potentials of the photomultiplier tubes. The gain shift persisted for 20 minutes after the phantom measurement was completed as thermal and space charge effects caused by the large electron current equilibrated.

The high activity created dead time that caused the coaxial system to continue counting after the detector platform had completed the scan and was returning to the start position. This study indicated that the activity content of the phantom was too high to be used for calibration of either counter. In addition, the results reinforce the fact that the routine counting protocols may not be useful for counting workers with large amounts of activity ( $\mathrm{uCi}$ ) and that alternate counting geometries would be needed. This size of phantom with a lower activity content is needed to better calibrate the whole body counting systems for the larger workers and plans are to purchase such a phantom in the near future. 


\subsubsection{NORMAN Voxel Phantom}

The IVMP staff received a copy of the NORMAN voxel phantom from the National Radiological Protection Bureau. It came as three files. The phantom data file was the output from an magnetic resonance imaging (MRI) scan of a healthy adult male and was scaled to a height of $176 \mathrm{~cm}$ and a weight of $73 \mathrm{~kg}$. The Norman phantom was implemented in MCNP and was combined with the model of the HPGe detectors developed in CY 2001 to produce a virtual chest counting configuration as shown in Figure 4.8. A virtual clone of the $600-\mathrm{nCi}^{241} \mathrm{Am}$ calibration lung phantom was developed. The virtual photons from the virtual ${ }^{241} \mathrm{Am}$ activity in the lungs were transported with the MCNP code from the lungs to the virtual germanium crystal. The calculated efficiency at $59.5 \mathrm{keV}$ was within $15 \%$ of the efficiency measured with the $600-\mathrm{nCi}^{241} \mathrm{Am}$ lungs in the LLNL torso phantom. The virtual spectrum is shown in Figure 4.9. Different tissue compositions affected the calculated efficiency by $<5 \%$. The next steps are to scale the NORMAN phantom up to a $95^{\text {th }}$ percentile male and down to a $5^{\text {th }}$ percentile male. Eventually, the MCNP simulations will be used to generate more worker-specific calibration factors that can be used to improve the accuracy of the in vivo measurements.

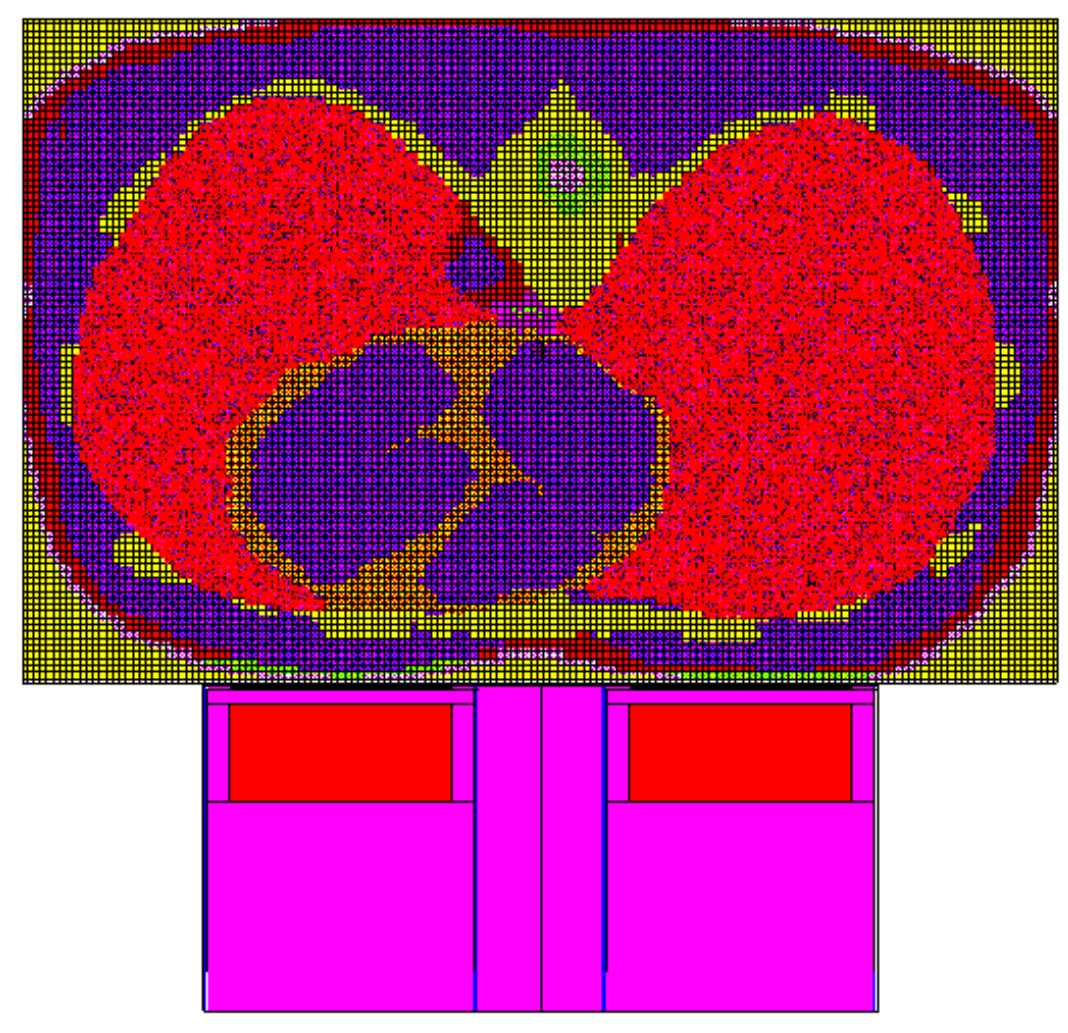

Figure 4.8. Plot of the Norman Phantom, Slice 650, Showing the Presence of Activity in the Lungs of the Phantom and the HPGe Detectors in Place in Front of the Phantom. (The red dots in the lungs of the phantom indicate the presence of radioactivity. The plot was drawn with the MCNP Vised program and the colors associated with the detectors and body tissues are determined by the program.) 


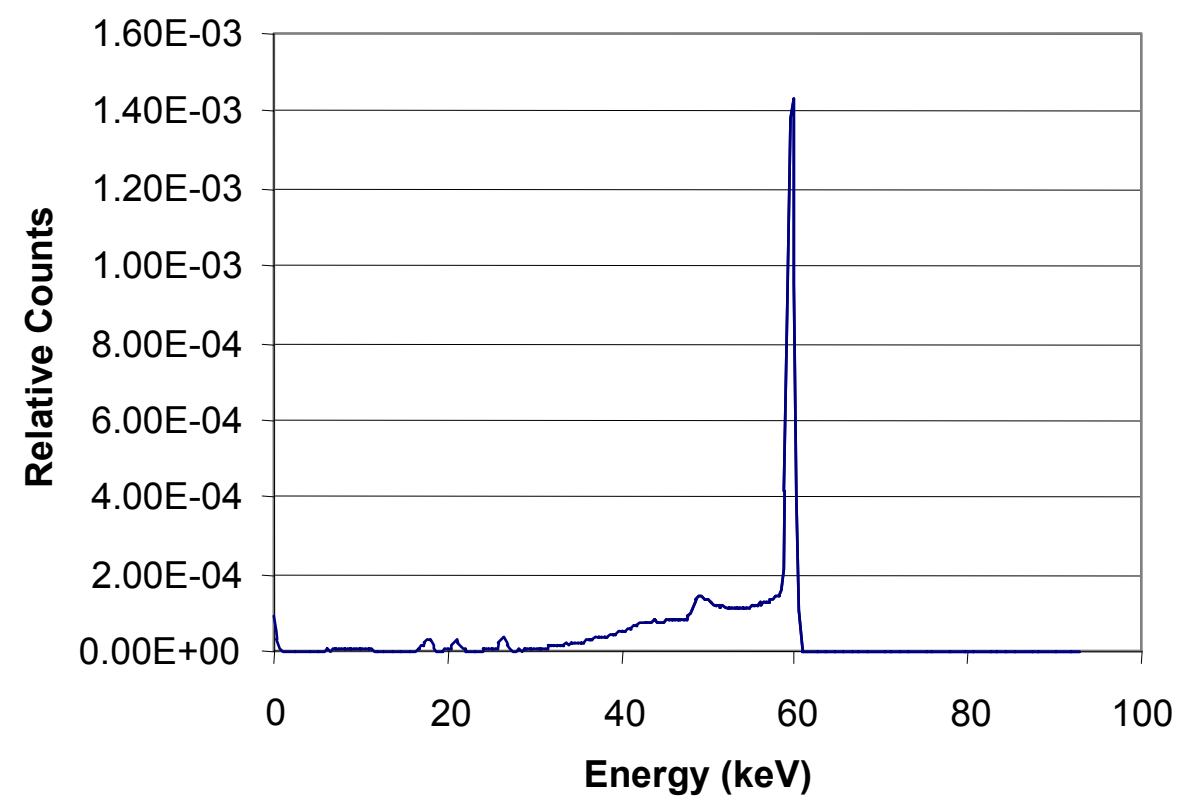

Figure 4.9. Virtual ${ }^{241}$ Am Spectrum from the NORMAN Phantom

\subsection{5 ${ }^{241} \mathrm{Am} /{ }^{152} \mathrm{Eu}$ Lung Phantom and Coincidence Summing}

The coincidence summing phenomenon observed when counting ${ }^{241} \mathrm{Am} /{ }^{152} \mathrm{Eu}$ lung phantoms with the $38 \mathrm{~cm}^{2}$ by $30-\mathrm{mm}$-thick HPGe detectors at the IVMP precludes their use as a calibration phantom as reported last year. Because they use similar although not identical style detectors, a collaborative study was undertaken with the Human Monitoring Laboratory (HML) in Canada and the Centro de Investigaciones Energeticas Medicambientales y Tecnologicas (CIEMAT) in Spain. Although the sum peaks were evident in spectra from all three laboratories, the preliminary results indicated the coincidence summing phenomenon was an operational issue at the HML and CIEMAT. A draft manuscript describing the study was written. Further investigation of the coincidence summing phenomenon is planned for next year.

\subsection{Program-Related Professional Activities}

Staff activities, presentations, and professional memberships during 2001 are listed in this section.

\subsubsection{Activities}

Timothy P. Lynch was the lead assessor for the onsite DOELAP assessment at the Savannah River Site and the Bechtel Jacobs Corporation oversight function of the East Tennessee Technology Park (formerly K-25), Y-12, and the gaseous diffusion plants at Paducah and Portsmouth. At the request of the DOELAP Performance Evaluation Program Administrator, the corrective action plans developed to address the findings were reviewed. 
Staff revised the manuscript "Three-Year Follow-up of an Acute ${ }^{241}$ Am Inhalation Intake" to omit the americium biokinetic model revision because basing the revision on a single case was not warranted. The revised paper will be resubmitted to the Health Physics Journal.

The manuscript "Distribution of ${ }^{235} \mathrm{U}$ and ${ }^{241}$ Am Activity in the Lungs", T.P. Lynch and V.L. Dedmond was submitted to the Health Physics Journal.

\subsubsection{Presentations}

None.

\subsubsection{Publications}

Lynch, T. P., D. E. Bihl, M. L. Johnson, J. A. MacLellan, and R. K. Piper. 2000. Hanford Radiological Protection Support Services Annual Report for 2000. PNNL-13542, Pacific Northwest National Laboratory, Richland, Washington. 


\subsection{Hanford Radiation Records Program}

The Hanford Radiation Records Program (HRRP) supports RL and Hanford contractor radiation protection programs by administering and preserving radiological exposure records for all Hanford workers and visitors, past and present, and by providing specified and requested reports using these records. The program is also responsible for maintaining the Hanford Radiation Protection Historical Files; operating the computer systems and library equipment necessary to input, store, verify, and retrieve the records; and producing the required reports and downloads.

\subsection{Overview}

The HRRP is organized into four major functional areas: data administration, dosimetry operations, exposure reporting, and the records library, as described in the following sections.

\subsubsection{Database Administration}

The database administrators evaluate systems, troubleshoot, resolve system and user problems, train users, oversee system security, serve as liaisons with the computer analysts, and initiate and test modifications of the databases for the REX database and Access Control Entry System (ACES). The ACES data administrator provides monthly reports of entry and dose data to $\mathrm{CHG}$ and FH. Upon request, the data administrator also provides personnel qualification reports to federal and state regulators, and adjusts the Administrative Control Limits (ACLs) for individuals in accordance with established policies. The data administrator monitors data downloads for accuracy, and is the point of contact for access qualification or system problems. The data administrator also initiates, tracks, and participates in the evaluation and review of system change requests.

The ACES was created to implement a system for computerized supplemental dose tracking and radiation area/hazardous waste site access control. It is a computerized access control program that electronically compares worker qualifications with controlled area access requirements. Although HRRP has data administration responsibilities for ACES, FH retains ownership. However, the HRRP manager works closely with the FH ACES manager and Lockheed Martin Services, Inc., (LMSI) personnel in the operation and maintenance of the system. ACES is a client-server system, hosted on an HP 9000 computer (four 180-MHz processors) using the Hewlett Packard Unix operating system and Oracle software to manage the database and provide entry screens and reports. Users access the server via personal computers (PCs) connected to the Hanford Local Area Network (HLAN) using Windows-based software residing on the users' (clients') computers. The database receives data from several other Hanford computer systems (e.g., PeopleSoft, REX, and PeopleCORE).

The REX system is a computerized database that maintains all of the radiological exposure records and supplementary and support data for individuals who have worked at the Hanford Site since 1944. The REX system contains the individual radiological exposure records on all Hanford DOE, contractor, and subcontractor employees as well as Hanford visitors. The system also contains other information 
used by site radiation protection organizations such as individual skin contamination reports and bioassay schedules and delivery addresses. These data are readily retrievable via a system of PCs and terminals operated by the HRRP and Hanford contractor dosimetry staffs. The REX system also includes supporting exposure documentation on microfilm and compact disc (CD) that are indexed into computer-assisted retrieval (CAR) systems. The CAR systems allow for rapid retrieval of the documents for any individual person using identifiers (IDs). These IDs include payroll numbers, social security numbers, names, and/or REX IDs, which are unique numbers generated by the computer for each individual to tie all of their records together. The HRRP also uses a CD-imaging subsystem for hard-copy documents. The imaging and storage hardware is used by two systems, a personnel exposure document system (LaserREX), and an instrument calibration record system (LaserCAL). Since January 1, 1992, all hardcopy exposure records have been preserved on LaserREX. Hard-copy records generated prior to 1992 are maintained on microfilm. The LaserREX also stores the electronic records created by the REX transaction log subsystem, which logs all changes to the database data fields.

\subsubsection{Dosimetry Operations}

In October, the Dosimetry Operations Team was transferred within Radiation and Health Technology from Dosimetry Services to the Radiation Records Program. Dosimetry operations functions includes entering data into the REX database and validating all data entry. Dosimetry Operations provides these services for DOE, CHG, and FH data, and PNNL Safety and Health Technology and Bechtel Radiological Control do their own data processing. Data validation is accomplished by reviewing field data entry, establishing audits to be matched to entries of results, resolving unmatched results, and interacting directly with contractor personnel. Data handlers also deal directly with contractor personnel and data suppliers to assist them and solve data problems. Dosimetry operations also issues, tracks, and processes dosimeters for FH, CHG, and DOE.

\subsubsection{Exposure Reporting}

The exposure reporting function is shared by exposure reporting and dosimetry operations. Dosimetry operations is responsible for generating and issuing routine exposure status reports to the contractors, quarterly person-rem and annual statistical reports to DOE, and annual reports to employees. This function requires close contact with RL, the contractors, and other personnel dosimetry functions. Special reports requested by former employees, as well as those requested by the contractors, RL, the USTUR, and Privacy Act and Freedom of Information Act petitions are the responsibility of exposure reporting.

\subsubsection{Records Library}

The Records Library staff maintains individual exposure records and backup documentation that are not reducible to database elements, as well as the HRRP Historical Files. The library staff scans, indexes, and retrieves hard-copy documents; prepares documents for long-term storage; and tracks and accounts for the documents through the imaging and indexing process. The library contains the individual exposure records of all Hanford personnel since Hanford's inception in 1944 (almost five million 
microforms), except for those individuals who transferred from Hanford when DuPont left in 1946. These exposure records and the Historical File microforms are retrievable through index systems that are maintained by the library staff.

Although the results from the dosimeter and excreta processing, as well as the in vivo counts, are received by electronic transmission, a large amount of data is entered manually by the field dosimetry organizations and the dosimetry operations staff. The hard copies are then sent to the library for preservation on the imaging systems. Records in the HRRP Historical Files include documents such as policies, procedures, reports, and important communications that define the Hanford radiological dosimetry and radiation protection programs throughout their history. The historical records are microfilmed and indexed into an additional CAR system. These records are retrievable by author, date, or range of dates, document number (if applicable), document title, and up to three keywords.

The LaserREX document scanning and retrieval hardware was shared with a document database for Instrument Services and Technology, LaserCAL. The system was cloned from LaserREX, and is operated by the Records Library staff.

The program is operated under the applicable sections of 10 CFR 830 and 10 CFR 835; ANSI N13.6, American National Standard Practice for Occupational Radiation Exposure Records Systems (ANSI 1999); as well as the following DOE directives: DOE Guide 1324.5B, Implementation Guide for Use with 36 CFR Chapter XII - Subchapter B Records Management (DOE 1996); DOE Guide 441.1-11, Occupational Radiation Protection Record-Keeping and Reporting Guide (DOE 1999c), DOE Order 231.1-1, Environment, Safety and Health Reporting (DOE 1997a); and DOE Manual 231.1-1, Environment, Safety and Health Reporting Manual (DOE 2000). The program also complies with the applicable sections of the Privacy Act (PA 1974) and the Freedom of Information Act (FOIA 1966).

\subsection{Routine Operations}

Staff routinely administer and process data, issue reports, and maintain the Records Library.

\subsubsection{Data Administration}

Over 2497 Radiation Work Permits (RWPs) were created/closed in ACES in 2001, and over 253,199 access instances occurred. The REX database administrator completed 40 software change requests in 2001 to REX Version 3.

\subsubsection{Dosimetry Operations}

In most categories, the number of documents sent from dosimetry operations to the Records Library were about the same in 2001 as 2000 (see Table 5.1). However, forms documenting visitor and subcontractor dosimeter issue and special process forms decreased. The total number of documents scanned increased by $20 \%$. The increase was due to the decision to start scanning archived instrument calibration records into LaserCAL. 
Table 5.1. Dosimetry Operations Activity for CY $2001^{(\mathrm{a})}$

\begin{tabular}{|l|c|c|}
\hline \multicolumn{1}{|c|}{ Activity } & Number Processed \\
\cline { 2 - 3 } & $\mathbf{2 0 0 0}$ & $\mathbf{2 0 0 1}$ \\
\hline $\begin{array}{l}\text { Document exposure history prior to Hanford/initiate a record for a new or rehired } \\
\text { employee - Personal Radiation Exposure History Form }\end{array}$ & 2,471 & 2,676 \\
\hline $\begin{array}{l}\text { Document personnel data or dosimetry changes - Employee and Dosimetry Change } \\
\text { Forms }\end{array}$ & 7,191 & 6,781 \\
\hline $\begin{array}{l}\text { Schedule In Vivo Bioassays (coordinate with medical physical schedule, and mail } \\
\text { notification letters) }\end{array}$ & 4,515 & 4,723 \\
\hline $\begin{array}{l}\text { Schedule Excreta Bioassays (combine analyses, verify address and availability, and } \\
\text { mail notification letter) }\end{array}$ & 2,436 & 2,256 \\
\hline Bioassays Waived (not required based on needs-test for radiological entries) & 1,564 & 1,746 \\
\hline $\begin{array}{l}\text { Issue temporary dosimeters to employees due to new hires, changes in dosimetry } \\
\text { requirements, multiple dosimetry needs, or employees who forgot their dosimeters - } \\
\text { Temporary Dosimeter Assignment Forms }\end{array}$ & 5,125 & 3,682 \\
\hline $\begin{array}{l}\text { Issue dosimetry to visitors and subcontractors who have not completed radiological } \\
\text { worker training - Visitor and Subcontractor Dosimeter Issue Forms }\end{array}$ & 1,689 & 2,159 \\
\hline $\begin{array}{l}\text { Estimate exposure for lost, damaged, or otherwise suspect dosimeter results - } \\
\text { Investigation of Dosimeter Result Forms and Change Letters }\end{array}$ & 494 & 595 \\
\hline Document data for specially processed dosimeters - Special Process Forms & 4,391 & 2,412 \\
\hline Radiological Work Restrictions Imposed & 2,472 & 1,437 \\
\hline
\end{tabular}

A discrepancy report, developed in 1999, that compares REX data with security data identified a number of name discrepancies. As each error was corrected, a change form was produced and indexed. About 1500 errors were identified and corrected in 2001, the same as in 2000.

\subsubsection{Exposure Reporting}

As shown in Tables 5.2 and 5.3 and Figures 5.1 through 5.5, work was relatively consistent with 2000. However, the Energy Employees Occupational Illness Compensation Program (EEOICP) began to impact operations in the last quarter of 2001. The EEOICP provides compensation and medical benefits for nuclear weapons workers who may have developed certain work-related illnesses. In support of that program, HRRP provides dosimetry histories and radiobioassay results of claimants to the National Institute of Occupational Safety and Health Office of Compensation Analysis and Support (OCAS), which will use the data to support radiation dose reconstruction for the claimants. Dosimetry history requests for over 600 claimants were received in 2001, and nearly 100 were completed (Table 5.2). In addition to the direct requests from OCAS, the EEOICP also increased Privacy Act (PA) and Freedom of Information Act (FOIA) requests for radiation dose records. Over 100 PA/FOIA requests were completed this year, compared to about 50 last year and less than 20 in previous years. 
Table 5.2. Number of Responses to Requests for Previous Exposure ${ }^{(a)}$

\begin{tabular}{|c|c|c|c|c|c|c|c|c|}
\hline & \multicolumn{4}{|c|}{2000} & \multicolumn{4}{|c|}{2001} \\
\hline & $1^{\text {st }} Q \operatorname{tr}$ & $2^{\text {nd }}$ Qtr & $3^{\text {rd }}$ Qtr & $4^{\text {th }} Q \operatorname{tr}$ & $1^{\text {st }} Q \operatorname{tr}$ & $2^{\text {nd }}$ Qtr & $3^{\text {rd }} Q \operatorname{tr}$ & $4^{\text {th }}$ Qtr \\
\hline Miscellaneous & 36 & 0 & 0 & 25 & 29 & 1 & 0 & 0 \\
\hline PA/FOIA Requests & 11 & 20 & 9 & 10 & 10 & 30 & 34 & 34 \\
\hline $\begin{array}{l}\text { From Current } \\
\text { Employees }\end{array}$ & 3 & 4 & 1 & 4 & 4 & 5 & 6 & 0 \\
\hline $\begin{array}{l}\text { From Former } \\
\text { Employees }\end{array}$ & 2 & 1 & 4 & 2 & 2 & 1 & 0 & 1 \\
\hline From Companies & 35 & 35 & 65 & 50 & 61 & 81 & 47 & 47 \\
\hline EEOICP & -- & -- & -- & -- & -- & -- & 19 & 75 \\
\hline $\begin{array}{l}\text { EEOICP = Energy } \\
\text { PA = Privacy Act. } \\
\text { FOIA = Freedom }\end{array}$ & $\begin{array}{l}\text { ployees } \\
\text { formatic }\end{array}$ & $\begin{array}{l}\text { cupation } \\
\text { Act. }\end{array}$ & & & & & & \\
\hline
\end{tabular}

Table 5.3. Number of Visitor Exposure Letters

\begin{tabular}{|l|c|c|c|c|c|c|c|c|}
\hline \multirow{2}{*}{} & \multicolumn{4}{|c|}{$\mathbf{2 0 0 0}$} & \multicolumn{5}{|c|}{$\mathbf{2 0 0 1}$} \\
\cline { 2 - 10 } & $\mathbf{1}^{\text {st }} \mathbf{Q t r}$ & $\mathbf{2}^{\text {nd }} \mathbf{Q t r}$ & $\mathbf{3}^{\text {rd }} \mathbf{Q t r}$ & $\mathbf{4}^{\text {th }} \mathbf{Q t r}$ & $\mathbf{1}^{\text {st }} \mathbf{Q t r}$ & $\mathbf{2}^{\text {nd }} \mathbf{Q t r}$ & $\mathbf{3}^{\text {rd }} \mathbf{Q t r}$ & $\mathbf{4}^{\text {th }} \mathbf{Q t r}$ \\
\hline DOE-HQ & 18 & 28 & 18 & 17 & 11 & 31 & 57 & 34 \\
\hline DNFSB $^{(\text {a) }}$ & 7 & 2 & 9 & 13 & 7 & 8 & 8 & 5 \\
\hline IAEA $^{(\text {b) }}$ & 4 & 5 & 5 & 10 & 2 & 3 & 9 & 1 \\
\hline Miscellaneous & 294 & 383 & 357 & 389 & 363 & 441 & 629 & 456 \\
\hline $\begin{array}{l}\text { (a) DNFSB = Defense Nuclear Facility Safety Board. } \\
\text { (b) IAEA = International Atomic Energy Agency. }\end{array}$
\end{tabular}

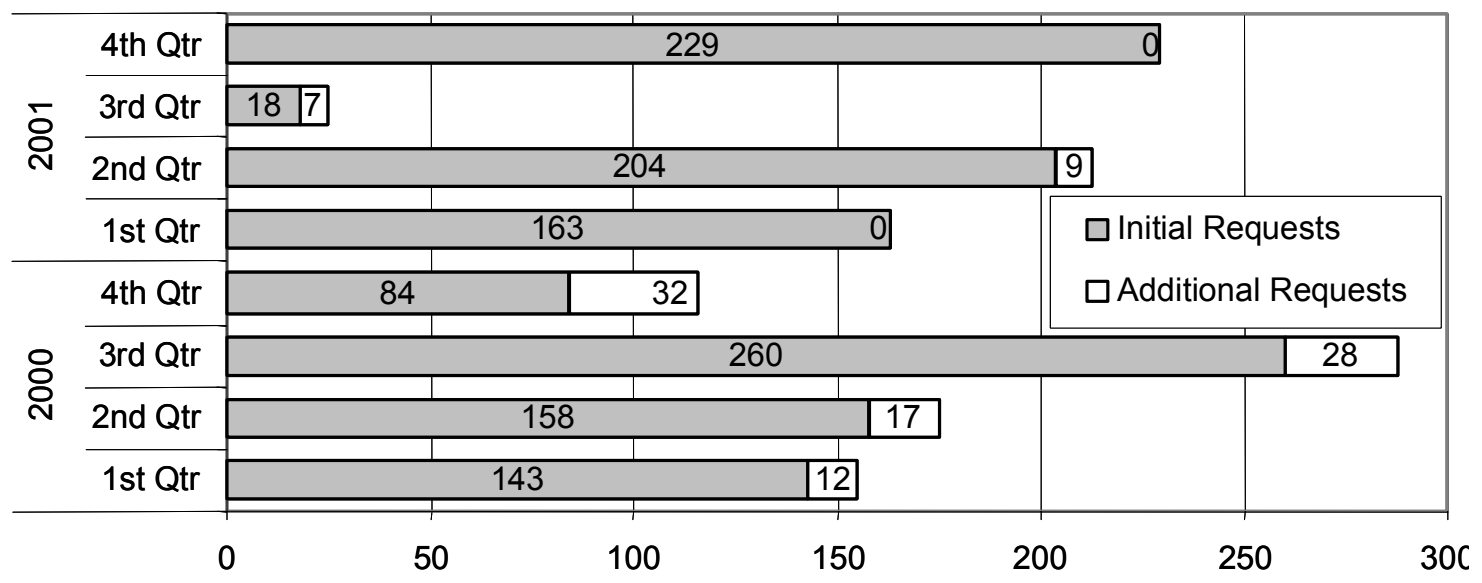

Figure 5.1. Dosimetry Records Requested by HRRP from Offsite Facilities 


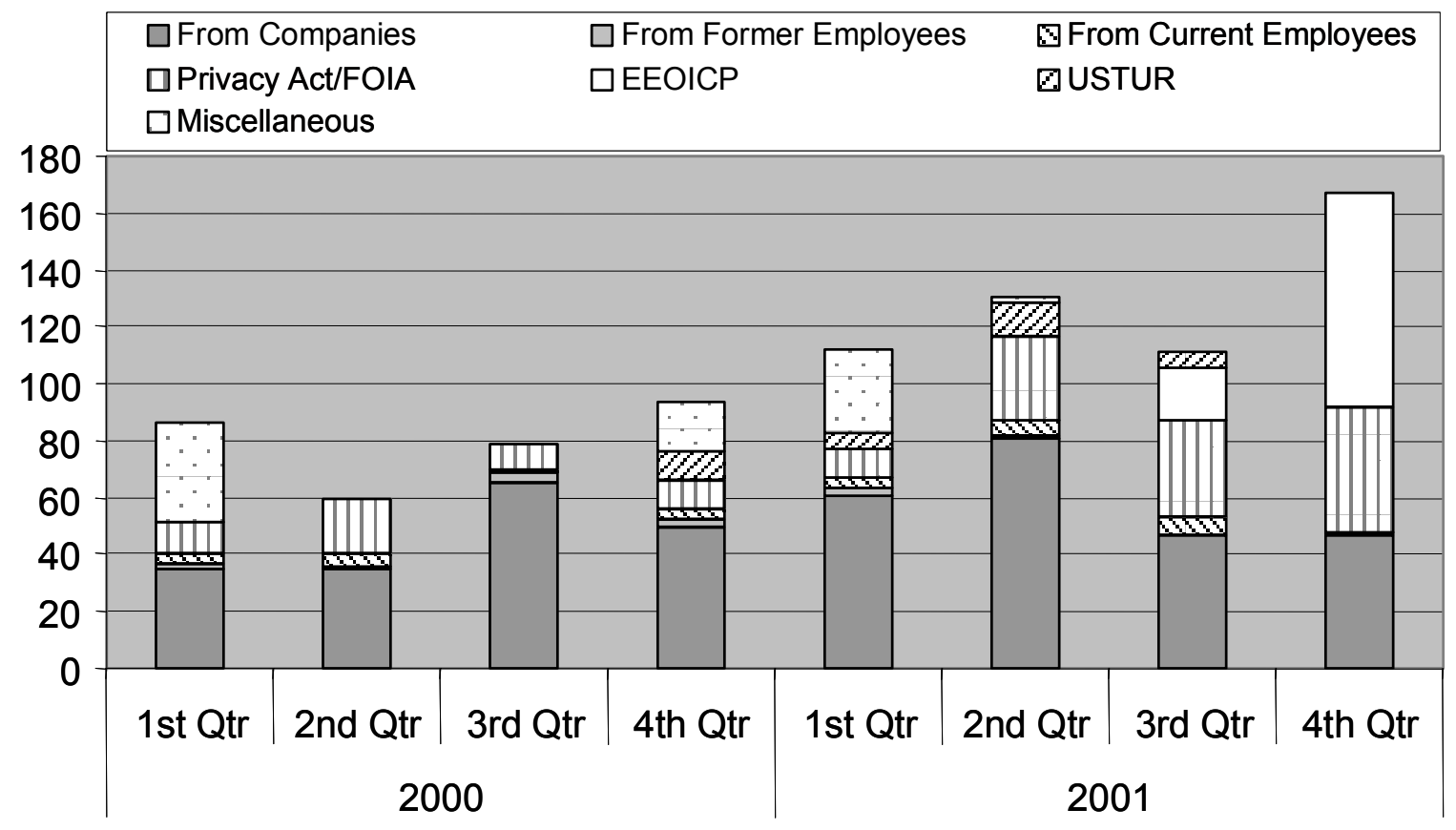

Figure 5.2. Number of Responses to Requests for Previous Exposure

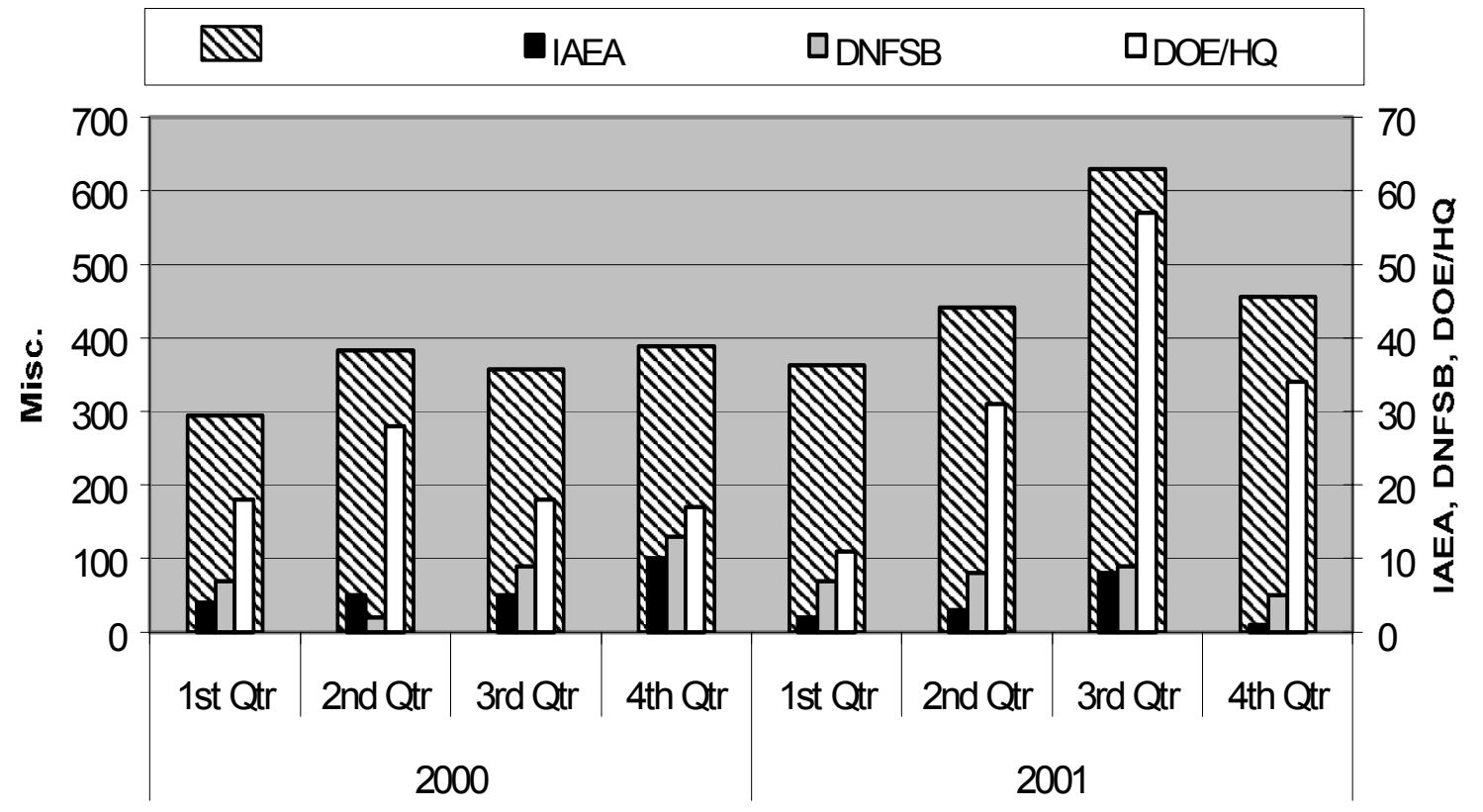

Figure 5.3. Number of Visitor Exposure Letters 


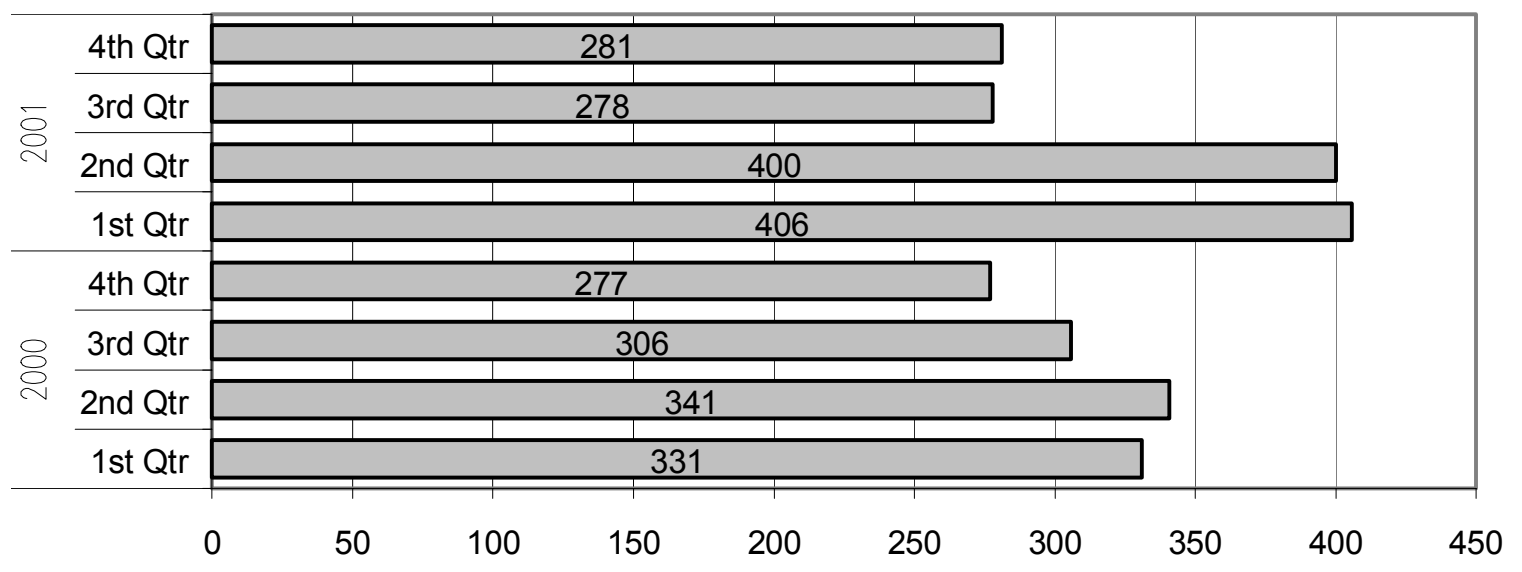

Figure 5.4. Number of Dosimetry Termination Letters

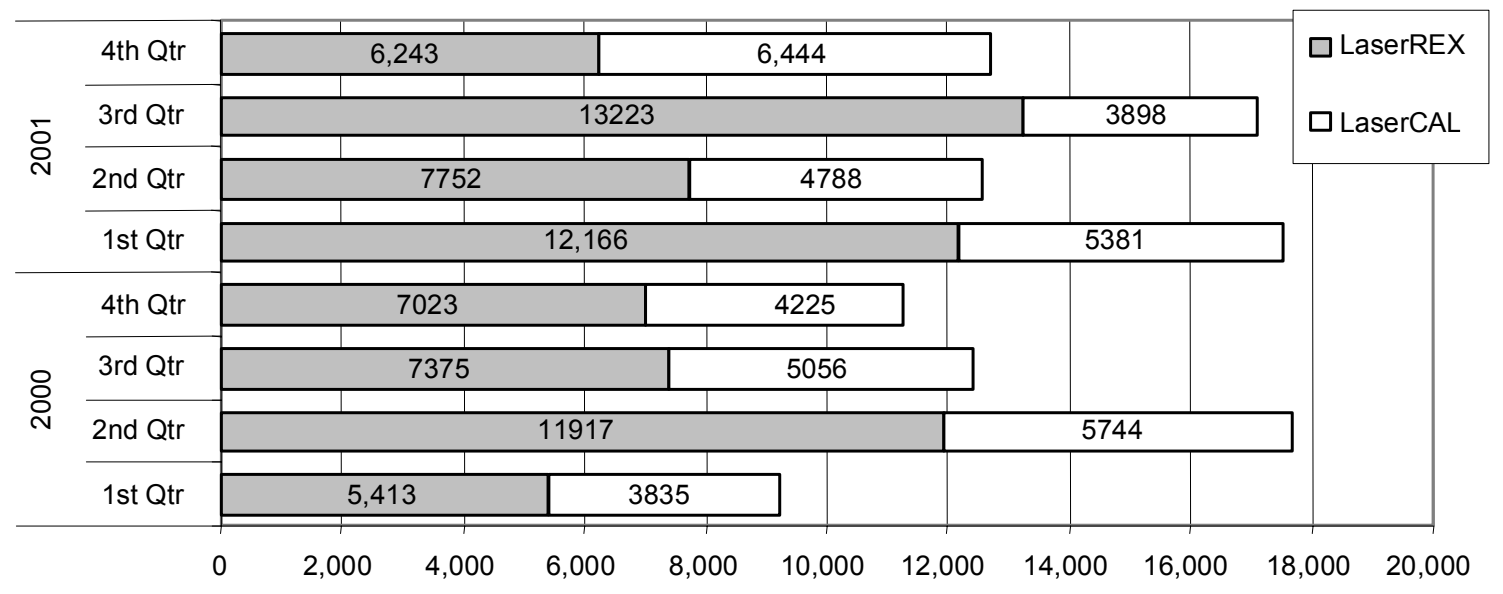

Figure 5.5. Number of Documents Scanned/Indexed

\subsubsection{Records Library}

The number of documents scanned and indexed into the LaserREX and LaserCAL systems this year was up $20 \%$ from 2000 , to about 60,000 documents. This was the second year of operation of the LaserCAL system, which accounted one-third of the Records Library workload in 2001. The additional documents are mostly from the exposure reporting function.

\subsection{Program Changes and Improvements}

Database and document-scanning capabilities were improved during the year, as described in the following sections. 


\subsubsection{ACES Database}

ACES 7.0 was implemented in February 2001. In order to incorporate the self-ACEing module, which would allow workers to create their own accesses without the assistance of a Radiation Control Technician (RCT), the basic functions of the main ACEing screen were reversed to retrieve the person data before the permit data. This structural change caused major processing problems that required several ensuing releases to patch and repair. LMSI expects to release a modularized version of ACES in 2002 .

\subsubsection{REX Database}

The Oracle-based REX Version 3 client server system was released for production use on October 2, 2000. The user interface was developed using the Oracle Developer 2000 suite of tools. REX Version 3 resides on an UNIX platform on a Sun Microsystems Enterprise server operated by PNNL.

The REX database performed very well all year. Most of the Software Change Requests (SCRs) issued during the year were for changes and enhancements to make the operations more efficient and data entry less cumbersome. The REX User's Group, initiated late in 1993, was instrumental in proposing and defining many of the enhancements and changes.

The REX database administrator and the programmer completed 42 software change requests for REX Version 3 in 2001. Some of the significant changes included the following:

- The annual personnel dosimetry report letters were reformatted to revise comparisons with background dose levels.

- The logic for the non-detection bioassay results letters was revised to allow more information about the analyses performed.

- The CU10 Termination Screen logic was revised to automatically close all open pregnancy declarations for the person being terminated.

- Logic was added to the ring-dosimeter issue screens to ensure rings are issued in pairs with sequential numbers.

\subsubsection{Document Scanning}

The LaserREX system consists of a single 350-MHz dual processor Gateway ALR 7200 server using Windows NT, coupled with two computer workstations, each with an optical scanner. There were no major periods of unavailability this year. 
LaserCAL uses existing LaserREX hardware with modified software cloned from LaserREX. LaserCAL provides a retrievable document database for the Instrument Services and Technology Program. About one-third of the documents scanned and indexed by Radiation Records are now for the Instrument Services and Technology Program.

\subsection{Program Assessment}

The Hanford contractor dosimetry representatives on the Hanford Personnel Dosimetry Advisory Committee conducted an assessment of the HRRP from October 31, 2001 through November 2, 2001. The assessment was performed to meet the requirement of 10 CFR 835.102 to perform an internal audit of all functional elements of the radiation protection program no less frequently than every 36 months. The assessment also met the requirements contained in 10 CFR 830.122 to perform assessments to identify and correct problems, measure the adequacy of work performance, and promote improvement.

The main focus of the assessment was to assess compliance with the requirements of 10 CFR 835 and those elements of contractor's radiation protection programs that address dosimetry records. These requirements formed the basis for the checklist containing the lines-of-inquiry used for performance of the assessment. As assessors evaluated the HRRP against the lines of inquiry, any non-compliant item or poor practice was identified and, depending upon its severity, it was classified as a finding or an observation according to the following definitions:

- Finding: A direct and significant departure from a requirement that could result in significant safety consequences or the violation of a contractual requirement. Findings should be promptly investigated. Corrective actions, if appropriate, should be administered as soon as practicable.

- Observation: A poor practice or weakness that, in the judgment of the assessor, does not pose the potential for significant safety or compliance consequences, but if not corrected could result in a finding. Observations should be investigated as soon as practical. Corrective actions, if appropriate, should be administered as soon as practicable.

No findings were identified during the course of the assessment but six observations were made that reflected needed improvements in the program. Most of these observations concerned existing practices that the assessors believed could be improved to better ensure the quality of the program.

\subsection{Supporting Projects}

None 


\subsection{Program-Related Professional Activities}

Jay A. MacLellan served as:

- Chair of the American Academy of Health Physics Appeals Committee

- President Elect, Columbia Chapter of the Health Physics Society (June 2000 to May 2001)

- President, Columbia Chapter of the Health Physics Society (from June 2001). 


\subsection{Instrumentation Services and Technology Program}

The Instrumentation Services and Technology Program (IS\&TP) provides complete and reliable calibration and maintenance and non-destructive analysis services for Hanford Site contractors. The program staff calibrate and maintain radiation protection instrumentation and measuring and test equipment that is used to ensure personnel safety in the Hanford workplace. The non-destructive analysis of waste containers is performed for Hanford Site customers. Specific tasks performed under this program during CY 2001 included calibration, maintenance, and repair of instrumentation; procurement and testing of new radiological control instruments; administration and technical support of the Hanford Instrument Evaluation Committee (HIEC); and maintenance of a pool of portable survey instruments available for use by site contractors.

The operation of a complete radiation protection instrument calibration and maintenance program is an integral part of the Hanford Site Radiological Control Program. During CY 2001, IS\&TP continued to provide complete instrument services including calibration, maintenance, repair, and records management.

Procurement of new instruments is initiated by the site contractors, or jointly by the contractors through the HIEC, and the procurement costs are charged to the contractor that uses the instruments. The Hanford contractors, through the evaluation, calibration, and maintenance programs of IS\&TP provide the site with high-quality instrumentation that is reliable, accurate, and capable of performing at the level necessary to ensure personnel safety as required by 10 CFR 835 . Calibrations are performed using the mandatory guidance in ANSI N323-1978, Radiation Protection Instrumentation Test and Calibration (ANSI 1978) and ANSI N323A-1997, Radiation Protection Instrumentation Test and Calibration, Portable Survey Instruments (ANSI 1997). IS\&TP activities fall under several basic tasks. These basic tasks are: 1) administration of the Hanford Site pool of portable survey instruments; 2) calibration and maintenance of radiation detection instruments; 3) calibration and maintenance of measuring and test equipment; 4) evaluation and publication to the Hanford Site of all site portable survey instrument environmental parameters; 5) maintenance of a calibration records database; 6) maintenance of all the necessary radiological, electronic, and mechanical standards traceable to NIST; and 7) administration and technical support of the HIEC. Several of these basic tasks and other important supporting tasks performed in CY 2001 are described in this chapter.

\subsection{Routine Operations}

Routine instrument pool management, calibration and maintenance services for radiological instruments and measuring and test equipment (M\&TE), and calibration record management are described in the following sections. 


\subsubsection{Administration of Portable Instrument Pool}

Administration of the portable instrument pool includes maintaining a sufficient inventory of commonly used instruments to ensure that there is a sufficient supply to meet the daily instrumentation needs of the field organizations. A second aspect of managing the portable instrument pool is identifying and disposing instruments that should be removed from service.

During CY 2001, Eberline neutron rem detectors (NRDs) were added to the pool to supplement the supply of neutron survey instruments. Until this year, Nuclear Research Corporation (NRC) AN/PDR-70 neutron survey instruments (aka "Snoopys") were used exclusively. The Snoopy weight is of concern to radiological control technicians who use the instruments daily. The Eberline NRD is substantially lighter than the Snoopys.

\subsubsection{Calibration and Maintenance Service - Radiation Detection Instruments}

During CY 2001, 13,780 calibrations were performed by IS\&TP. Table 6.1 details the number of instruments calibrated by calibration class and compares the volume with the number of calibrations performed previous calendar years. Because the measuring and test equipment (M\&TE) calibrations were performed by another organization prior to CY 2000, statistics for M\&TE are not provided for previous years. Tables 6.2 through 6.5 provide additional detail on the number of calibrations performed for each prime contractor during CY 2001. Figure 6.1 illustrates the total number of calibrations performed each month for the Hanford Site. The figure is provided because it illustrates the cyclic nature of the calibration volume.

The total number of calibrations performed decreased slightly from the 14,546 calibrations performed in CY 2000, indicating a continuing decrease in calibration volume.

Table 6.1. Instrument Calibrations by Unit-Price Category and by CY

\begin{tabular}{|c|c|c|c|c|c|c|}
\hline \multirow[b]{2}{*}{ Calibration Class } & \multirow[b]{2}{*}{ Description of Class } & \multicolumn{5}{|c|}{ Number of Calibrations by CY } \\
\hline & & CY 1997 & CY 1998 & CY 1999 & CY 2000 & CY 2001 \\
\hline CAMs & Continuous air monitors & 495 & 458 & 465 & 444 & 506 \\
\hline Exposure Rate & Exposure or dose rate survey instrument & 2,219 & 1,896 & 1,808 & 1,836 & 1,632 \\
\hline Probes & Probe or detector only & 3,944 & 3,670 & 3,406 & 3,551 & 3,142 \\
\hline $\begin{array}{l}\text { Electronic } \\
\text { Dosimeters }\end{array}$ & Direct reading, electronic dosimeter & 804 & 647 & 842 & 969 & 1,250 \\
\hline Mini Scaler ${ }^{(a)}$ & Integral meter and detector & 265 & 320 & 293 & 130 & 160 \\
\hline Air Flow & & & & & 352 & 446 \\
\hline Meter only & Electronic calibration of meter or readout & 3,973 & 3,558 & 3,593 & 3,915 & 3,253 \\
\hline Pencils & Pocket ionization chamber dosimeter & 3,946 & 3,149 & 2,690 & 2,501 & 2,148 \\
\hline Smart Probes & Stand-alone calibration of a "smart" detector & 487 & 486 & 597 & 485 & 359 \\
\hline Sources & Certification of source activity or emission rate & 386 & 324 & 300 & 283 & 280 \\
\hline $\begin{array}{l}\text { Special } \\
\text { Calibrations }\end{array}$ & Complex calibrations charged by the hour & 68 & 112 & 87 & 66 & 154 \\
\hline M\&TE - all others & & & & & 14 & 450 \\
\hline Total & & 16,637 & 14,620 & 14,173 & 14,546 & 13,780 \\
\hline
\end{tabular}


Table 6.2. CY 2001 Calibration Volume for All Hanford Contractors

\begin{tabular}{|c|c|c|c|c|c|c|c|c|c|c|c|c|c|}
\hline \multirow[b]{2}{*}{ Calibration Class } & \multicolumn{13}{|c|}{ Calibrations Completed, by Month, for CY 2001} \\
\hline & Jan & Feb & Mar & Apr & May & Jun & Jul & Aug & Sep & Oct & Nov & Dec & $\begin{array}{c}\text { Total } \\
\text { Hanford } \\
\text { Units } \\
\end{array}$ \\
\hline Exposure Rate & 106 & 127 & 128 & 170 & 119 & 144 & 188 & 115 & 189 & 120 & 132 & 94 & 1,632 \\
\hline Mini Scaler & 10 & 12 & 13 & 12 & 14 & 11 & 12 & 7 & 23 & 12 & 18 & 16 & 160 \\
\hline Meter & 204 & 266 & 321 & 341 & 252 & 233 & 313 & 265 & 355 & 188 & 274 & 241 & 3,253 \\
\hline Electronic Dosimeter & 144 & 56 & 93 & 96 & 88 & 121 & 123 & 52 & 191 & 83 & 147 & 56 & 1,250 \\
\hline Probe & 198 & 247 & 329 & 289 & 218 & 224 & 291 & 233 & 359 & 196 & 300 & 258 & 3,142 \\
\hline Smart Probe & 20 & 22 & 34 & 34 & 39 & 19 & 45 & 23 & 58 & 25 & 19 & 21 & 359 \\
\hline CAM & 44 & 45 & 38 & 47 & 31 & 51 & 48 & 59 & 44 & 27 & 41 & 31 & 506 \\
\hline Pencil & 61 & 265 & 145 & 190 & 149 & 43 & 306 & 192 & 231 & 263 & 142 & 161 & 2,148 \\
\hline Source & 10 & 49 & 26 & 28 & 19 & 14 & 36 & 4 & 43 & 14 & 24 & 13 & 280 \\
\hline Specials & 3 & 13 & 15 & 7 & 15 & 22 & 11 & 8 & 16 & 8 & 18 & 18 & 154 \\
\hline Air Flow & 0 & 68 & 36 & 56 & 43 & 50 & 26 & 11 & 30 & 68 & 24 & 34 & 446 \\
\hline M\&TE - all others & 21 & 86 & 92 & 30 & 32 & 17 & 38 & 29 & 36 & 42 & 11 & 16 & 450 \\
\hline Total & 821 & 1,256 & 1,270 & 1,300 & 1,019 & 949 & 1,437 & 998 & 1,575 & 1,046 & 1,150 & 959 & 13,780 \\
\hline
\end{tabular}


Table 6.3. CY 2001 Calibration Volume for Fluor Hanford, Inc.

\begin{tabular}{|c|c|c|c|c|c|c|c|c|c|c|c|c|c|}
\hline \multirow[b]{2}{*}{ Calibration Class } & \multicolumn{13}{|c|}{ Calibrations Completed, by Month, for CY 2001} \\
\hline & Jan & Feb & Mar & Apr & May & Jun & Jul & Aug & Sep & Oct & Nov & Dec & $\begin{array}{c}\text { Total } \\
\text { FHI } \\
\text { Units }\end{array}$ \\
\hline Exposure Rate & 79 & 77 & 80 & 101 & 69 & 97 & 133 & 75 & 115 & 63 & 85 & 49 & 1,023 \\
\hline Mini Scaler & 8 & 9 & 6 & 7 & 13 & 7 & 8 & 5 & 22 & 10 & 14 & 13 & 122 \\
\hline Meter & 118 & 133 & 160 & 168 & 151 & 156 & 159 & 130 & 182 & 118 & 157 & 125 & 1,757 \\
\hline Electronic Dosimeter & 89 & 38 & 64 & 78 & 50 & 58 & 67 & 10 & 161 & 71 & 117 & 30 & 833 \\
\hline Probe & 120 & 151 & 184 & 156 & 136 & 172 & 165 & 136 & 186 & 116 & 177 & 121 & 1,820 \\
\hline Smart Probe & 0 & 2 & 1 & 0 & 4 & 2 & 1 & 0 & 3 & 0 & 0 & 3 & 16 \\
\hline CAM & 43 & 44 & 35 & 35 & 25 & 36 & 44 & 49 & 41 & 23 & 37 & 27 & 439 \\
\hline Pencil & 17 & 160 & 52 & 141 & 95 & 26 & 189 & 86 & 126 & 70 & 65 & 33 & 1,060 \\
\hline Source & 8 & 46 & 17 & 24 & 16 & 13 & 21 & 4 & 31 & 14 & 22 & 13 & 229 \\
\hline Specials & 1 & 0 & 1 & 5 & 3 & 2 & 4 & 1 & 4 & 0 & 5 & 4 & 30 \\
\hline Air Flow & 0 & 31 & 13 & 6 & 15 & 19 & 10 & 5 & 14 & 20 & 15 & 6 & 154 \\
\hline Total & 483 & 691 & 613 & 721 & 577 & 588 & 801 & 501 & 885 & 505 & 694 & 424 & 7,483 \\
\hline
\end{tabular}


Table 6.4. CY 2001 Calibration Volume for CH2M Hill Hanford Group, Inc.

\begin{tabular}{|c|c|c|c|c|c|c|c|c|c|c|c|c|c|}
\hline \multirow[b]{2}{*}{ Calibration Class } & \multicolumn{13}{|c|}{ Calibrations Completed, by Month, for CY 2001} \\
\hline & Jan & Feb & Mar & Apr & May & Jun & Jul & Aug & Sep & Oct & Nov & Dec & $\begin{array}{l}\text { Total } \\
\text { CHG } \\
\text { Units }\end{array}$ \\
\hline Exposure Rate & 8 & 25 & 14 & 27 & 13 & 17 & 28 & 21 & 35 & 12 & 19 & 16 & 235 \\
\hline Mini Scaler & 0 & 1 & 4 & 3 & 0 & 2 & 0 & 1 & 0 & 0 & 4 & 0 & 15 \\
\hline Meter & 32 & 33 & 41 & 82 & 42 & 19 & 48 & 32 & 36 & 33 & 35 & 38 & 471 \\
\hline Electronic Dosimeter & 21 & 7 & 5 & 2 & 35 & 7 & 1 & 38 & 25 & 1 & 2 & 14 & 158 \\
\hline Probe & 40 & 26 & 47 & 60 & 31 & 18 & 35 & 35 & 33 & 30 & 43 & 55 & 453 \\
\hline Smart Probe & 0 & 0 & 0 & 0 & 0 & 0 & 0 & 0 & 0 & 0 & 1 & 0 & 1 \\
\hline CAM & 0 & 0 & 0 & 2 & 0 & 0 & 0 & 3 & 1 & 1 & 2 & 0 & 9 \\
\hline Pencil & 39 & 34 & 77 & 32 & 37 & 16 & 81 & 97 & 67 & 93 & 49 & 50 & 672 \\
\hline Source & 2 & 0 & 6 & 3 & 1 & 1 & 15 & 0 & 12 & 0 & 2 & 0 & 42 \\
\hline Specials & 0 & 0 & 0 & 0 & 0 & 0 & 0 & 0 & 0 & 2 & 0 & 0 & 2 \\
\hline Air Flow & 0 & 28 & 13 & 49 & 22 & 27 & 3 & 2 & 12 & 0 & 0 & 20 & 176 \\
\hline Total & 142 & 154 & 207 & 260 & 181 & 107 & 211 & 229 & 221 & 172 & 157 & 193 & 2,234 \\
\hline
\end{tabular}


Table 6.5. CY 2001 Calibration Volume for Bechtel Hanford, Inc.

\begin{tabular}{|c|c|c|c|c|c|c|c|c|c|c|c|c|c|}
\hline \multirow[b]{2}{*}{ Calibration Class } & \multicolumn{13}{|c|}{ Calibrations Completed, by Month, for CY 2001} \\
\hline & Jan & Feb & Mar & Apr & May & Jun & Jul & Aug & Sep & Oct & Nov & Dec & $\begin{array}{l}\text { Total } \\
\text { BHI } \\
\text { Units }\end{array}$ \\
\hline Exposure Rate & 10 & 17 & 9 & 17 & 21 & 18 & 15 & 9 & 23 & 29 & 14 & 17 & 199 \\
\hline Mini Scaler & 0 & 0 & 0 & 0 & 0 & 0 & 1 & 1 & 0 & 0 & 0 & 1 & 3 \\
\hline Meter & 32 & 50 & 86 & 47 & 35 & 28 & 29 & 33 & 60 & 14 & 34 & 53 & 501 \\
\hline Electronic Dosimeter & 34 & 8 & 22 & 16 & 1 & 53 & 44 & 4 & 5 & 1 & 16 & 8 & 212 \\
\hline Probe & 15 & 26 & 56 & 25 & 20 & 15 & 21 & 13 & 57 & 10 & 31 & 32 & 321 \\
\hline Smart Probe & 20 & 20 & 33 & 34 & 35 & 17 & 44 & 23 & 55 & 25 & 18 & 18 & 342 \\
\hline CAM & 0 & 0 & 0 & 3 & 0 & 11 & 2 & 5 & 0 & 1 & 0 & 0 & 22 \\
\hline Pencil & 0 & 21 & 5 & 0 & 11 & 0 & 9 & 0 & 31 & 13 & 4 & 32 & 126 \\
\hline Source & 0 & 0 & 1 & 0 & 0 & 0 & 0 & 0 & 0 & 0 & 0 & 0 & 1 \\
\hline Specials & 0 & 0 & 2 & 0 & 0 & 0 & 0 & 0 & 0 & 0 & 0 & 0 & 2 \\
\hline Air Flow & 0 & 3 & 5 & 0 & 0 & 0 & 0 & 3 & 0 & 40 & 0 & 0 & 51 \\
\hline Total & 111 & 145 & 219 & 142 & 123 & 142 & 165 & 91 & 231 & 133 & 117 & 161 & 1,780 \\
\hline
\end{tabular}


Table 6.6. CY 2001 Calibration Volume for PNNL

\begin{tabular}{|c|c|c|c|c|c|c|c|c|c|c|c|c|c|}
\hline \multirow[b]{2}{*}{ Calibration Class } & \multicolumn{13}{|c|}{ Calibrations Completed, by Month, for CY 2001} \\
\hline & Jan & Feb & Mar & Apr & May & Jun & Jul & Aug & Sep & Oct & Nov & Dec & $\begin{array}{c}\text { Total } \\
\text { PNNL } \\
\text { Units }\end{array}$ \\
\hline Exposure Rate & 9 & 8 & 25 & 25 & 16 & 12 & 12 & 10 & 16 & 16 & 14 & 12 & 175 \\
\hline Mini Scaler & 2 & 2 & 3 & 2 & 1 & 2 & 3 & 0 & 1 & 2 & 0 & 2 & 20 \\
\hline Meter & 22 & 50 & 34 & 44 & 24 & 30 & 77 & 70 & 77 & 23 & 48 & 25 & 524 \\
\hline Electronic Dosimeter & 0 & 3 & 2 & 0 & 2 & 3 & 11 & 0 & 0 & 10 & 12 & 4 & 47 \\
\hline Probe & 23 & 44 & 42 & 48 & 31 & 19 & 70 & 49 & 83 & 40 & 49 & 50 & 548 \\
\hline Smart Probe & 0 & 0 & 0 & 0 & 0 & 0 & 0 & 0 & 0 & 0 & 0 & 0 & 0 \\
\hline CAM & 1 & 1 & 3 & 7 & 6 & 4 & 2 & 2 & 2 & 2 & 2 & 4 & 36 \\
\hline Pencil & 5 & 50 & 11 & 17 & 6 & 1 & 27 & 9 & 7 & 87 & 24 & 46 & 290 \\
\hline \begin{tabular}{|l|} 
Source \\
\end{tabular} & 0 & 3 & 2 & 1 & 2 & 0 & 0 & 0 & 0 & 0 & 0 & 0 & 8 \\
\hline \begin{tabular}{|l|} 
Specials \\
\end{tabular} & 2 & 13 & 12 & 2 & 12 & 20 & 7 & 7 & 12 & 6 & 13 & 14 & 120 \\
\hline Air Flow & 0 & 6 & 5 & 1 & 6 & 4 & 13 & 1 & 4 & 8 & 9 & 8 & 65 \\
\hline M\&TE - all others & 21 & 86 & 92 & 30 & 32 & 17 & 38 & 29 & 36 & 42 & 11 & 16 & 450 \\
\hline Total & 85 & 266 & 231 & 177 & 138 & 112 & 260 & 177 & 238 & 236 & 182 & 181 & 2,283 \\
\hline
\end{tabular}




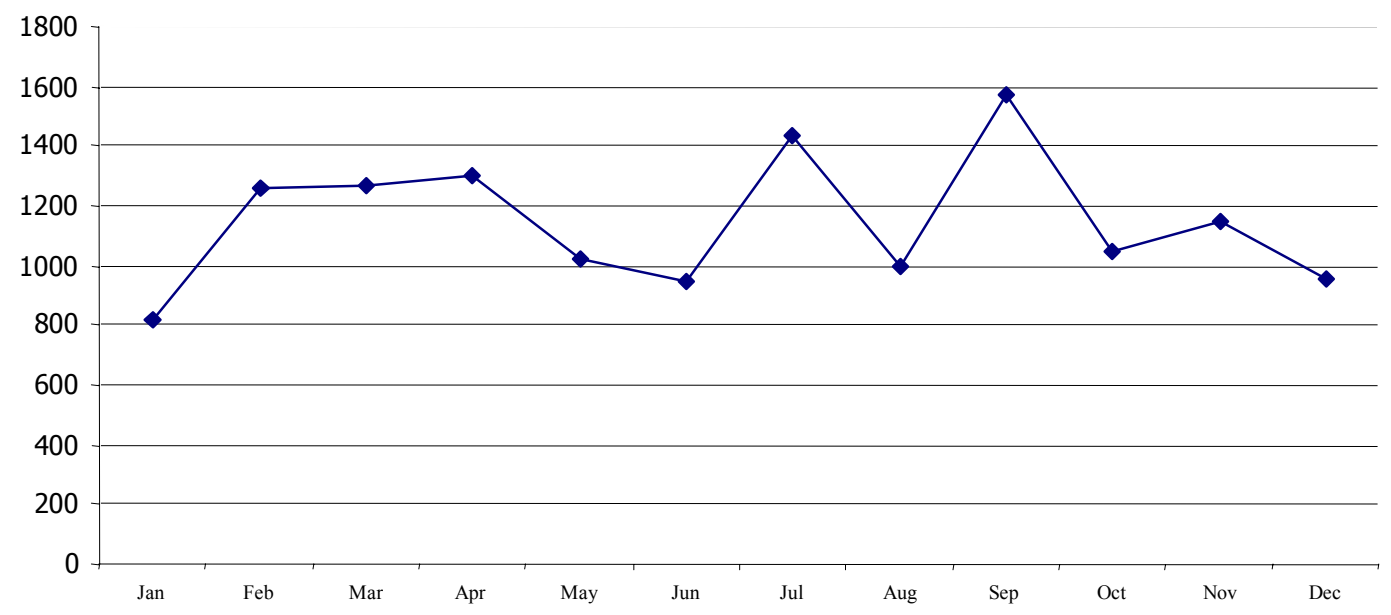

Figure 6.1. Total Number of Calibrations for Hanford Clients During CY 2001

\subsubsection{Calibration and Maintenance Services; Measuring and Test Equipment}

The M\&TE calibration laboratory provides calibration services for a wide range of physical and electrical instruments. Disciplines included in the laboratories capabilities include voltage, current, resistance, capacitance, frequency, temperature, humidity, dew point, pressure, vacuum gas flow, $\mathrm{pH}$, conductivity, time, rotational speed, and wind speed. A detailed summary of the M\&TE calibration capabilities can be found at http:/www.pnl.gov/eshs/cap/ice/mte.html. The M\&TE calibration program complies with ANSI/NCSL Z540-1 (1994).

The volume of calibration work performed by the M\&TE calibration project is included in Tables 6.1 through 6.4.

\subsubsection{Calibration of As-Founds Out-of-Tolerance}

Part of the calibration service provided by IS\&TP is quantifying the as-found condition of each instrument when it is returned for calibration. The as-found condition is typically documented as the instrument's response to the calibration standards and is recorded before any adjustments are made to the instrument's response.

A total of 132 instruments calibrated during CY 2001 were found to be significantly out of tolerance when returned for calibration (that is, the instrument's response was not within $\pm 20 \%$ of the conventionally true value of the calibration field). The number of out-of-tolerance notifications issued is consistent with previous years (last year's total was 102 notices). This is an indication that the instruments in the portable instrument pool are not aging to the point of being unreliable. 


\begin{tabular}{|c|c|}
\hline Year & $\begin{array}{c}\text { Number of Out- } \\
\text { of-Tolerance } \\
\text { Notices Issued }\end{array}$ \\
\hline 1999 & 101 \\
\hline 2000 & 102 \\
\hline 2001 & 132 \\
\hline
\end{tabular}

The total does not include instruments that were returned for calibration with flaws or defects that would render the instrument obviously unusable to the user. Nor does it include instruments that were repaired prior to calibration because any repairs would invalidate the as-found readings. In each case, the organization that used the instrument was notified of the out-of-tolerance condition.

When a single instrument model seems to have a large number of calibration as-founds out-oftolerance, a detailed review of all calibration as-founds for that instrument model is conducted. If more than $15 \%$ of the instruments returned for calibration have as-founds out of tolerance, the calibration interval for that instrument model is shortened. During CY 2001, as-found data for several instrument models were investigated for adverse trends. The models investigated were the Eberline E-600, lapel air samplers, and the Portable Alpha Monitor (PAM). As-found data for the lapel air samplers and PAMs were acceptable. The Eberline E-600 showed an unacceptably high rate of out-of-tolerance as-found high voltage settings. The result of the E-600 assessment was an evaluation and revision of the calibration procedure to ensure a meaningful high voltage tolerance was used. Consequently, calibration intervals for none of the instrument models investigated were adjusted.

\subsubsection{Maintenance of the Calibration Records}

IS\&TP manages the calibration records for all instruments, sources, and dosimeters calibrated by IS\&TP. The records are scanned using the LaserCAL system, and stored on computer disks to allow for ready retrieval before being sent to record storage. Upon request, copies of calibration records are provided to customers.

\subsection{Program Improvements in Calibration and Maintenance Operations}

Until the mid-1990s, PNNL maintained an internal manual, PNL-MA-562, Instrument Manual, which provided technical information on instruments commonly used at the Hanford Site. In the mid-1990s maintenance of the manual was eliminated in an effort to reduce costs. By the late 1990s, though, it became apparent that there was a need on the Hanford Site for a sitewide instrument manual. Consequently, the manual was updated and, in 2001, was issued as a web-based document available to other Hanford contractors. 


\subsection{Hanford Instrument Evaluation Committee}

The HIEC was established to provide a mechanism for Hanford intercontractor information exchange to ensure that the highest-quality portable and semi-portable radiological protection instrumentation program is maintained at Hanford. The responsibilities of the committee include the following:

- Discuss and propose solutions to ongoing or potential radiological instrumentation problems and needs onsite.

- Identify new radiological instrumentation available from manufacturers that may be useful to Hanford Site operations.

- Oversee the procurement of the instruments and review the evaluations performed by contractor organizations.

- Establish or review minimum acceptable operational criteria for portable and semi-portable radiological instrumentation used for safety on the Hanford Site.

- Promote information exchange between contractors on radiological protection instrumentation usage and problems/resolutions.

Representatives from all of the Hanford prime contractors and a representative of RL are on this committee.

During CY 2001, the HIEC continued to perform evaluations on instruments identified as needing further evaluations before being approved and placed on the "approved instrument list." The HIEC maintains the "approved instrument list" as a mechanism to demonstrate compliance with the 10 CFR 835 requirement that instruments "shall be appropriate for their environment." Instruments added to the approved instrument list in CY2001 were the Eberline E-600/NRD neutron survey instrument and the Siemens Mk 2.3 electronic pocket dosimeter.

IS\&TP staff supports the HIEC by serving as the organization's secretary and providing administrative and technical support. In this role, IS\&TP staff maintain the approved instrument list and the record files of all instrument evaluations completed for Hanford Site customers. IS\&TP also provides technical support in the areas of instrument testing and design.

\subsection{Supporting Technical Studies}

No supporting technical studies were performed during the year.

\subsection{Program-Related Professional Activities}

Staff presentations and external professional activities during CY 2001 are listed in this section. 


\subsubsection{External Professional Activities}

Johnson, M. L., Co-Chairperson of the Working Group for ANSI N323C, Radiation Protection Instrumentation Test and Calibration - Air Monitoring Instruments

Johnson, M. L., Member of the Working Group for ANSI N323A, Radiation Protection Instrumentation and Calibration - General Requirements and Portable Instruments.

Johnson, M. L., Member of the Working Group for ANSI N323D, Radiation Protection Instrumentation and Calibration - Fixed Instruments. 


\subsection{Radiation Standards and Calibrations Program}

The primary function of the Radiation Standards and Calibrations Program (RS\&CP) is to maintain the necessary radiological reference fields to facilitate appropriate characterizations and calibrations within the Hanford IS\&TP and HEDP. In support of this task, special instrument and dosimeter responsecharacterizing equipment and supplemental radiological reference fields are maintained, as necessary. This activity provides the means to characterize instrument and dosimeter response to various radiation fields encountered at Hanford and to ensure that calibration capabilities are available in accordance with recommended standards and guides. The RS\&CP is coordinated by the Calibration Research and Accreditation (CR\&A) subgroup of the IS\&TP technical group. This group also supports other Hanford entities as well as DOE-HQ, other departments of the U.S. Government, and the private sector within its NVLAP scope of accreditation as a Calibration Laboratory for Ionizing Radiation, which has been maintained since 1994. Standards and methodologies developed in support of non-Hanford applications serve to enhance the capabilities available to the Hanford Site. Typical project activities include the following:

- providing a pathway of traceability for the calibration sources to the NIST

- maintaining radioactive sources, X-ray-generating devices, and instruments that serve as radiological standards

- reviewing calibration standards, regulations, and handbooks to ensure that calibration and characterization protocols agree with technically accepted methods.

Program activities conducted during CY 2001 are discussed in the following sections. A detailed description of the project's capabilities can be found in PNNL-10354, Rev 1, Radiation and Health Technology Laboratory Capabilities (Goles et al. 2001).

\subsection{Routine Operations}

Routine activities conducted by program personnel involved maintenance of radiological standards, including reference class instruments and reference fields traceable to national standards, and the development of new and/or specialized capabilities. These existing and new capabilities support a variety of applications at the Hanford Site, within the DOE and other U.S. Government communities, and throughout the international radiological protection industry, in both the private sector and government programs. The activities related to radiological standards and capabilities and applications are discussed in the following sections.

\subsubsection{Standards and Capabilities}

The radiological reference fields maintained include gamma, beta, and neutron isotopic sources and X-ray-generating devices. These standards and capabilities are configured to deliver well-characterized 
and reproducible quantities of radiation dose or exposure to environmental or personnel dosimeters, radiological survey instruments, etc., for providing NIST-traceable calibration and/or response characterization. In addition, reference-class instrumentation is maintained for the purpose of calibration, characterization, constancy verification, and traceability transfer.

\subsubsection{Quantitative and Qualitative Confirmation of Standards}

Radiological reference fields originating from isotopic sources are dynamic in their output due to both the effects of radioactive decay and to the general content of the source material. If the isotopes are generally pure, then changes are typically limited to source decay. If impurities exist or if the decay of the primary isotope results in a radioactive decay product, then changes in the apparent strength and quality of the reference field are more complex. Reference fields generated by X-ray devices may also be dynamic. The eventual degradation of the components of the system may affect the quality and intensity of the primary beam. Furthermore, filters used to condition the useable beam may degrade over time, also potentially altering the radiation quality.

Initial calibrations and characterizations are designed to ensure that PNNL reference fields are adequate and comply with industry standards as identified above. Subsequent measurements are performed at suitable intervals to ensure that source dynamics are as expected. As a minimum, these measurements take into consideration the following criteria for isotopic sources:

- the general content (including possible impurities) of the source material

- the half-life

- the age and/or historical stability

- whether or not an automated positioning system is used to obtain a continuum of exposure/dose equivalent rates and, if so, the stability of such a system

- the stability and/or reproducibility of the source position or positioning system

- the constancy of ambient conditions (e.g., addition of major structures, equipment, or other sources of potential scatter)

For X-ray reference fields, criteria for consideration include the following:

- the constancy/stability of the X-ray equipment

- the quantity of use

- the properties of the materials used within the various beam filters 
- the constancy of ambient conditions (e.g., addition of major structures, equipment, or other sources of potential scatter).

Given the above criteria, both the initial and subsequent constancy verification measurements of reference field quantity and quality are typically unique for each capability.

\subsection{Operational Improvements}

During 2001, staff made the following operational improvements to develop and enhance techniques, systems, and processes:

- upgraded the ${ }^{241} \mathrm{Am}$ exposure facility (aka "PacMan") to meet requirements for a radiation generating device (RGD).

- began development of a new capability to characterize and calibrate radioactive seeds used for medical applications.

- measured the scatter contribution to Shepherd and High Exposure Facility (HEF) gamma irradiations.

- verified the formula needed for correcting for the change in decay of ${ }^{252} \mathrm{Cf}$ as the source gets older and influence from contaminated isotopes becomes more significant.

- characterized "dose soaking" effect for neutron rem detectors (NRDs) and, consequently, improved the accuracy of calibration transfer to the ${ }^{252} \mathrm{Cf}$ Well.

An operational improvement of some significance was to verify the formula to correct for ${ }^{250} \mathrm{Cf}$ "ingrowth" in ${ }^{252} \mathrm{Cf}$ neutron sources. Neutron sources, nominally consisting of the spontaneously fissile element ${ }^{252} \mathrm{C}$, tend to also contain some ${ }^{250} \mathrm{Cf}$, which is also spontaneously fissile. The amount of ${ }^{250} \mathrm{Cf}$, or at least the neutron emission rate from the ${ }^{250} \mathrm{Cf}$, is usually fairly small at the time of construction of the source but, because of the longer half-life of ${ }^{250} \mathrm{Cf}$, the concentration of this isotope "grows in", i.e., increases with time. Unfortunately, the amount of ${ }^{250} \mathrm{Cf}$ in the source is usually not known, and this fact raises problems when predicting the emission rate of a source some time after measurement. Measurements performed of the neutron emission rate over a period of time allowed staff to estimate the "birth" ratio of ${ }^{250} \mathrm{Cf}$ to ${ }^{252} \mathrm{Cf}$ and, consequently, to more accurately decay correct the source activity.

\subsection{Program-Related Professional Activities}

Staff presentations and external professional activities during 2001 are listed in this section. 


\subsubsection{Presentations}

Murphy M.K., S.D. Miller, A. Kovács, W.L. McLaughlin, and I. Slezsák. 2001. "Characterization of a New Photo-Fluorescent Dosimetry System for High-Dose Applications." Presented at $12^{\text {th }}$ International Meeting on Radiation Processing, Avignon, France.

Kovács A., M. Baranyai, L. Wojnarovits, S.D. Miller, M.K. Murphy, W.L. McLaughlin, and I. Slezsák. 2001. "Applicability of the Sunna Dosimeter for Food Irradiation Control." Presented at the $12^{\text {th }}$ International Meeting on Radiation Processing, Avignon, France.

\subsubsection{Standards Activities}

As Task Group Chair in ASTM subcommittee on Radiation Processing Dosimetry, Mark M. Murphy wrote the standard titled Standard Practice for Use of a Photo-Fluorescent Film Dosimetry System. This has passed ballot and will be published in 2002 .

Piper, R. K. and R. A. Fox. 2000. "Dosimetry Testing at PNNL.” Presented at the Ninth Annual Meeting of the Council on Ionizing Radiation Measurements and Standards (CIRMS), October 30 to November 1, 2000, Gaithersburg, Maryland.

\subsubsection{Publications}

Piper, R. K., M. K. Murphy, J. E. Tanner, A. K. Thompson, ${ }^{(a)}$ and R. B. Schwartz ${ }^{(a)}$. 2000. “A Summary and Status of Traceability to National Standards for ${ }^{252} \mathrm{Cf}$ Used at the Pacific Northwest National Laboratory." In Proceedings of the $33^{\text {rd }}$ Midyear Topical Meeting of the Health Physics Society. Medical Physics Publishing, Madison, Wisconsin.

Murphy M.K., A. Kovács, S.D. Miller, and W.L. McLaughlin. "Dose Response Characteristics of the Sunna Model $\gamma$ Photo-Fluorescent Film Dosimeter." Radiation Physics and Chemistry, (in press).

Murphy M.K., A. Kovács, S.D. Miller, and W.L. McLaughlin. "Post-Irradiation Stability and Heat Treatment of the Sunna Model $\gamma$ Photo-Fluorescent Film Dosimeter." Radiation Physics and Chemistry, (in press).

Murphy M.K., A. Kovács, W.L. McLaughlin, S.D. Miller, and J.M. Puhl. "The Sunna Model $\gamma$ PhotoFluorescent Film Dosimeter Response to Different Environmental Conditions." Radiation Physics and Chemistry, (in press).

(a) National Institute of Standards and Technology, Gaithersburg, Maryland 20899-8461. 


\subsubsection{External Professional Activities}

Fox, R. A., Member of the Working Group for ANSI N13.11, Personnel Dosimetry PerformanceCriteria for Testing.

Murphy, M. K., Member of the ASTM Subcommittee E10.01, Radiation Processing Dosimetry, and Chair of the Task Group for Standard Practice for Use of Photo-fluorescent Dosimetry Systems. 


\subsection{References}

10 CFR 835. 1998. U.S. Department of Energy (DOE). "Occupational Radiation Protection." Revision 1. U.S. Code of Federal Regulations.

10 CFR 830. 2000. U.S. Department of Energy (DOE). "Nuclear Safety Management." U.S. Code of Federal Regulations.

American National Standards Institute (ANSI). 1999. American National Standard Practice for Occupational Radiation Exposure Records Systems. ANSI N13.6, New York.

American National Standards Institute (ANSI). 1975. An American National Standard, Performance, Testing, and Procedural Specifications for Thermoluminescence Dosimetry (Environmental Applications). ANSI N545, New York.

American National Standards Institute (ANSI). 1978. An American National Standard, Radiation Protection Instrumentation Test and Calibration. ANSI N323, New York.

American National Standards Institute (ANSI). 1993. An American National Standard, Personnel Dosimetry Performance — Criteria for Testing. ANSI/HPS N13.11, American National Standards Institute, New York.

American National Standards Institute (ANSI). 1994. American National Standard for CalibrationCalibration Laboratories and Measuring and Test Equipment - General Requirements.

ANSI/NCSL Z540-1, Boulder, Colorado.

American National Standards Institute (ANSI). 1997. An American National Standard, Radiation Protection Instrumentation Test and Calibration Program, Portable Survey Achievements.

ANSI N323A, New York.

American Society of Mechanical Engineers (ASME). 1989. Quality Assurance Program Requirements for Nuclear Facilities. Current edition, ASME NQA-1, New York.

Freedom of Information Act, Public Law 89-847, July 4, 1966.

Goles, R. W., M. L. Johnson, R. K. Piper, J. D. Peters, M. K. Murphy, M. S. Mercado, D. E. Bihl, T. P. Lynch. 2001. Radiation and Health Technology Laboratory Capabilities. PNNL-10354, Pacific Northwest National Laboratory, Richland, Washington.

Health Physics Society (HPS). 1995. An American National Standard, Performance Testing of Extremity Dosimeters. HPS N13.32, McLean, Virginia. 
Health Physics Society (HPS). 2001. American National Standard, Personnel Dosimetry Performance-Criteria for Testing. HPS N13.11, McLean, Virginia.

International Commission on Radiological Protection (ICRP). 1991. "1990 Recommendations of the International Commission on Radiological Protection." (ICRP publication 60). Annals of ICRP, 21:1-3, Elsevier Science, Inc., Tarrytown, New York.

International Commission on Radiological Protection (ICRP). 1994. "Human respiratory tract model for radiological protection.” (ICRP publication 66). Annals of ICRP, 24:1-3, Elsevier Science, Inc., Tarrytown, New York.

International Standards Organization (ISO). 1999. General Requirements for the Competence of Testing and Calibration Laboratories. ISO/IEC 17025, Geneva, Switzerland.

Lynch, T. P., J. A. MacLellan, D. E. Bihl, R. K. Piper, and M. L. Johnson. 2001. Hanford Radiological Protection Support Services Annual Report for 2000. PNNL-13542, Pacific Northwest National Laboratory, Richland, Washington.

Privacy Act, 44 Federal Regulations 510777 (1974).

Scherpelz, R. I., J. J. Fix, and B. A. Rathbone. 2000. Validation of Hanford Personnel and Extremity Dosimeters in Plutonium Environments. PNNL-13136, Pacific Northwest National Laboratory, Richland, Washington.

U.S. Department of Energy (DOE). 1986. Handbook for the Department of Energy Accreditation Program for Personnel Dosimetry Systems. DOE/EH-0026, Washington, D.C.

U.S. Department of Energy (DOE). 1996. Implementation Guide for Use with 36 CFR Chapter XII Subchapter B Records Management. DOE G 1324.5B, Washington, D.C.

U.S. Department of Energy (DOE). 1997. Environment, Safety and Health Reporting. DOE Order 231.1-1 Change 2, Washington, D.C.

U.S. Department of Energy (DOE). 1999a. Internal Dosimetry Program Guide. DOE G 441.1-3, Washington, D.C.

U.S. Department of Energy (DOE). 1999b. DOE Standard Internal Dosimetry. DOE-STD-1121-98. Washington, D.C.

U.S. Department of Energy (DOE). 1999c. Occupational Radiation Protection Record-Keeping and Reporting Guide. DOE G 441.1-11, Washington, D.C.

U.S. Department of Energy (DOE). 2000. Environment, Safety and Health Reporting Manual. DOE Manual 231.1-1 Change 2, Washington, D.C. 
U.S. Department of Energy (DOE). 2001. “Acceptable Approach for Developing Air Concentration Values for Controlling Exposures to Special Tritium Compounds," Radiological Control Technical Position 2001-02, Washington, D.C.

U.S. Department of Energy, Richland Field Office (DOE-RL). 1994. Hanford Site Radiological Control Manual. HSRCM-1, Revision 2, Richland, Washington. 
PNNL-13940

\section{Distribution}

No. of

Copies

OFFSITE

(This distribution list receives only a notification of the availability of the electronic version of the report on the PNNL website)

DOE EM-4

M. Gavrilas-Guinn

Radiological Control Program Advisor

Environmental Management

U.S Department of Energy

1000 Independence Ave., S.W.

Washington, DC 20585

DOE EH-54

R. M. Loesch

U.S. Department of Energy

Mail Stop - 5142

19901 Germantown Rd

Germantown, MD 20874-1290

DOE Albuquerque Field Office

M. G. Knight

Radiological Control Manager

Battelle Pantex Plant

P.O. Box 30020

Amarillo, TX 79120

J. J. Maisler

BWXT of Ohio

P.O. Box 3030

Miamisburg, $\mathrm{OH}$ 45343-3030

A. Andrade

Los Alamos National Laboratory

P.O. Box 1663

Los Alamos, NM 87545
No. of

Copies

S. Eisele

Los Alamos National Laboratory

MS G761

PO Box 1663

Los Alamos, NM 87545

S. Baker

RMRS

Rocky Flats Environmental

Technology Site

P.O. Box 464

Golden, CO 80402-0464

DOE Chicago Field Office

S. Layendecker

Radiological Control Section

Brookhaven National Laboratory

P.O. Box 5000

Upton, NY 11973

E. H. Dolecek

Argonne National Laboratory

9700 South Cass Avenue

Argonne IL 60439

DOE Idaho Field Office

P. E. Ruhter

Bechtel Idaho

PO Box 1625

Idaho Falls, ID 83414-4147

DOE Nevada Field Office

C. T. Bastian

Bechtel Nevada

P.O. Box 98521

Las Vegas, NV 89193

Distr.1 
PNNL-13940

No. of

Copies

DOE Oak Ridge Field Office

M. Thein

Oak Ridge National Laboratory

MS-6105.

P.O. Box 2008

Oak Ridge, TN 37831

J. B. Hunt

Y-12 Plant

P.O. Box 2009

Oak Ridge, TN 37831

\section{DOE San Francisco Field Office}

C. T. Prevo

Lawrence Livermore National Laboratory

P.O. Box 808

Livermore, CA 94550

DOE Savannah River Field Office

K. W. Crase

Westinghouse Savannah River Company

Savannah River Plant -B707

P.O. Box 616

Aiken, SC 29808

\section{ONSITE}

(The non-PNNL onsite distribution list receives only a notification of the availability of the electronic version of the report on the PNNL website.)

\section{DOE Richland Operations Office}

T. L. Aldridge

K8-50

W. M. Glines

A2-15

B. M. Pangborn

E. Parsons
A5-17

A5-17
No. of

Copies

\section{Environmental Restoration Contractor}

$\begin{array}{lr}\text { E.W. Carlson } & \text { L5-64 } \\ \text { D. E. Gergely } & \text { H0-15 } \\ \text { C. L. Hellier } & \text { X0-34 } \\ \text { J. E. Tarpinian } & \text { H0-09 } \\ \text { S. L. Winslow } & \text { L5-64 }\end{array}$

\section{Hanford Environmental Health Foundation}

S. M. McInturff

H1-77

\section{Fluor Daniel Hanford}

P. A. Olsen

H5-26

S. R. Johnson

H5-26

Washington State University (Tri-Cities)

R. Filipy

$\mathrm{H} 2-52$

\section{CH2M Hill Hanford Group}

D. R. Hekkala

S7-75

R. M. Pierson

S7-75

\section{Pacific Northwest National Laboratory}

D. E. Bihl (2)

P7-02

E. H. Carbaugh

P7-01

S. K. Ennor

K1-01

J. J. Fix

K3-55

S. D. Dossett

$\mathrm{P} 7-75$

J. R. Hoyt

P7-78

M. L. Johnson (10)

P7-01

R. A. Jones

P7-78

T. P. Lynch (2)

B1-60

J. C. McDonald

K3-53

J. A. MacLellan

P7-01

R. K. Piper (2)

P7-03

B. A. Rathbone

P7-02

W. J. Apley

K9-01

K. L. Soldat

K3-53

Radiation Protection Historical

Files (c/o M. C. Flaherty) (2)

P7-01

Information Release Office (5)

K1-06 